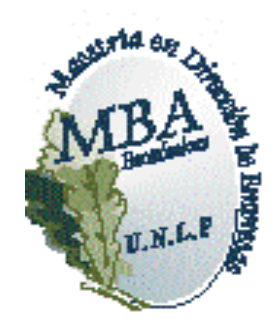

Universidad Nacional de La Plata

Facultad de Ciencias Económicas

MBA - Maestría en Dirección de Empresas

\title{
Indicadores comunitarios para la Ciudad de Ensenada
}

Autor: Esteban Jesús Cabanillas

Directora: Gabriela Mollo

La Plata

Mayo de 2017 


\section{AGRADECIMIENTOS}

Esta tesis es un paso más en este intento de ser un mejor profesional, y como en todo final de etapa es importante mirar lo vivido y pensar en lo bueno y malo que queda atrás. Tan esencial como esto, es agradecer a todos los que me acompañaron en este período:

- gracias a los profesores, por las enseñanzas del programa de estudios, y por las que no estaban estipuladas,

- gracias a Gabriela, que me guío en este último paso tan fundamental,

- gracias a los compañeros, que me ayudaron y acompañaron con temas relacionados al estudio, y con otros que no tenían nada que ver,

- gracias a mis viejos, que me enseñaron y ayudaron a ser lo que hasta ahora soy,

- y muchas gracias a Sol, Juani y Nico, que sacrificaron tiempo compartido para que pudiera llevar adelante esta etapa.

Esteban. 


\section{ÍNDICE}

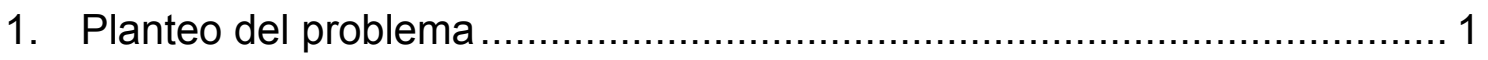

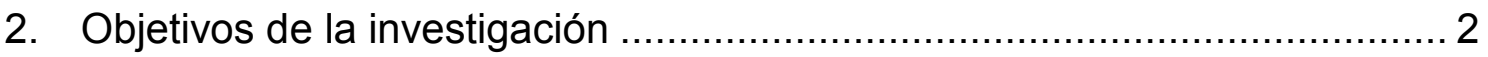

3. Alcance de la investigación.............................................................. 2

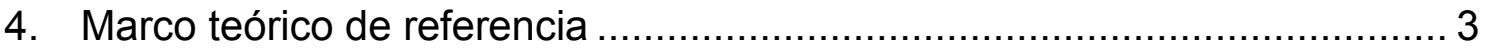

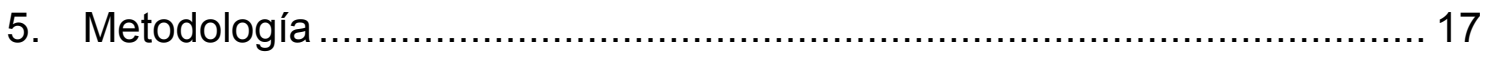

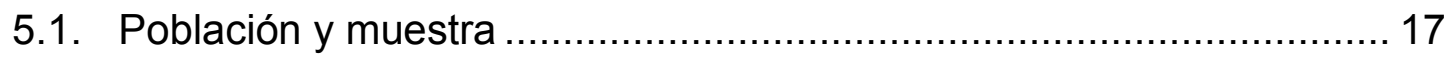

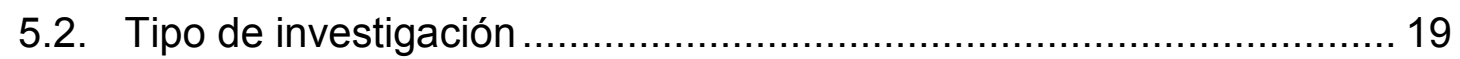

5.3. Técnicas de recolección de datos.............................................. 20

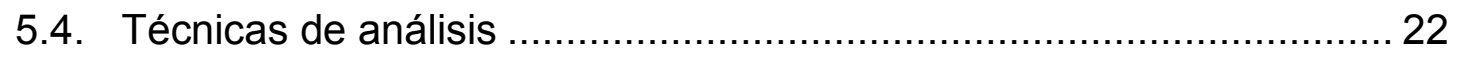

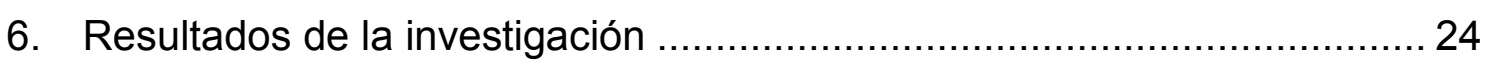

6.1. Perfil de los encuestados.................................................. 24

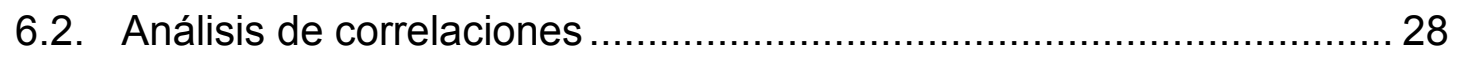

6.3. Resultados en la ciudad de Ensenada ........................................ 28

6.4. Situación comparativa: Ensenada con La Plata y alrededores ............ 34

6.5. Situación comparativa: Ensenada con Australia.............................. 44

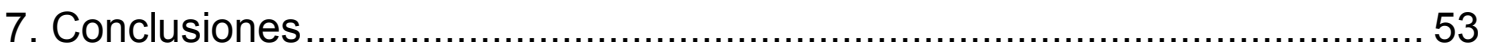

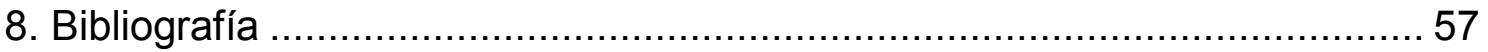

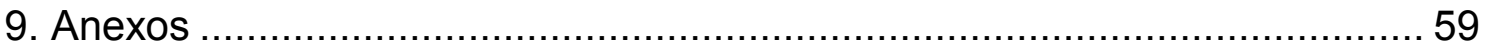

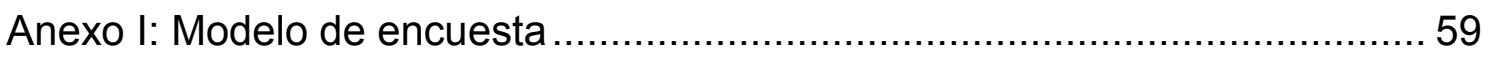

Anexo II: Resultados obtenidos a través del análisis Etha Cuadrado .............. 61

Anexo III: Resultados del "Proyecto Nacional de la Ciudadanía" .....................66 


\section{Planteo del problema}

El pensamiento economicista predominante en el mundo en los años 80 y 90 apuntaba a que lo único sustancial para alcanzar una sociedad desarrollada eran los factores macroeconómicos. Se razonaba en términos de que para ser prósperos la tasa de inflación debía ser baja, y que si el producto bruto interno per cápita era alto se estaría en pleno bienestar. Con el paso de los años la realidad fue mostrando que esto no es suficiente.

Actualmente se está dando paso a una visión mucho más amplia en la discusión sobre cómo se alcanza el desarrollo y el bienestar de una sociedad. Sin dejar de valorar el aporte de la teoría económica y la necesidad de herramientas técnicas en pos de un crecimiento económico sostenido, se está cuestionando la posición de privilegio que tienen en detrimento de otros factores. De esta manera empiezan a aparecer nuevos indicadores que consideran factores como educación, sustentabilidad ambiental, corrupción, cultura, felicidad, entre otros.

Las sociedades exitosas desde una perspectiva social e integral, presentan rasgos distintivos con los que se las puede identificar y explicar el porqué de su bienestar social, económico y político. Lo mismo sucede con las sociedades menos exitosas, las cuales poseen una serie de factores en común que las caracterizan, y a través de los cuales se podrían identificar los motivos que obstaculizan su desarrollo.

Por esto, hoy en día, se buscan indicadores para poder medir el "bienestar social", pero dada la amplitud y abstracción del concepto, la poca evidencia empírica sobre cuáles son los factores que los ciudadanos consideran más importantes, y que cada sociedad valora de diferente manera esos múltiples factores, cualquier medición resulta compleja y siempre cuestionable.

Intentar identificar cuáles son estos factores y hacer un diagnóstico de la situación en que se encuentran los mismos es el punto de partida para comenzar cualquier discusión sobre cuál es el camino a recorrer para lograr una sociedad desarrollada. 


\section{Objetivos de la investigación}

- Identificar cuáles son los factores que los habitantes de la ciudad de Ensenada consideran importantes para alcanzar el bienestar y desarrollo de su sociedad.

- Realizar un diagnóstico del desempeño que presentan estos factores identificados según la percepción de sus ciudadanos.

- Evaluar si los factores identificados como importantes y su desempeño en la ciudad de Ensenada son diferentes a los de la región conformada por las ciudades de La Plata, Berisso y Ensenada.

- Evaluar si los factores identificados como importantes y su desempeño en la ciudad de Ensenada son diferentes a los de Australia, país que tiene sistematizada esta información.

\section{Alcance de la investigación}

Los resultados del presente trabajo son el producto de un proyecto de investigación basado en el análisis comparativo entre:

- El "Proyecto Nacional de la Ciudadanía", originado a partir de la encuesta nacional ("Puntos de referencia de la ciudadanía australiana"), que se realizó entre junio y julio de 1999 en tres regiones del estado de Victoria, Australia. En el mismo se tomó una muestra aleatoria estratificada a través de siete grupos socioeconómicos diferentes, identificados a partir de los índices presentados por la Oficina de Estadísticas de Australia.

- Los resultados que se obtuvieron del estudio realizado a través de esa misma encuesta, distribuida en la región conformada por las ciudades de La Plata, Berisso y Ensenada, entre mayo y junio del año 2013.

Este trabajo posee un tronco común con la mirada sobre toda la región conformada por las ciudades de La Plata, Berisso y Ensenada, analizando en detalle los resultados obtenidos en la ciudad de Ensenada, formada por 55.629 habitantes. 


\section{Marco teórico de referencia}

\section{Medir el bienestar social}

El concepto "bienestar social" es de naturaleza amplia y abstracta, por lo tanto posee múltiples definiciones y orientaciones, siendo cualquier intento de medición complejo y cuestionable. Los debates sobre su significado, y la forma de cuantificarlo, no son modernos. Hace más de 2000 años, Aristóteles ya consideraba que la definición de "buena sociedad" es la tarea central de la filosofía.

Apuntando a encontrar una respuesta más allá de la filosofía, un "buen" índice debe combinar tres características esenciales: ser simple (algo indispensable para que sea entendible y aplicable), no ser manipulable (para dar la transparencia necesaria a un indicador tan importante), y analizar un número suficiente de factores que tengan influencia en el bienestar de la sociedad (para que sea lo más representativo posible).

Esta última característica lo hace extremadamente complicado, ya que para los países de la franja mediterránea estos factores podrían ser la calidad de la alimentación o el número de días de sol, pero para el Reino Unido o Alemania factores a tener en cuenta serían el porcentaje de reciclaje o el nivel de corrupción. Para un país budista un factor primordial sería el número de horas semanales dedicadas a la meditación, que poco importaría en un país sudamericano por ejemplo.

\section{Indicadores económicos}

Se puede considerar como la primera aproximación a su medición, cuándo en la literatura económica de 1920, se relacionaba al bienestar con el desarrollo, el progreso y el crecimiento, por lo que se argumentaba que el incremento del producto bruto interno $(\mathrm{PBI})$ se correlacionaría con una mejora del bienestar para todos.

EI PBI es una magnitud macroeconómica que expresa el valor monetario de la producción de bienes y servicios de demanda final de un país (o una región) durante un período determinado de tiempo (normalmente un año), es decir, mide simplemente el tamaño de la economía.

Su mismo creador, Simon Kuznets, fue siempre muy crítico de la pretensión de medir el bienestar exclusivamente sobre la base de la renta nacional de una sociedad. En sus palabras: "Hay que tener en cuenta las 
diferencias entre cantidad y calidad de crecimiento, entre sus costos $y$ beneficios, y entre corto y largo plazo. [...] Los objetivos de más crecimiento deberían especificar de qué y para qué." (Kuznets, 1962).

Los opositores al PBI lo critican porque es un indicador engañoso, es decir una mala medida de la real condición de la economía y de la sociedad, y excesivamente potente, porque influye en la conformación de la comprensión cotidiana de progreso y bienestar. Estas preocupaciones vinieron originalmente desde distintos actores de la sociedad: ambientalistas, movimientos de mujeres, activistas de derechos humanos, religiosos, entre otros. Con el paso del tiempo, todos comenzaron a converger en un movimiento de gran alcance y de amplia base.

El argumento central que la mayoría de estos grupos acuerdan es simple: medir el valor de mercado de la producción económica dice muy poco acerca de la salud general de la comunidad o el medio ambiente, y nada acerca de los costos sociales de lo que se ha producido en la economía, o sobre su utilidad o sostenibilidad. Como explica John Ralston Saúl, "los productores de acero no tienen ningún incentivo para reducir la contaminación, en la medida en que no pagan las facturas de lavandería o de salud que generan. Como resultado, el mecanismo de mercado no sirve con precisión a uno de los fines que se pretende cumplir, a saber, la presentación de la sociedad con una evaluación precisa de los costos relativos de la producción de las cosas." (Saúl, 1997).

En el otro extremo, están quienes resisten la idea de que el PBI no pueda mapear el bienestar, argumentando que el crecimiento económico no resolverá todos los problemas, pero un incremento de la riqueza puede conducir a una disminución de la mortalidad infantil, a un aumento de la expectativa de vida, a mayor investigación en medicina, a una ampliación de la disponibilidad de alimentos sanos, o a la construcción de viviendas de mejor calidad, entre muchos ejemplos.

Para estos defensores del PBI como medida general del bienestar, los líderes políticos no necesitan más que anunciar la tasa de crecimiento de la economía al final de cada año, para convencerlos de que todo está evolucionando bien. Pero en definitiva, esta medida sólo define nuestro papel como consumidores: incrementando el consumo, la economía crece, y por consiguiente el bienestar colectivo también.

Los gastos de nafta por los problemas de tráfico, el consumo de calmantes para el dolor de cabeza, las pérdidas generadas por guerras, o los desastres ecológicos que requieren grandes operaciones de limpieza, serán buenos para la economía, pero difícilmente tengan un beneficio sobre el bienestar humano. Por el contrario, una vibrante comunidad de apoyo, el trabajo voluntario, el tiempo libre, el amor, y tantas otras cosas, no están incluidas en el $\mathrm{PBI}$, pero claramente tienen relación con el bienestar. 
A mediados de 1960 empezó a hacerse manifiesta la preocupación por la calidad de vida de las personas, y que la misma difícilmente fuera representada por el PBI. Un claro ejemplo es la conferencia en la universidad de Kansas en 1968, dónde Robert F. Kennedy denunció, siendo candidato a la presidencia de Estados Unidos, las limitaciones de esta medida:

"El producto bruto interno incluye la contaminación del aire y la publicidad de los cigarrillos, y las ambulancias para despejar nuestras carreteras. Cuenta cerraduras especiales para nuestras puertas y las cárceles para las personas que las rompen. El producto bruto interno incluye la destrucción de los bosques de secuoyas y la muerte del Lago Superior. Crece con la producción de napalm, misiles y cabezas nucleares. Y si el producto bruto interno incluye todo esto, hay mucho que no comprende. No incluye la salud de nuestras familias, la calidad de su educación, o la alegría de sus juegos. Es indiferente a la decencia de nuestras fábricas y a la seguridad de nuestras calles por igual. No incluye la belleza de nuestra poesía o la fortaleza de nuestros matrimonios, la inteligencia de nuestro debate público o la integridad de nuestros funcionarios. El producto bruto tampoco mide nuestro ingenio ni nuestro coraje, ni nuestra sabiduría ni nuestro aprendizaje, ni nuestra compasión ni nuestra devoción a otro. En pocas palabras, mide todo menos aquello que hace que la vida valga la pena." (Kennedy, 1968).

Intentando corregir estas deficiencias, se desarrolló el índice de progreso genuino (IPG) o real (IPR), que incluye más de veinte variables que no se consideran en el $\mathrm{PBI}$, diferenciando entre las que aportan al crecimiento económico, es decir añaden bienestar, de las que no lo hacen.

EI IPG parte de los mismos datos de consumo personal que se calculan en el $\mathrm{PBI}$, a los cuales se le agregan las actividades que no son remuneradas por el mercado (trabajo doméstico no remunerado, actividades de voluntariado, cuidado de familiares), se le quitan los costos derivados de las actividades que no añaden bienestar (pérdida de recursos naturales, contaminación, delincuencia, divorcios, gastos de traslados, gastos médicos, reparaciones generadas por accidentes), y se lo ajusta con otros factores (distribución del ingreso por capas sociales, deuda pública, jornada laboral versus tiempo de ocio).

Desde ya que este es un primer paso importante en la dirección de intentar medir lo que realmente genera bienestar y desarrollo para la sociedad, pero sigue sin considerar otros factores que tienen gran influencia en los mismos. 


\section{Indicadores sociales}

En este camino, por los años 70, la Organización de las Naciones Unidas (ONU) inició la construcción de los denominados indicadores sociales, como complemento al sistema de indicadores económicos. Fue al final de la década, cuándo el filósofo y economista Amartya Kumar Sen le dio solidez teórica al concepto de bienestar, incorporando la "diversidad humana" en su evaluación: el bienestar humano se origina en las realizaciones personales, y la libertad para lograrlas está dada por el desarrollo de las capacidades propias de las personas. Entonces, es posible hablar de desarrollo cuando, las personas son capaces de hacer más cosas, no cuando son capaces de comprar más bienes y/o servicios, que sólo son los medios para la obtención de fines. El valor del nivel de vida radica en cómo se vive, entonces más libertad y más capacidad de elección incrementan el bienestar humano. (Sen, 1980, 1996, 1998).

Al final de los años 80, basado en las ideas de Sen, el economista pakistaní Mahbub ul Haq, dentro del Programa de las Naciones Unidas para el Desarrollo (PNUD), elabora el índice de desarrollo humano (IDH) que es calculado desde 1990. El indicador surge como una iniciativa para clasificar los países a partir de otras variables que no fueran las usadas tradicionalmente en economía (PBI, inflación, balanza comercial, consumo energético, desempleo, etcétera), incorporando datos de educación (índice de alfabetización, número de matriculados según nivel educacional, etcétera), y de salud (tasa de natalidad, esperanza de vida, etcétera). EI IDH combina dichas variables a través de un índice compuesto por tres dimensiones: vida larga y saludable, educación y nivel de vida digno.

Para su cálculo se consideran estas medidas de las dimensiones:

- Vida larga y saludable: medida según la esperanza de vida al nacer.

- Educación: medida por la tasa de alfabetización de adultos y la tasa bruta combinada de matriculación en educación primaria, secundaria y superior.

- Nivel de vida digno: medida por el PBI per cápita a paridad de poder adquisitivo en dólares internacionales.

El indicador permite examinar las desigualdades existentes entre los diferentes países del mundo y, a la vez, observar la evolución de estos países a lo largo de los años y comprobar si las desigualdades existentes se acortan o se agravan. 
EI IDH toma valores entre cero y uno (mínimo y máximo desarrollo humano, respectivamente). La PNUD clasifica a los países en tres grandes grupos:

- Países con alto desarrollo humano: IDH >=0,80.

- Países con medio desarrollo humano: 0,80 >IDH > = 0,50.

- Países con bajo desarrollo humano: IDH $<0,50$.

El informe presentado en 2013 destaca que en la última década todos los países aceleraron sus logros en las dimensiones de salud, educación e ingresos. Además, ningún país sobre el cual había datos disponibles, tuvo un valor del IDH más bajo en 2012 que en el 2000, en contraposición con lo ocurrido en la década anterior, en la que dieciocho países en el 2000 registraron valores del IDH inferiores a los de 1990. Entre 1990 y 2012, prácticamente todos los países mejoraron su estado de desarrollo humano. De ciento treinta y dos países de los que se dispone series de datos completos, sólo dos registraron en 2012 un IDH inferior al de 1990.

Sobre finales del siglo pasado, empieza a tomar fuerza globalmente la idea de la necesidad de complementar indicadores como el PBI y el IDH, con otros más amplios que reflejen con mayor precisión las cosas que valoran los ciudadanos, así como también la compleja y multifacética naturaleza del bienestar social, económico y ambiental. La justificación de esta idea es que los indicadores utilizados por los gobiernos determinan las políticas públicas, generan los debates marco, dirigen la planificación, afectan los presupuestos y motivan a la acción, por lo que según que se mide es lo que se puede mejorar.

De esta manera se comenzaron a incluir otras medidas importantes de bienestar social y comunitario, que por lo general se pasaban por alto en las cuentas nacionales, como ser el capital social, la sustentabilidad, la participación ciudadana, la equidad social, la justicia, e incluso la robustez de la democracia misma.

Desde 1995 la organización no gubernamental Transparencia Internacional (TI) publica el índice de percepción de la corrupción (IPC) que mide, en una escala de cero (percepción de altos niveles de corrupción) a cien (percepción de ausencia de corrupción), los niveles de percepción de corrupción en el sector público en un país determinado, y consiste en un índice compuesto, que se basa en encuestas de opinión a expertos y empresas. Para poder evaluar el IPC de un país se debe disponer de al menos tres fuentes diferentes. Al ser un índice basado en sondeos, los resultados son subjetivos, además de que legalmente el concepto de corrupción difiere de un país a otro. Para la organización la corrupción es "el abuso del poder encomendado para beneficio personal."

Uno de los principales desafíos globales pasa por cómo garantizar la inclusión de una población mundial que crece a ritmo sostenido. En 1950 la 
población mundial era de 2.500 millones de habitantes, mientras que en la actualidad supera los 7.000 millones. De acuerdo a diversos indicadores y mediciones, la pobreza impacta en millones de personas en el mundo. El Banco Mundial sostiene que hay 1.200 millones de personas que viven en grado de pobreza extrema, con apenas 1,25 dólares diarios. Si tomamos como parámetro un ingreso menor a 2 dólares diarios, la cifra crece a 2.800 millones.

En 1997 la ONU desarrolló el índice de pobreza humano (IPH), un nuevo parámetro estadístico para medir el nivel de vida de los países, reflejando mejor el nivel de privación, en comparación con el IDH. Desde 2010, el nuevo índice de pobreza multidimensional (IPM), elaborado en colaboración con Iniciativa de Pobreza y Desarrollo Humano de Oxford, suplanta al IPH.

El índice estima la índole y la intensidad de la pobreza a nivel individual con diez parámetros agrupados en tres aspectos básicos:

- Educación: años de escolarización y niños escolarizados.

- Asistencia sanitaria y salud: mortalidad infantil y nutrición.

- Calidad de vida y bienestar social: saneamiento, agua potable, electricidad, suelo del hogar, combustible de hogar, y bienes en el hogar.

Una persona se considera pobre si no tiene acceso al menos a tres de los parámetros definidos. La intensidad de la pobreza indica la proporción de los indicadores a los que no se tiene acceso.

Otro desafío de impacto global es la demanda de los recursos planetarios necesarios para abastecer el consumo. Según el "Informe Planeta Vivo" lanzado por la organización ecologista Fondo Mundial para la Naturaleza, la población mundial utilizó el equivalente a un planeta y medio para abastecerse en 2007. Además, en dicho informe se pone de manifiesto que se necesitarán dos planetas para atender las demandas en 2030, y tres en 2050, si se mantienen las tendencias actuales.

Entre 1999 y 2005, el Centro de Política y Ley Ambiental de la Universidad de Yale, en conjunto con la Red de Información del Centro Internacional de Ciencias de la Tierra de la Universidad de Columbia, desarrollaron el índice de sustentabilidad ambiental (ISA) para evaluar la sustentabilidad relativa entre países. Desde 2006, debido a cambios en el enfoque del equipo de investigación, el ISA fue reemplazado por el índice de desempeño ambiental (IDA), que utiliza indicadores orientados hacia resultados, por lo que sirve como índice de comparación, permitiendo así una mejor comprensión por parte de políticos, científicos, defensores del medio ambiente y el público en general.

El índice evalúa veinticinco indicadores agrupados en dos grandes objetivos: salud ambiental y vitalidad de los ecosistemas. A su vez, la salud 
ambiental se divide en tres categorías de políticas: el impacto del ambiente en la salud, agua potable y saneamiento básico, y los efectos de la calidad del aire en la salud. La vitalidad de los ecosistemas se divide en cinco categorías de políticas: contaminación del aire, recursos hídricos, biodiversidad y hábitat, recursos naturales productivos, y cambio climático (gases efecto invernadero).

Buscando conseguir una mayor atención sobre la calidad de vida generadas y sobre las consecuencias ambientales que las políticas gubernamentales tienen, desde el año 2006 la Fundación para una Nueva Economía ("economía como si la gente y el planeta importaran") publica cada tres años el índice del planeta feliz (IPF).

El mismo utiliza datos globales de los países para medir el desarrollo con base en la satisfacción subjetiva de la gente, la esperanza de vida y la huella ecológica:

- Satisfacción subjetiva de la gente (SG): para conocer el nivel de satisfacción de las personas se hace una encuesta a una parte significativa de la población, con la pregunta: "En general, ¿en qué grado diría que está satisfecho con su vida?". La respuesta para evaluar el nivel de vida tiene un valor numérico de cero (la peor vida posible) a diez (la mejor vida posible).

- Esperanza de vida (EV): para estimar la esperanza de vida del país se utilizan los datos que publica el PNUD en el IDH.

- Huella ecológica (HE): para determinar la huella ecológica se utilizan los datos que elabora la organización ecologista Fondo Mundial para la Naturaleza. La misma es una medida per cápita de la cantidad de tierra necesaria para mantener el consumo del país. Su medida son hectáreas globales.

La pregunta utilizada para determinar la SG, llamada "escalera de la vida", puede parecer demasiado simple y subjetiva, pero la Fundación evaluó que la respuesta a esta pregunta viene muy determinada por el tamaño y solidez de las redes sociales de un individuo, su nivel de educación, si sus necesidades materiales están cubiertas, la riqueza de los recursos naturales en su zona o la bondad del clima. Por lo tanto existe un alto índice de correlación entre las respuestas a la pregunta y medidas de bienestar más complejas y difíciles de obtener.

El índice tiene una escala de cero a cien y se calcula luego de algunos ajustes estadísticos con la fórmula simplificada:

$$
\mathrm{IPF}=(\mathrm{SG} \times \mathrm{EV}) / \mathrm{HE}
$$

En la última emisión del índice en 2012 se observó una notoria caída en sus valores respecto al 2009, siendo Costa Rica el país con mayor índice los 
dos años, pero disminuyendo de 76,1 a 64,0 su valor. En el informe del 2009 el primer país con un índice menor a 64,0 se encontraba en el octavo puesto.

Los resultados del índice muestran que no vivimos en un planeta feliz y ningún país es capaz de combinar los niveles adecuados de las variables. Algunos países con ingresos altos tienen puntuación muy baja debido a la fuerte huella ecológica. Por otro lado, los países más pobres descienden el nivel por la baja esperanza de vida. Y muchos de los países con buenos resultados tienen problemas de todo tipo, por ejemplo muchos países de alto rango tienen importantes problemas en lo que a derechos humanos se refiere. En conclusión el IPF tampoco mide todo, por lo que hay que tener consideraciones al analizarlo como a todo índice.

Cómo aseveran Stiglitz, Sen, Fitoussi en su libro "Medir nuestras vidas" (Mis-measuring our Lives), "En una sociedad cada vez más orientada a la medición del desempeño, tener las métricas correctas importa mucho. Lo que medimos afecta lo que decidimos y hacemos. Si usamos las métricas erróneas, aspiraremos e impulsaremos las cosas equivocadas." (Stiglitz, Sen, Fitoussi, 2010). Ante esta coyuntura, financiada por fundaciones privadas y con el apoyo técnico de la Universidad de Harvard y del Instituto Tecnológico de Massachusetts, se formó la organización sin ánimos de lucro Progreso Social Imperativo (PSI), que lanzó en 2013 el índice de progreso social (IPS), como "una nueva forma de definir lo que significa ser una comunidad exitosa." Para la organización el progreso social es "la capacidad de una sociedad para satisfacer las necesidades humanas básicas de sus ciudadanos, establecer las bases que permitan a los ciudadanos y las comunidades mejorar y sostener su calidad de vida, y crear las condiciones para que todos los individuos puedan alcanzar su verdadero potencial."

El índice no considera indicadores económicos, sólo se enfoca en los "resultados" sociales y ambientales. Mide el desempeño de cada país con cincuenta y dos variables reunidas en grupos de dimensiones que intentan responder estas preguntas:

- ¿El país provee a la gente sus necesidades básicas?: nutrición y asistencia médica básica, agua y saneamiento, vivienda, y seguridad personal.

- ¿Las bases del país están construidas para que la gente mejore su vida?: acceso a conocimientos básicos, acceso a información y comunicaciones, salud y bienestar, y sustentabilidad del ecosistema.

- ¿Hay oportunidades para que la gente mejore su posición en la sociedad?: derechos personales, libertad personal y de elección, tolerancia e inclusión, y acceso a educación superior.

El índice resulta una herramienta muy útil para ponderar el desempeño de los países en el intento por alcanzar sus metas de desarrollo social y 
sustentabilidad medioambiental en base a su economía, pues permite observar como algunos países altamente desarrollados fallan al producir bienestar y comprometen su propio futuro ambiental. La PSI ofrece apoyo para la conformación de equipos multidisciplinarios de impulso local con el objetivo de generar el índice a nivel regional, de ciudades o de comunidades, para transformar los resultados que se obtengan en propuestas concretas de acción en esa zona, articulando agendas de trabajo entre los diversos actores involucrados: gobiernos, empresas, organizaciones de base, entidades donantes, etcétera.

\section{Indicadores comunitarios}

Todos estos índices que incluyen diferentes factores y dimensiones no evalúan cuáles son los componentes "importantes" para una comunidad en particular. Ninguno considera la situación de las escuelas y parques locales, el estado de los ríos y lagos de la zona, la calidad de los barrios de la ciudad, el tipo de puestos de trabajo que la economía local genera, el nivel de participación de los ciudadanos en las actividades de voluntariado, el grado de confianza que existe entre los vecinos y el gobierno, el estado de la calle principal, por nombrar algunos ejemplos.

Lo antes expuesto da lugar a los llamados "Indicadores Comunitarios", los cuales son un intento de poner las ideas sobre el bienestar, a nivel local o regional, mediante la participación y la acción de los ciudadanos. Son herramientas para la búsqueda de mejores medidas de progreso y desarrollo de las comunidades. Esta tarea, al convocar a los ciudadanos a considerar cómo medir su bienestar general, estimula a la comunidad en su conjunto a crear nuevas visiones del futuro, definir sus activos, detectar sus problemas e identificar sus oportunidades de nuevas maneras, proporcionando una oportunidad para ampliar la participación significativa en la gestión pública.

El proceso comienza con las personas que se unen para expresar sus ideas sobre el tipo de sociedad o comunidad en la que les gustaría vivir. Esta visión amplia es luego trabajada con una serie de objetivos concretos en las esferas clave, que luego deben ser ordenados por orden de importancia. El siguiente paso es definir las normas que se deben cumplir para el logro de los objetivos o puntos de referencia, y las estadísticas o indicadores específicos que demuestran el progreso en su logro. El vínculo entre los puntos de referencia e indicadores es crucial: al igual que un viajero necesita tanto un mapa y una brújula, así también las comunidades necesitan saber hacia dónde van (los puntos de referencia o "mapa") y dónde están ahora (los indicadores o "brújula"). 
El valor clave del desarrollo de indicadores de la comunidad es que los ciudadanos trabajan juntos hacia una meta común, a pesar de sus diferentes orígenes, pensamientos políticos, credos religiosos o ideas culturales, participando en la medición del progreso hacia la misma, con mayor información acerca de los recursos necesarios y las limitaciones existentes.

En estas tareas los ciudadanos trabajan con el gobierno local y expertos en distintas temáticas, y lo hacen mediante una relación de colaboración, no de dependencia. No existe garantía que los indicadores comunitarios desarrollados de esta manera sean adoptados en procesos formales por el gobierno del momento, pero por su legitimidad crearán una poderosa presión para los sistemas institucionales que trabajan para las prioridades de la comunidad.

El éxito de los proyectos de indicadores de la comunidad se consigue cuándo se crean cambios duraderos en los valores y capacidades, en la comunidad y las agencias gubernamentales. Los resultados deben ser, no sólo los puntos de referencia e indicadores en sí mismos, sino que deben generar el aumento de la actividad de la comunidad, la mejora en los procesos de gobierno, el aumento de la conciencia y la comprensión, y con el tiempo, una capacidad ampliada para la participación y por tanto una comunidad más empoderada.

Estas metas más grandes son más complejas y utilizan muchos recursos en la técnica de identificar los puntos de referencia e indicadores específicos, pero en el largo plazo son más importantes. Sin atención a los procesos existe el riesgo de que estos nuevos indicadores terminen convirtiéndose en una nueva forma de tiranía de dirección o de un mero truco político.

El caso de Bután, un pequeño país de 700.000 habitantes, localizado en los Himalayas, con la práctica del budismo como religión, puede ser tomado como ejemplo de este tipo de procesos, considerando las particularidades propias que dicha comunidad tiene.

En este país se elaboró el indicador de felicidad bruta interna (FBI) para medir el progreso. Aunque el término fue nombrado por primera vez en 1972 por el rey Jigme Singye Wangchuck, en su discurso de asunción: "La felicidad bruta interna es mucho más importante que el producto bruto interno", el concepto aparece un par de siglos antes. El código legal de 1729, que data desde la unificación de Bután, declara que "si el gobierno no puede crear dekid (felicidad) para su pueblo, no existe un propósito para que el gobierno exista."

En palabras de Wangchuck: "La felicidad es subjetiva, y no podemos asegurar que la gente sea feliz; sería muy naif pensar así. Sin embargo, desde el Estado sí podemos establecer las condiciones para que los butaneses tengan la posibilidad de ser felices." Aunque no hay una única definición oficial 
para el término, la siguiente descripción es ampliamente utilizada: "La felicidad bruta interna mide la calidad de un país en una manera más holística que el producto bruto interno, y considera que el desarrollo beneficioso de la sociedad humana tiene lugar cuando el desarrollo material y espiritual se producen lado a lado, para complementarse y reforzarse mutuamente."

Los cuatro pilares definidos sobre los que se sostiene la FBI son:

- Desarrollo económico equilibrado

- Preservación y fomento de la cultura

- Conservación del medio ambiente

- Buena gestión de los asuntos públicos

A pesar de priorizar esta filosofía, y de ser una de las economías más pequeñas del mundo, en cuatro décadas, se ha logrado lo que otros países consiguen en cientos de años: educación gratuita y en inglés, sanidad y comida asegurada para sus habitantes, electricidad casi totalmente subvencionada, agricultura completamente ecológica, planificación urbanística estrictamente regulada, y un turismo de alto valor y poco volumen cuyos ingresos pagan la mayor parte de los impuestos que dejan de pagar sus habitantes. Durante este período de desarrollo, la esperanza de vida de los butaneses se ha incrementado en veintidós años, llegando a ser de sesenta y seis años de vida, y la alfabetización que únicamente se conseguía en los monasterios o fuera del país, ha alcanzado a más del cincuenta por ciento de la población. Además Bután, en el 2007, fue la segunda economía que más rápido creció a nivel mundial, alcanzando una renta per cápita de 1.350 dólares anuales, la mayor de todo el Sudeste Asiático.

La materia prima del indicador es un cuestionario con ciento ochenta preguntas, que se realiza cada dos años a una muestra de ciudadanos butaneses, y cuyas respuestas se agregan en treinta y tres variables agrupadas en nueve dimensiones:

- Nivel de vida: bienes, vivienda, e ingreso per cápita.

- Salud: salud mental, estado de salud autoinformada, días saludables, y discapacidad.

- Educación: alfabetismo, enseñanza, conocimiento, y valores.

- Uso del tiempo: trabajo, y sueño.

- Buena gobernancia: desempeño del gobierno, derechos fundamentales, servicios, y participación política.

- Diversidad y resistencia ecológica: problemas ecológicos, responsabilidad hacia el medio ambiente, daño de la vida silvestre (rural), y problemas de urbanización.

- Bienestar psicológico: satisfacción de vida, emociones positivas, emociones negativas, y espiritualidad. 
- Vitalidad de la comunidad: donaciones (tiempo y dinero), relaciones con la comunidad, familia, y seguridad.

- Diversidad y resistencia cultural: hablar un idioma nativo, participación cultural, habilidades artísticas, y Driglam Namzha (comportamiento esperado de consumo, vestimenta y movimiento).

Algunas preguntas del cuestionario son:

- ¿Definiría su vida como: a) Muy estresante, b) Algo estresante, c) Nada estresante, d) No lo sé?

- ¿Ha perdido mucho sueño por sus preocupaciones?

- ¿Ha percibido cambios en el último año en el diseño arquitectónico de las casas de Bután?

- ¿En su opinión, cómo de independientes son nuestros tribunales?

- ¿En el último mes, con qué frecuencia socializó con sus vecinos?

- ¿Cuenta usted cuentos tradicionales a sus hijos?

Cada dimensión del índice es independiente, útil para fines prácticos de diferentes organismos. A su vez para obtener la FBI se ponderan las nueve dimensiones, comparando su valor a lo largo del tiempo, entre distritos, por géneros, por grupos de edad, por niveles de educación, por ocupaciones, etcétera. Estos análisis proporcionan al gobierno los indicios que guían sus políticas.

\section{Comparación de indicadores}

A modo de resumen, en la tabla de abajo, se puede ver una comparación de los índices repasados, evaluando sus principales objetivos de medición, el total de dimensiones y variables que incluyen, y una desagregación de las mismas en las dimensiones definidas en cada índice, clasificándolas por distintos aspectos del bienestar.

Para los indicadores PBI, IPG e IPC no están explícitamente definidas las variables, por lo que los principales conceptos de cada índice se enumeran en los aspectos del bienestar con los que están relacionados.

Puede verse que hay indicadores que tienen dimensiones compuestas por variables que corresponden a más de un aspecto. Por ejemplo la dimensión "calidad de vida y bienestar social" del IPM está definida por seis variables de las cuales dos ("saneamiento" y "agua potable") se relacionan con el aspecto "agua potable y saneamiento", tres ("electricidad", "suelo del hogar" y "combustible del hogar") con "vivienda y servicios básicos", y uno ("bienes en el hogar") con "equipamiento en la vivienda". 
También hay indicadores en los que un aspecto se encuentra alcanzado por variables de distintas dimensiones. Por ejemplo en el IPS las cinco variables ("tasa de alfabetización en adultos", "matriculación en educación primaria", "matriculación en educación secundaria a nivel inicial", "matriculación en educación secundaria a nivel bachillerato" y "paridad de género en educación secundaria") de la dimensión "acceso a conocimientos básicos", y las cuatro ("años de educación terciaria", "años promedio de escolaridad de las mujeres", "inequidad en logro educativo" y "universidades de clase mundial") de la dimensión "acceso a educación superior", están relacionadas con el aspecto "educación".

Tabla 1: Comparación de los índices.

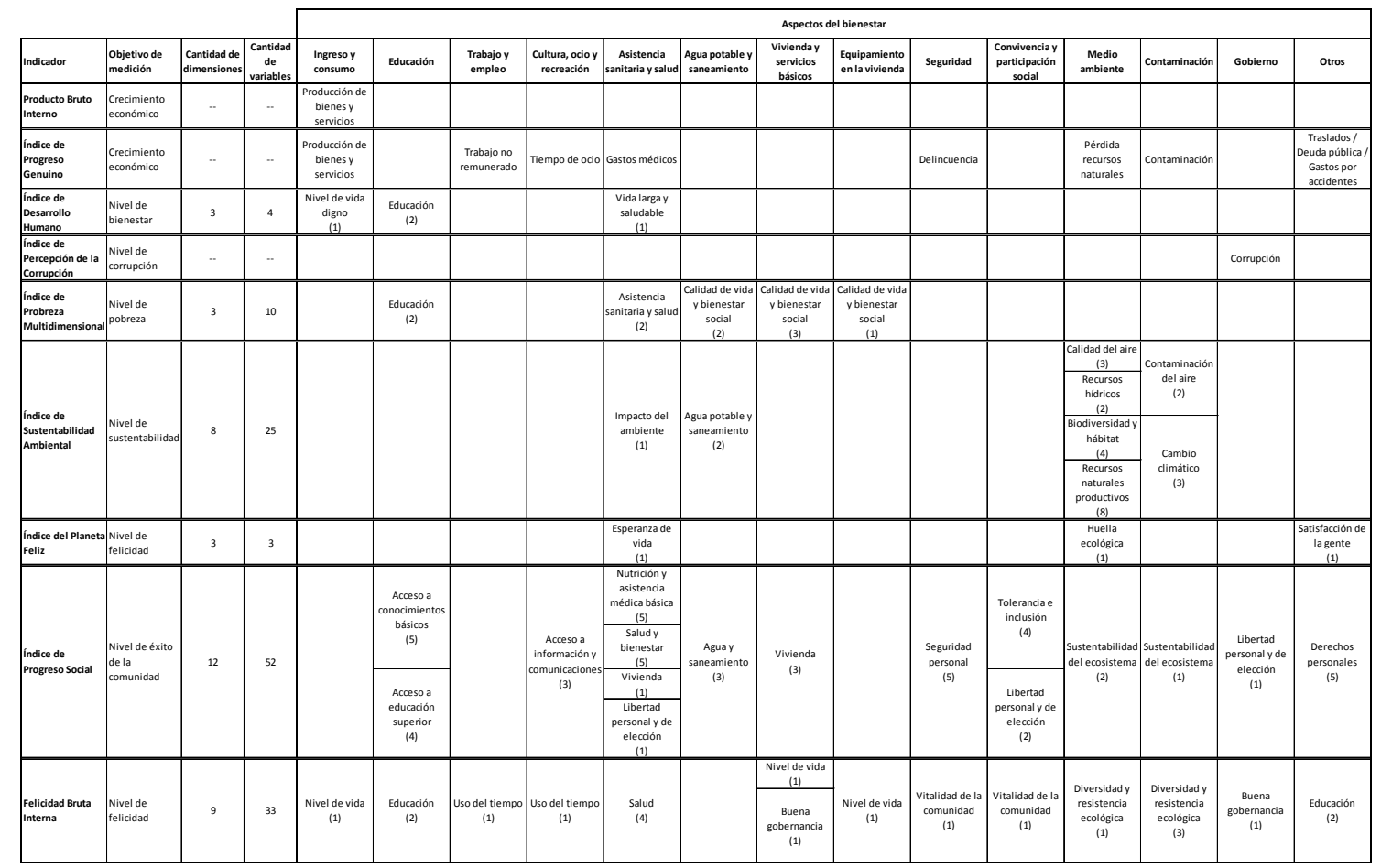

Fuente: Elaboración propia.

\section{Modelo seleccionado}

Dentro de esta búsqueda de indicadores comunitarios, durante los años 90 , se realizaron distintos estudios basados en indicadores sociales y culturales en Australia. Uno de ellos es el proyecto marco que la presente tesis considera como base para determinar el cuestionario realizado a la población tomada como muestra y definir las bases de análisis del mismo.

El proyecto se conoció como "Proyecto Nacional de la Ciudadanía" y exploró cuestiones relacionadas con la ciudadanía y la democracia, los indicadores sociales, y el desarrollo de la comunidad. 
Se inició en 1995 a través de la Universidad Tecnológica de Swinburne, Melbourne (SUT) y el Consejo de Victoria de Servicio Social (VCOSS). El Consejo Australiano de Investigación y la Fundación Myer realizaron la financiación. Además participaron otras universidades, entre ellas Deakin, RMIT, y las universidades de Nueva Gales del Sur y Tasmania.

El objetivo general del proyecto fue la determinación de puntos de referencia e indicadores que identifican una "buena sociedad" (a nivel nacional), y "buenas comunidades" (a nivel local), procurando que se combinen en "estándares de mejores prácticas", con un fuerte desarrollo de la comunidad democrática y elementos de participación ciudadana (es decir, las comunidades y los ciudadanos se pronuncian sobre las metas y prioridades que consideran importantes para su comunidad).

La idea que subyace en el proyecto es que en la sociedad australiana contemporánea las formas más influyentes de la descripción de "progreso" y "bienestar", y los indicadores y puntos de referencia en los que la mayor parte del desarrollo de políticas de influencia se centran, son los que se relacionan principalmente con el crecimiento económico de salida (PBI por ejemplo). Estos indicadores establecen efectivamente las prioridades políticas y sociales, y definen los términos del debate público, pero no se corresponden necesariamente con los valores y aspiraciones de los habitantes de la comunidad en cuanto a la clase de sociedad que quieren. Al mismo tiempo, no crean una imagen precisa o veraz del estado de la sociedad en su conjunto, especialmente en áreas como la salud de la comunidad, la equidad y la justicia, el capital social y la confianza, entre otras, por lo que son limitados para ser utilizados en la política y el debate público.

Los indicadores basados en la comunidad pueden ser un vehículo importante para identificar, y si es necesario reafirmar de manera concreta, lo que se considera significativo y valioso en la sociedad. El "Proyecto Nacional de la Ciudadanía" se inició con una revisión exhaustiva de los diferentes modelos de política de los indicadores y puntos de referencia para una "buena sociedad".

En otros ejemplos a nivel internacional se analizó: la forma en que fueron diseñados (por comités o comunidades, por consenso o experiencia), qué tipo de problemas se incluyeron (salud social, educación, etcétera), valores y conceptos generales en los que estaban enmarcados, los elementos considerados claves en el "mapa" de una "buena sociedad" (cultura, valores espirituales, bienestar material, etcétera), la forma en que se han aplicado (como controles de gestión, como herramientas de planificación, como instrumentos de cambio social o, simplemente, fueron utilizados para una mejor presentación de informes), y el éxito que han tenido en la práctica.

El modelo australiano tiene como principal ventaja que permite definir qué es lo "importante" para cada comunidad, es decir el tipo de sociedad que 
quiere ser, para luego evaluar la situación actual en que se encuentra, y así poder generar indicadores y planes de acción a seguir. Por lo tanto el modelo es totalmente integral, fue utilizado efectivamente en la práctica, y está apoyado en una democracia.

\section{Metodología}

\subsection{Población y muestra}

La población analizada se encuentra conformada por las ciudades de La Plata, Berisso y Ensenada. Con el dato del tamaño de la población seleccionada, obtenido del Censo 2010, realizado por el Instituto Nacional de Estadísticas y Censos (INDEC), se determinó el tamaño de la muestra en trescientos (300) habitantes, a través de la fórmula de muestreo de proporciones con "N" conocido:

$$
n=\frac{Z_{\alpha}^{2} \cdot N \cdot p \cdot q}{e^{2} \cdot(N-1)+Z_{\alpha}^{2} \cdot p \cdot q}
$$

Dónde:

$\mathrm{N}=654.324$ habitantes (población total de las ciudades de La Plata, Berisso y Ensenada)

$\mathrm{p}$ = prevalencia esperada del parámetro a evaluar, que en caso de desconocerse, se aplica la opción más desfavorable $(p=0,5)$, que hace mayor el tamaño muestral

$\mathrm{q}$ = complemento de la prevalencia esperada del parámetro a evaluar, es decir $1-p=0,5$

$Z_{\alpha}=1,96$ para $\alpha=5 \%$, o sea un nivel de confianza del $95 \%$

e $\quad=5,66 \%$ error de muestreo

El casco urbano de la ciudad de La Plata fue dividido en cuatro (4) zonas con similar cantidad de habitantes basándose en el dato de los radios censales de la ciudad, utilizados para la realización de los censos nacionales, que proveen información poblacional y geográfica. Sumando las localidades de Berisso y Ensenada, como zonas adicionales, la muestra total de trescientas (300) encuestas se dividió por afijación simple, realizando cincuenta (50) encuestas en cada subzona. 
Figura 1: Zonas definidas en el casco urbano de la ciudad de La Plata, junto a las ciudades de Berisso y Ensenada

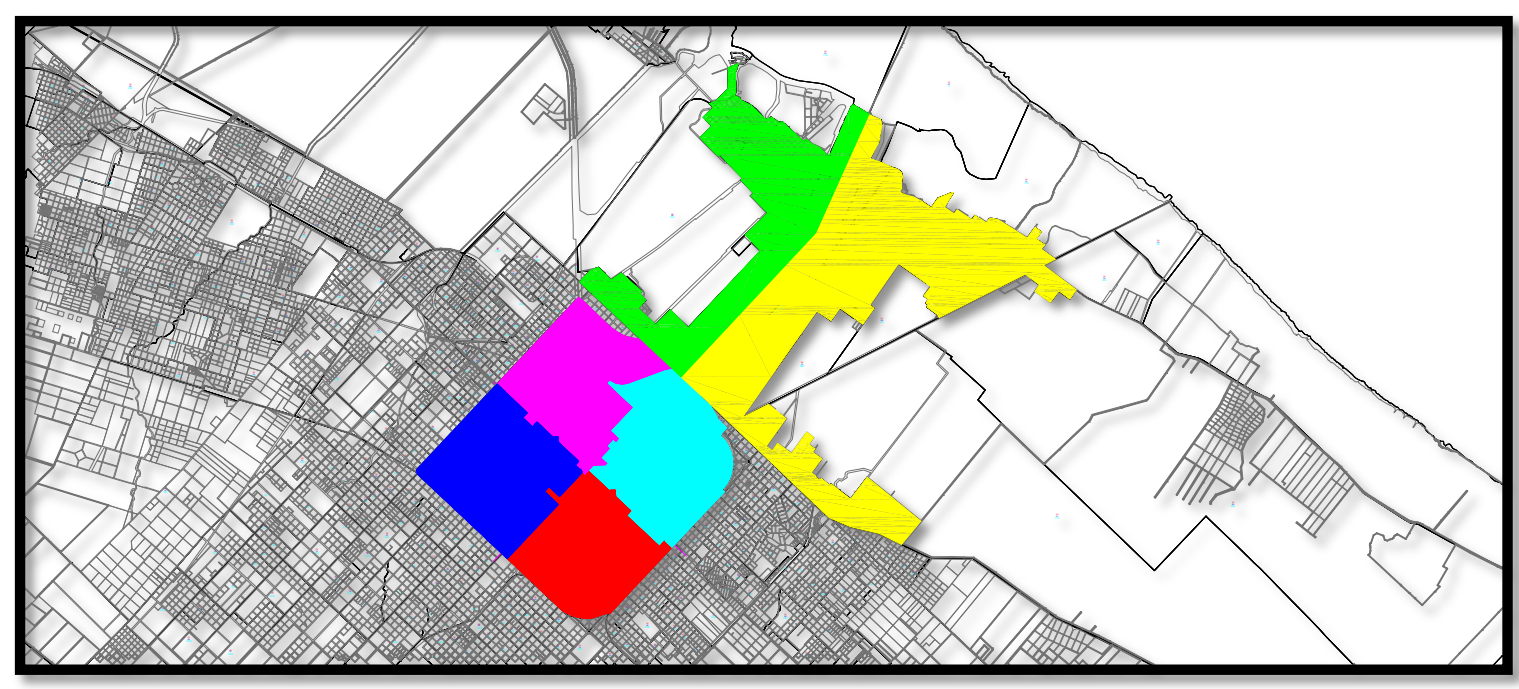

Fuente: Elaboración propia.

- Color magenta: zona norte de la ciudad de La Plata, comprendida entre las calles $120,51,13$ y 32 , con 54.034 habitantes.

- Color celeste: zona este de la ciudad de La Plata, comprendida entre las calles $120,72,13$ y 51 , con 56.080 habitantes.

- Color rojo: zona sur de la ciudad de La Plata, comprendida entre las calles $13,72,31$ y 51 , con 50.372 habitantes.

- Color azul: zona oeste de la ciudad de La Plata, comprendida entre las calles 13, 51, 31 y 32, con 52.731 habitantes.

- Color amarillo: ciudad de Berisso, donde se circunscribieron las encuestas al centro y alrededores, con 88.123 habitantes.

- Color verde: ciudad de Ensenada, con 55.629 habitantes.

En función de la distribución poblacional que tienen estas ciudades, se determinó qué cantidad de personas por edad y sexo debían ser encuestadas en cada subzona para que la muestra sea representativa.

La tabla de abajo fue desarrollada por el INDEC con los datos obtenidos del censo 2010 en todo el partido de La Plata en su conjunto. En la tabla se divide a las edades en intervalos de 5 años y establece qué cantidad de personas existen en el partido en ese intervalo. 
Tabla 2: Provincia de Buenos Aires, partido La Plata. Población total por sexo e índice de masculinidad, según grupos quinquenales de edad. Año 2010.

\begin{tabular}{|c|c|c|c|c|}
\hline \multirow{2}{*}{ Edad } & \multirow{2}{*}{ Población total } & \multicolumn{2}{|c|}{ Sexo } & \multirow{2}{*}{$\begin{array}{c}\text { Índice de } \\
\text { masculinidad }\end{array}$} \\
\hline & & Varones & Mujeres & \\
\hline Total & 654.324 & 315.263 & 339.061 & 93,0 \\
\hline $0-4$ & 49.454 & 25.193 & 24.261 & 103,8 \\
\hline $5-9$ & 48.403 & 24.648 & 23.755 & 103,8 \\
\hline $10-14$ & 46.994 & 23.930 & 23.064 & 103,8 \\
\hline $15-19$ & 51.821 & 25.906 & 25.915 & 100,0 \\
\hline $20-24$ & 61.433 & 30.630 & 30.803 & 99,4 \\
\hline $25-29$ & 55.898 & 27.904 & 27.994 & 99,7 \\
\hline $30-34$ & 53.465 & 26.311 & 27.154 & 96,9 \\
\hline $35-39$ & 46.612 & 22.887 & 23.725 & 96,5 \\
\hline $40-44$ & 39.148 & 19.284 & 19.864 & 97,1 \\
\hline $45-49$ & 35.908 & 17.565 & 18.343 & 95,8 \\
\hline $50-54$ & 33.455 & 15.796 & 17.659 & 89,5 \\
\hline $55-59$ & 30.535 & 14.122 & 16.413 & 86,0 \\
\hline $60-64$ & 27.344 & 12.476 & 14.868 & 83,9 \\
\hline $65-69$ & 22.089 & 9.767 & 12.322 & 79,3 \\
\hline $70-74$ & 17.540 & 7.322 & 10.218 & 71,7 \\
\hline $75-79$ & 14.480 & 5.551 & 8.929 & 62,2 \\
\hline $80-84$ & 11.005 & 3.654 & 7.351 & 49,7 \\
\hline $85-89$ & 6.002 & 1.720 & 4.282 & 40,2 \\
\hline $90-94$ & 2.134 & 499 & 1.635 & 30,5 \\
\hline $95-99$ & 530 & 84 & 446 & 18,8 \\
\hline 100 y más & 74 & 14 & 60 & 23,3 \\
\hline
\end{tabular}

Nota: la población total incluye a las personas viviendo en situación de calle.

$\boxminus$ índice de masculinidad indica la cantidad de varones por cada 100 mujeres.

Fuente: INDEC. Censo Nacional de Población, Hogares y Viviendas 2010.

En el presente estudio se considera que la distribución por edades y sexo se mantiene en la zona analizada, concentrando esta investigación en la población económicamente activa (desde los 20 a los 64 años).

\subsection{Tipo de investigación}

El presente trabajo de investigación es de carácter exploratorio. 


\subsection{Técnicas de recolección de datos}

El proyecto realizado en Australia $^{1}$ se encuentra dividido en tres (3) secciones, cada una basada en la anterior. Las primeras dos (2) son cuestionarios, el primero sobre ciudadanía, comunidad y valores sociales, y el segundo sobre valores y prioridades nacionales, el buen gobierno y la constitución. La tercera sección fue una actividad de focus group para realizar un relevamiento cualitativo con la participación de voluntarios encuestados previamente.

En esta investigación se utilizó como herramienta de recolección de datos la utilizada en la primera sección del proyecto australiano (ciudadanía, comunidad y valores sociales), eliminando de la misma tres (3) aspectos de los treinta y ocho (38) evaluados:

- Cuidado especial en proteger las comunidades rurales y lejanas.

- Respeto por la cultura de los indígenas.

- Aceptación de refugiados, incluso con algún costo para nosotros.

Para cada aspecto se asignó una valoración de cuán importante era lo expresado para esa sociedad (variable Importancia), y luego otra valoración calificando en qué medida se cumple lo expresado en la sociedad (variable Desempeño). Las preguntas fueron del tipo "cerrado", solicitando a cada encuestado que calificara de uno (nada importante/no se cumple) a diez (muy importante/se cumple siempre).

Las encuestas fueron personales y anónimas, pero para analizar la existencia o no de relación entre las respuestas obtenidas y el perfil demográfico de los encuestados, se solicitaron datos referidos al perfil: edad, sexo, nivel de educación y situación laboral.

La selección de participantes fue al azar en las subzonas definidas. En cada situación de contacto, se explicó al potencial encuestado sobre el origen y temática del cuestionario, informando que sus respuestas serían para un estudio realizado por la Maestría en Dirección de Empresas de la Universidad de La Plata. Con el consentimiento de la persona, se leyó el cuestionario al mismo tiempo que se fueron registrando las valoraciones otorgadas por el encuestado en cada planilla. El tiempo promedio de contacto fue de aproximadamente veinticinco (25) minutos por encuesta.

\footnotetext{
${ }^{1}$ Proyecto Nacional de la Ciudadanía - Región de Victoria. Julio 1999
} 
En la segunda sección del proyecto australiano se intentó definir qué tipo de sociedad quieren sus ciudadanos. Los dieciséis (16) tipos de sociedad definidos en el proyecto son:

1. Eficiente: el gobierno, las empresas, las comunidades y las ciudades son ordenados, bien planificados y gestionados, gastan el dinero sabiamente, y proporcionan de manera eficiente y responsable los servicios e instalaciones comunitarios.

2. Ética: hace hincapié en los valores de honestidad y ética en el gobierno, las empresas, y las relaciones personales; respeta los derechos humanos, las creencias religiosas y espirituales, los conocimientos, el aprendizaje; alienta la responsabilidad por los demás y por el medio ambiente.

3. Económicamente fuerte y productiva: industrial y tecnológicamente desarrollada, con una economía nacional e internacional fuertes y productivas, y con amplios recursos naturales.

4. Segura: habitantes respetuosos de la ley, que valoran las tradiciones y a la familia, con bajos niveles de delincuencia y violencia, y con un gran bienestar y una fuerte protección social (desempleo, salud, jubilación, etcétera)

5. Medioambientalmente responsable: protege y mejora el medio ambiente, los recursos naturales y la biodiversidad; reduce la basura y la contaminación; fomenta la responsabilidad global, el desarrollo sustentable y las energías renovables.

6. Satisfecha: con altos niveles de felicidad, salud y satisfacción, y bajos niveles de estrés, delincuencia, y violencia; con buenas relaciones y confianza entre las personas y comunidades.

7. Creativa: promueve la innovación, el espíritu empresarial y la imaginación en los negocios, el gobierno y la sociedad; valora la educación, la cultura, las artes, las nuevas ideas, las opiniones disidentes, y los debates públicos intensos.

8. Internacionalmente (regionalmente) responsable: su política exterior es independiente y justa, promueve la paz y las buenas relaciones, y es un "buen vecino" en su región; respeta la ley internacional y los derechos humanos; ayuda a los países marginados.

9. Comunitariamente inclusiva: permite desarrollarse a todas las personas, ser valoradas y participar en la sociedad; sus comunidades locales son prósperas y con cantidad de recursos; sus ciudadanos son activos y responsables; posee altos niveles de confianza y de apoyo mutuo entre las personas.

10.Políticamente activa: influyente en el mundo o su región, con poderosas fuerzas armadas o alianzas militares, que la protegen de amenazas externas. 
11. Diversa y tolerante: alienta la diversidad cultural, los diferentes estilos de vida, las opiniones disidentes, la libertad de expresión, y la libre elección de religión; respeta a los indígenas.

12. Propensa a la tecnología: incentiva la innovación y el desarrollo de la ciencia, la tecnología, la investigación, la educación, la informática, y las comunicaciones; posee ciudades modernas, industrias avanzadas y versátiles, y una fuerza laboral con habilidades y capacidades desarrolladas.

13. Justa: distribuye la riqueza, el poder, el trabajo y las oportunidades de manera equitativa; valora la igualdad y los derechos humanos; tiene un gobierno honesto y leyes objetivas; brinda a todos la oportunidad de desarrollar su potencial; protege a las personas desfavorecidas y vulnerables.

14. Competitiva: fomenta y premia la competencia y la iniciativa individual; valora las libertades personales, la autosuficiencia, el autodesarrollo, el liderazgo, y los mercados de "libre empresa".

15. Democrática: posee instituciones democráticas abiertas y activas, un gobierno efectivo y confiable, leyes equitativas, derechos y libertades desarrolladas, y personas capaces de participar en la toma de decisiones que los afectan.

16. Con alto nivel de vida: alcanza altos estándares de vida en sus ciudadanos con buenos niveles de ingresos, salud, educación, vivienda, trabajo, recreación, transporte, desarrollo urbano, etcétera.

Con los aspectos relevados en las encuestas realizadas en esta investigación y los tipos de sociedad mencionados, identificaremos los factores que son "importantes" para los ciudadanos de la ciudad de Ensenada y las principales clases de sociedad en que prefieren vivir.

\subsection{Técnicas de análisis}

El procesamiento de los datos se llevó a cabo a partir de la clasificación, registro y codificación de los mismos. Todas las encuestas obtenidas se cargaron en una matriz donde en las columnas se situaron las valoraciones y datos demográficos, y las filas se correspondían con cada individuo encuestado. Las respuestas a los datos demográficos fueron codificadas numéricamente para facilitar su carga en la base de datos.

Como en el proyecto australiano se calcularon dos (2) variables adicionales a la de Importancia y Desempeño obtenidas con las respuestas de las encuestas, combinándolas de la siguiente manera:

1. Discrepancia $=$ Desempeño - Importancia

2. Gravedad Percibida $=-1$ * Discrepancia * Importancia 
De todas las variables numéricas se obtuvieron los promedios para poder jerarquizarlas y las varianzas para tener una idea de la dispersión de las mismas, determinando así los valores más importantes para la sociedad de la ciudad de Ensenada y compararlos con los resultados obtenidos para la región y en Australia.

La tabla de abajo muestra en la columna (a) la valoración promedio que los encuestados dieron a la Importancia de los treinta y cinco (35) aspectos evaluados, y en la columna (a') la jerarquización de las mismas.

Tabla 3

\begin{tabular}{|l|l|c|c|}
\cline { 3 - 3 } \multicolumn{2}{l|}{} & \multicolumn{2}{c|}{ Importancia } \\
\hline Item & Características & $\begin{array}{c}\text { Calificación 1-10 } \\
\text { (a) }\end{array}$ & $\begin{array}{c}\text { Jerarquía 1-35 } \\
\text { (a') }\end{array}$ \\
\hline
\end{tabular}

Fuente: Elaboración propia.

En la tabla de abajo la columna (b) muestra la valoración promedio que los encuestados dieron al Desempeño de los treinta y cinco (35) aspectos, y en la columna (b') la jerarquización de las mismas.

Tabla 4

\begin{tabular}{|c|c|c|c|}
\hline & & \multicolumn{2}{|c|}{ Desempeño } \\
\hline Item & Características & $\begin{array}{l}\text { Calificación 1-10 } \\
\text { (b) }\end{array}$ & $\begin{array}{c}\text { Jerarquía 1-35 } \\
\text { (b') }\end{array}$ \\
\hline
\end{tabular}

Fuente: Elaboración propia.

En la siguiente tabla la columna (d) muestra la Discrepancia entre la Importancia y el Desempeño.

Tabla 5

\begin{tabular}{|l|l|c|}
\cline { 3 - 3 } Item & Características & Discrepancia \\
\hline
\end{tabular}

Fuente: Elaboración propia.

En la última tabla se muestra en la columna ( $\mathrm{g}$ ) la ponderación de la Discrepancia de cada atributo con la Importancia asignada al mismo, dando una idea de la Gravedad Percibida en cada uno, y en la columna ( $g$ ') la jerarquización de las mismas.

Tabla 6

\begin{tabular}{|l|l|c|c|}
\cline { 3 - 3 } \multicolumn{2}{c|}{} & \multicolumn{2}{c|}{ Gravedad Percibida } \\
\hline Item & Características & $\begin{array}{c}\text { Ponderación } \\
\left(\mathrm{g}^{2}=-\mathrm{d}^{*} \mathrm{a}\right)\end{array}$ & $\begin{array}{c}\text { Jerarquía 1-35 } \\
\left(\mathrm{g}^{\prime}\right)\end{array}$ \\
\hline
\end{tabular}

Fuente: Elaboración propia. 
También se analizó la existencia de relación entre las respuestas y los distintos grupos demográficos encuestados. Para esto se realizó la prueba etha-cuadrado que mide la correlación entre una variable categórica y una real:

$$
\eta=\sqrt{\frac{V_{\text {entre }}}{V}}
$$

Dónde:

$\mu \quad=\frac{1}{N} \sum N_{k} \mu_{k}$

La media de la variable sobre el conjunto de la variable cualitativa es la media de las medias de los grupos $\left(\mu_{k}\right)$, ponderados por las frecuencias absolutas de los grupos $\left(N_{k}\right)$.

$V_{\text {entre }}=\frac{1}{N} \sum N_{k} \mu_{k}^{2}-\mu^{2}$

La varianza entre los grupos (o entre las clases) es la varianza de las medias.

$V_{\text {dentro }}=\frac{1}{N} \sum N_{k} V_{k}$

La varianza dentro de los grupos (o dentro de las clases) es la media de las varianzas.

$V=V_{\text {entre }}+V_{\text {dentro }} \quad$ La varianza total es la sumatoria de la varianza entre con la varianza dentro.

Los valores de este índice están comprendidos entre cero (0) y uno (1), tomando el valor cero cuando la varianza entre es nula, lo cual evidencia la ausencia de vínculo entre ambas variables. Por el contrario, el valor es uno cuándo la varianza entre es igual a la varianza total, demostrando un fuerte vínculo entre ambas variables.

\section{Resultados de la investigación}

\subsection{Perfil de los encuestados}

\section{Sexo y Edad}

La tabla de abajo muestra los datos del censo poblacional del 2010 sobre la población económicamente activa, sub-grupo seleccionado para esta investigación. 
Tabla 7: Provincia de Buenos Aires, partido La Plata. Población total por sexo e índice de masculinidad, según grupos quinquenales de edad de la población económicamente activa. Año 2010.

\begin{tabular}{|c|c|c|c|c|c|}
\hline \multirow{2}{*}{ Edad } & \multirow{2}{*}{ Población total } & \multicolumn{2}{|c|}{ Sexo } & \multirow{2}{*}{$\begin{array}{c}\text { Índice de } \\
\text { masculinidad }\end{array}$} & \multirow{2}{*}{$\begin{array}{l}\text { Porcentaje } \\
\text { participación }\end{array}$} \\
\hline & & Varones & Mujeres & & \\
\hline Total & 383.798 & 186.975 & 196.823 & 95,0 & $100,00 \%$ \\
\hline $20-24$ & 61.433 & 30.630 & 30.803 & 99,4 & $16,01 \%$ \\
\hline $25-29$ & 55.898 & 27.904 & 27.994 & 99,7 & $14,56 \%$ \\
\hline $30-34$ & 53.465 & 26.311 & 27.154 & 96,9 & $13,93 \%$ \\
\hline $35-39$ & 46.612 & 22.887 & 23.725 & 96,5 & $12,14 \%$ \\
\hline $40-44$ & 39.148 & 19.284 & 19.864 & 97,1 & $10,20 \%$ \\
\hline $45-49$ & 35.908 & 17.565 & 18.343 & 95,8 & $9,36 \%$ \\
\hline $50-54$ & 33.455 & 15.796 & 17.659 & 89,5 & $8,72 \%$ \\
\hline $55-59$ & 30.535 & 14.122 & 16.413 & 86,0 & $7,96 \%$ \\
\hline $60-64$ & 27.344 & 12.476 & 14.868 & 83,9 & $7,12 \%$ \\
\hline
\end{tabular}

Nota: la población total incluye a las personas viviendo en situación de calle.

$\boxminus$ índice de masculinidad inc tidad de varones por cada 100 mujeres.

Fuente: INDEC. Censo Nacional de Población, Hogares y Viviendas 2010.

En la última columna de la derecha se calcularon los porcentajes de participación de cada intervalo de edades en el total de la población seleccionada.

La tabla de abajo muestra los datos obtenidos del procesamiento de resultados de todas las encuestas realizadas en la región.

Tabla 8

\begin{tabular}{|c|c|c|c|c|c|}
\hline \multirow{2}{*}{ Edad } & \multirow{2}{*}{ Población total } & \multicolumn{2}{|c|}{ Sexo } & \multirow{2}{*}{$\begin{array}{c}\text { Índice de } \\
\text { masculinidad }\end{array}$} & \multirow{2}{*}{$\begin{array}{l}\text { Porcentaje } \\
\text { participación }\end{array}$} \\
\hline & & Varones & Mujeres & & \\
\hline Total & 300 & 146 & 154 & 94,8 & $100,00 \%$ \\
\hline $20-24$ & 48 & 15 & 33 & 45,5 & $16,00 \%$ \\
\hline $25-29$ & 51 & 25 & 26 & 96,2 & $17,00 \%$ \\
\hline $30-34$ & 53 & 31 & 22 & 140,9 & $17,67 \%$ \\
\hline $35-39$ & 32 & 14 & 18 & 77,8 & $10,67 \%$ \\
\hline $40-44$ & 32 & 18 & 14 & 128,6 & $10,67 \%$ \\
\hline $45-49$ & 25 & 12 & 13 & 92,3 & $8,33 \%$ \\
\hline $50-54$ & 20 & 7 & 13 & 53,8 & $6,67 \%$ \\
\hline $55-59$ & 17 & 11 & 6 & 183,3 & $5,67 \%$ \\
\hline $60-64$ & 22 & 13 & 9 & 144,4 & $7,33 \%$ \\
\hline
\end{tabular}

Fuente: Elaboración propia.

El índice de masculinidad resultante con las encuestas realizadas fue de 94,8. Este índice es muy cercano al 95,0 obtenido en el censo poblacional de 
2010 sobre la población económicamente activa. El valor del índice de masculinidad de las encuestas realizadas en la ciudad de Ensenada fue de 92,6 como se observa en la tabla de abajo.

Tabla 9

\begin{tabular}{|c|c|c|c|c|c|c|c|}
\hline Sexo & La Plata Norte & La Plata Sur & La Plata Oeste & La Plata Este & Ensenada & Berisso & Total \\
\hline Total & 51 & 48 & 49 & 50 & 52 & 50 & 300 \\
\hline Varones & 24 & 24 & 24 & 24 & 25 & 25 & 146 \\
\hline Mujeres & 27 & 24 & 25 & 26 & 27 & 25 & 154 \\
\hline $\begin{array}{c}\text { Índice de } \\
\text { masculinidad }\end{array}$ & 88,9 & 100,0 & 96,0 & 92,3 & 92,6 & 100,0 & 94,8 \\
\hline
\end{tabular}

Fuente: Elaboración propia.

En la figura de abajo se comparan los porcentajes de participación de cada intervalo de edades en el total de la población seleccionada de las tablas 7 y 8 , observándose que ambas son bastante similares.

\section{Figura 2}

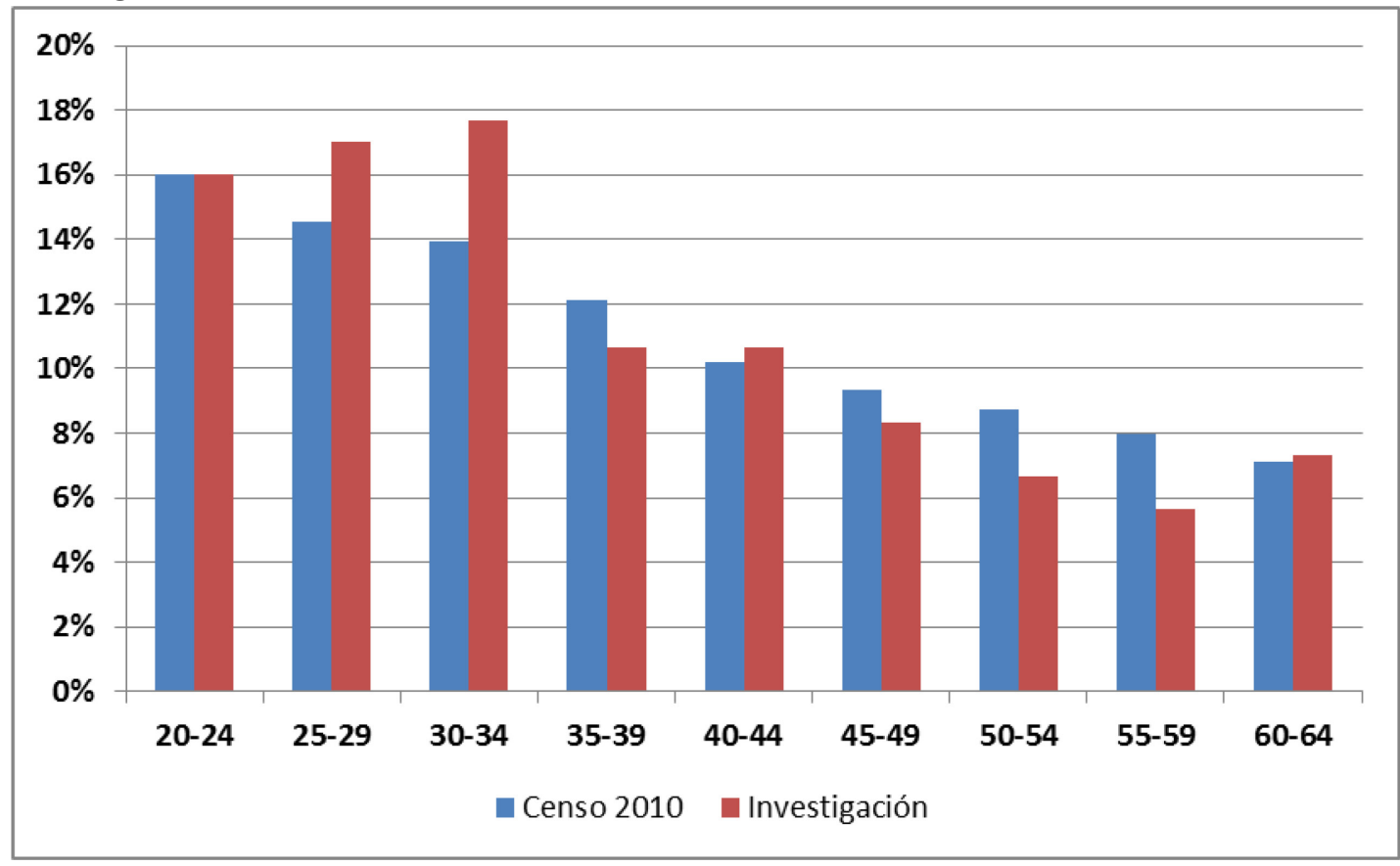

Fuente: Elaboración propia.

La edad promedio de la población encuestada fue de 37,5 años y en la ciudad de Ensenada de 39,7 años. 


\section{Educación y Situación Laboral}

En la siguiente figura se muestra la participación de los niveles de educación alcanzados en el total de las encuestas realizadas.

\section{Figura 3}

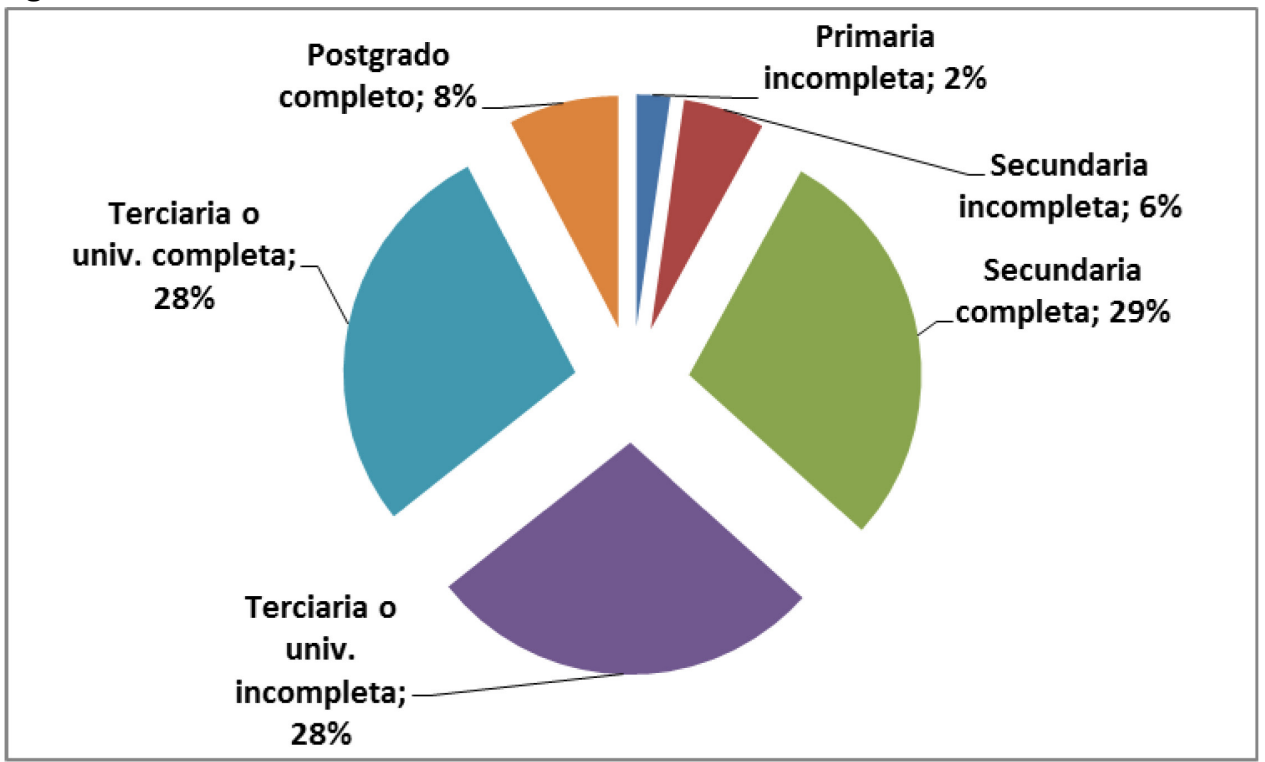

Fuente: Elaboración propia.

A continuación se muestra la participación de las distintas situaciones laborales de los encuestados.

\section{Figura 4}

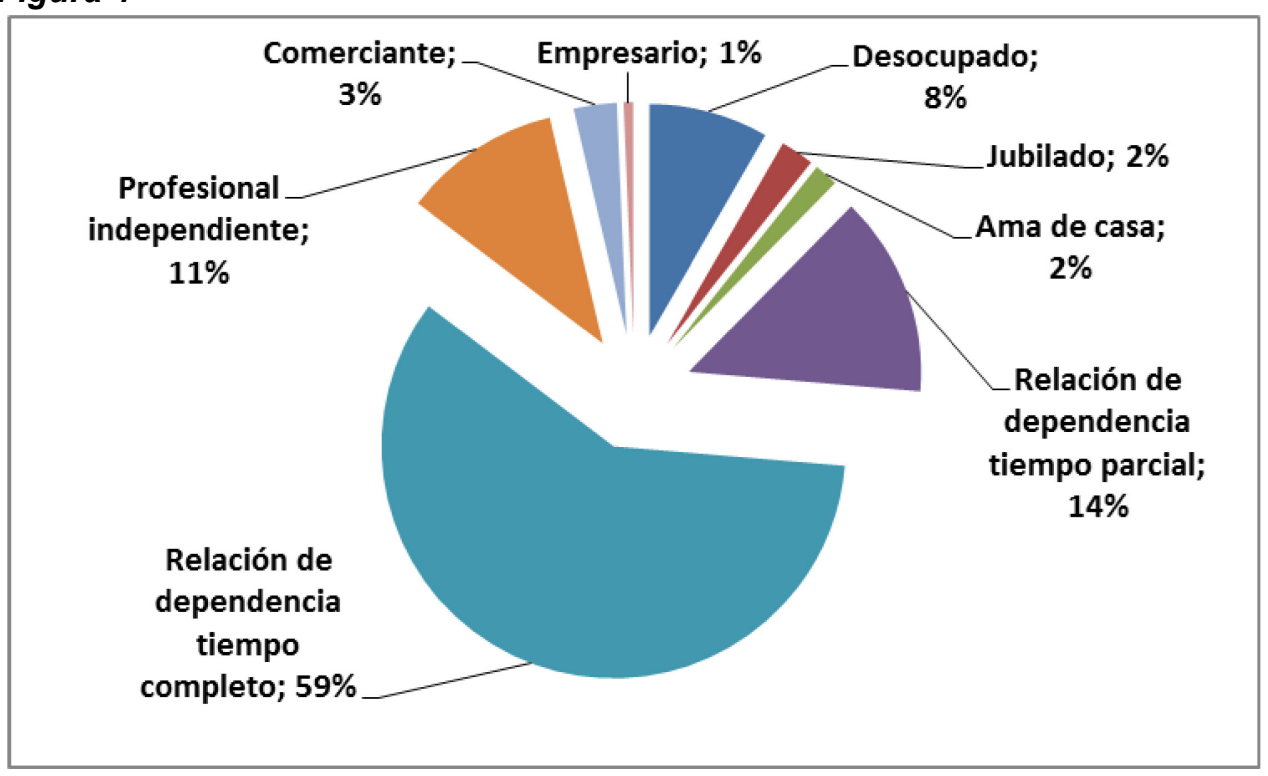

Fuente: Elaboración propia. 


\subsection{Análisis de correlaciones}

En el Anexo I se muestran los valores obtenidos al realizar la prueba etha-cuadrado entre las variables categóricas (zona, sexo, grupo etario, nivel de educación, y situación laboral) y las variables reales (importancia, desempeño, discrepancia y gravedad percibida) para cada uno de los aspectos.

Como todos los valores se encuentran entre 0 y 0,25 no existe relación significativa entre las respuestas dadas por los encuestados y las variables categóricas consideradas.

\subsection{Resultados en la ciudad de Ensenada}

\section{Importancia}

La siguiente tabla resume los resultados de la encuesta, ordenados por su jerarquía de importancia, que dan respuesta a la pregunta: "¿Cuán importante es para usted ..."

Tabla 10

\begin{tabular}{|c|l|c|c|}
\cline { 3 - 4 } \multicolumn{2}{l|}{} & \multicolumn{2}{c|}{$\begin{array}{c}\text { Importancia en la } \\
\text { ciudad de Ensenada }\end{array}$} \\
\hline Item & Características & $\begin{array}{c}\text { Calificación 1-10 } \\
\text { (a) }\end{array}$ & $\begin{array}{c}\text { Jerarquía 1-35 } \\
\text { (a') }\end{array}$ \\
\hline 5 & Eliminación del crimen y la violencia & 9,75 & 1 \\
\hline 3 & Los derechos humanos básicos de todos los ciudadanos están fuertemente protegidos & 9,71 & 2 \\
\hline 2 & Todos son tratados igualitaria y equitativamente por la ley & 9,67 & 3 \\
\hline 4 & Buena calidad de los servicios básicos (salud, educación, etc.) para todos & 9,65 & 4 \\
\hline 9 & Confianza justificada en que las instituciones públicas actúan con limpieza y justicia & 9,52 & 5 \\
\hline 1 & Altos niveles de honestidad en la pollíca y la vida pública & 9,48 & 6 \\
\hline 7 & Igualdad de oportunidades para hombres y mujeres & 9,46 & 7 \\
\hline 18 & Respeto por, y estricta aplicación de las leyes & 9,44 & 8 \\
\hline 26 & Vigorosa libertad de opinión, múltiples opiniones públicas (disensos) & 9,38 & 9 \\
\hline 30 & Libertad para hacer lo que nos gusta siempre que no perjudiquemos a otros & 9,37 & 10 \\
\hline 20 & Fuerte protección social (edad, enfermedad, desempleo, etc.) & 9,29 & 11 \\
\hline 8 & Todos pagan impuestos equitativamente, acorde con el ingreso y riqueza & 9,27 & 12 \\
\hline 31 & Generosidad en ayudar a regiones perjudicadas & 9,21 & 13 \\
\hline 11 & Buena atención a las personas vulnerables, disminuidos y de clase baja & 9,15 & 14 \\
\hline 15 & Se alienta la vida familiar y los valores de la familia & 9,12 & 15 \\
\hline 10 & Las comunidades locales tienen buena calidad de servicios públicos (transporte, luz, etc.) & 9,10 & 16 \\
\hline 6 & Protección del medioambiente, recursos y fauna & 9,08 & 17 \\
\hline 19 & Trabajos seguros, satisfactorios y equitativamente pagados para todos los que quieren trabajar & 9,06 & 18 \\
\hline 12 & Reducción de la contaminación medioambiental, desarrollo de fuentes de energía renovables & 9,04 & 19 \\
\hline 17 & Eliminación de la pobreza & 9,02 & 20 \\
\hline
\end{tabular}




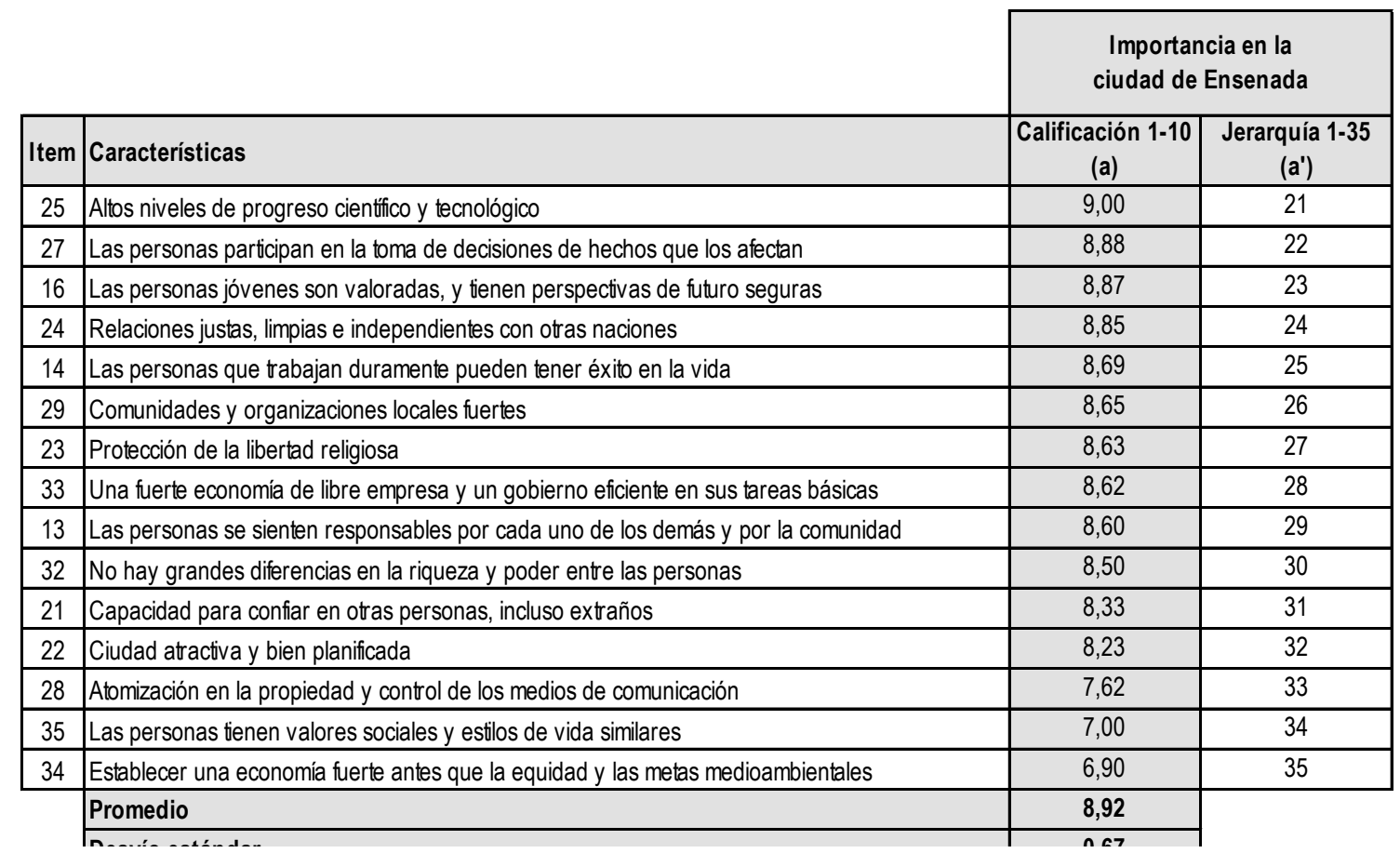

Fuente: Elaboración propia.

Analizando la tabla vemos que para los ciudadanos de Ensenada los treinta y cinco (35) aspectos evaluados son muy valorados, con un promedio de importancia de 8,92.

Veintiún (21) atributos tienen una importancia mayor a nueve (9) y del total sólo tres (3) no están altamente valorados, con una importancia menor a ocho (8).

Los cinco (5) atributos más importantes, con valores de importancia mayores a 9,50, tienen una relación directa con estos tipos de sociedades:

- "Eliminación del crimen y la violencia" con sociedades seguras y satisfechas.

- "Los derechos humanos básicos de todos los ciudadanos están fuertemente protegidos" con sociedades éticas, democráticas, y comunitariamente inclusivas.

- "Todos son tratados igualitaria y equitativamente por la ley" con sociedades éticas, justas, democráticas, y diversas y tolerantes.

- "Buena calidad de los servicios básicos (salud, educación, etc.) para todos" con sociedades eficientes y con alto nivel de vida.

- "Confianza justificada en que las instituciones públicas actúan con limpieza y justicia" con sociedades éticas. 


\section{Desempeño}

La próxima tabla resume los resultados de la encuesta, ordenados por su jerarquía de desempeño, respuesta a la pregunta: "Califique en qué medida se da en la realidad..."

Tabla 11

\begin{tabular}{|c|c|c|c|}
\hline \multirow[b]{2}{*}{ Item } & \multirow[b]{2}{*}{ Características } & \multicolumn{2}{|c|}{$\begin{array}{l}\text { Desempeño en la } \\
\text { ciudad de Ensenada }\end{array}$} \\
\hline & & $\begin{array}{c}\text { Calificación 1-10 } \\
\text { (b) }\end{array}$ & $\begin{array}{c}\text { Jerarquía 1-35 } \\
\text { (b') }\end{array}$ \\
\hline 23 & Protección de la libertad religiosa & 7,54 & 1 \\
\hline 7 & Igualdad de oportunidades para hombres y mujeres & 7,00 & 2 \\
\hline 31 & Generosidad en ayudar a regiones perjudicadas & 6,40 & 3 \\
\hline 26 & Vigorosa libertad de opinión, múltiples opiniones públicas (disensos) & 6,12 & 4 \\
\hline 15 & Se alienta la vida familiar y los valores de la familia & 5,81 & 5 \\
\hline 24 & Relaciones justas, limpias e independientes con otras naciones & 5,54 & 6 \\
\hline 25 & Altos niveles de progreso cientifico y tecnológico & 5,29 & 7 \\
\hline 30 & Libertad para hacer lo que nos gusta siempre que no perjudiquemos a otros & 5,29 & 7 \\
\hline 3 & Los derechos humanos básicos de todos los ciudadanos están fuertemente protegidos & 5,21 & 9 \\
\hline 34 & Establecer una economía fuerte antes que la equidad y las metas medioambientales & 5,19 & 10 \\
\hline 11 & Buena atención a las personas vulnerables, disminuidos y de clase baja & 5,13 & 11 \\
\hline 14 & Las personas que trabajan duramente pueden tener éxito en la vida & 5,10 & 12 \\
\hline 29 & Comunidades y organizaciones locales fuertes & 5,06 & 13 \\
\hline 4 & Buena calidad de los servicios básicos (salud, educación, etc.) para todos & 4,92 & 14 \\
\hline 6 & Protección del medioambiente, recursos y fauna & 4,92 & 14 \\
\hline 28 & Atomización en la propiedad y control de los medios de comunicación & 4,90 & 16 \\
\hline 22 & Ciudad atractiva y bien planificada & 4,88 & 17 \\
\hline 20 & Fuerte protección social (edad, enfermedad, desempleo, etc.) & 4,83 & 18 \\
\hline 27 & Las personas participan en la toma de decisiones de hechos que los afectan & 4,77 & 19 \\
\hline 17 & Eliminación de la pobreza & 4,73 & 20 \\
\hline 10 & Las comunidades locales tienen buena calidad de servicios públicos (transporte, luz, etc.) & 4,69 & 21 \\
\hline 16 & Las personas jóvenes son valoradas, y tienen perspectivas de futuro seguras & 4,60 & 22 \\
\hline 19 & Trabajos seguros, satisfactorios y equitativamente pagados para todos los que quieren trabajar & 4,54 & 23 \\
\hline 13 & Las personas se sienten responsables por cada uno de los demás y por la comunidad & 4,42 & 24 \\
\hline 2 & Todos son tratados igualitaria y equitativamente por la ley & 4,40 & 25 \\
\hline 35 & Las personas tienen valores sociales y estilos de vida similares & 4,40 & 25 \\
\hline 8 & Todos pagan impuestos equitativamente, acorde con el ingreso y riqueza & 4,38 & 27 \\
\hline 12 & Reducción de la contaminación medioambiental, desarrollo de fuentes de energía renovables & 4,31 & 28 \\
\hline 18 & Respeto por, y estricta aplicación de las leyes & 4,12 & 29 \\
\hline 33 & Una fuerte economía de libre empresa y un gobierno eficiente en sus tareas básicas & 4,10 & 30 \\
\hline 9 & Confianza justificada en que las instituciones públicas actúan con limpieza y justicia & 4,04 & 31 \\
\hline 21 & Capacidad para confiar en otras personas, incluso extraños & 3,77 & 32 \\
\hline 1 & Altos niveles de honestidad en la política y la vida pública & 3,75 & 33 \\
\hline 5 & Eliminación del crimen y la violencia & 3,46 & 34 \\
\hline \multirow[t]{3}{*}{32} & No hay grandes diferencias en la riqueza y poder entre las personas & 3,29 & 35 \\
\hline & Promedio & 4,88 & \\
\hline & Desvío estándar & 0,91 & \\
\hline
\end{tabular}

Fuente: Elaboración propia.

Analizando la tabla vemos que ninguno de los aspectos evaluados puede considerarse con un alto desempeño, ya que ninguno supera el valor ocho (8), siendo el promedio de desempeño de todos los atributos de 4,88.

Los únicos cuatro (4) aspectos con desempeño mayor a seis (6) tienen una relación directa con estos tipos de sociedades: 
- $\quad$ "Protección de la libertad religiosa" con sociedades éticas, y diversas y tolerantes.

- "Igualdad de oportunidades para hombres y mujeres" con sociedades justas, democráticas, y comunitariamente inclusivas.

- "Generosidad en ayudar a regiones perjudicadas" con sociedades regionalmente responsables.

- "Vigorosa libertad de opinión, múltiples opiniones públicas (disensos)" con sociedades creativas y competitivas.

\section{Discrepancia}

La tabla a continuación muestra las discrepancias de las características analizadas, es decir las diferencias entre los desempeños y las importancias obtenidas como resultados en la encuesta, ordenadas de menor a mayor, junto con su jerarquía de importancia.

Tabla 12

\begin{tabular}{|c|c|c|c|}
\hline & & $\begin{array}{c}\text { Discrepancia en } \\
\text { la ciudad de } \\
\text { Ensenada }\end{array}$ & $\begin{array}{l}\text { Importancia en } \\
\text { la ciudad de } \\
\text { Ensenada }\end{array}$ \\
\hline Item & Características & $\begin{array}{c}\text { Valor } \\
(d=b-a)\end{array}$ & $\begin{array}{c}\text { Jerarquía 1-35 } \\
\left(a^{\prime}\right)\end{array}$ \\
\hline 5 & Eliminación del crimen y la violencia & $-6,29$ & 1 \\
\hline 1 & Altos niveles de honestidad en la politica y la vida pública & $-5,73$ & 6 \\
\hline 9 & Confianza justificada en que las instituciones públicas actúan con limpieza y justicia & $-5,48$ & 5 \\
\hline 18 & Respeto por, y estricta aplicación de las leyes & $-5,33$ & 8 \\
\hline 2 & Todos son tratados igualitaria y equitativamente por la ley & $-5,27$ & 3 \\
\hline 32 & No hay grandes diferencias en la riqueza y poder entre las personas & $-5,21$ & 30 \\
\hline 8 & Todos pagan impuestos equitativamente, acorde con el ingreso y riqueza & $-4,88$ & 12 \\
\hline 4 & Buena calidad de los servicios básicos (salud, educación, etc.) para todos & $-4,73$ & 4 \\
\hline 12 & Reducción de la contaminación medioambiental, desarrollo de fuentes de energía renovables & $-4,73$ & 19 \\
\hline 21 & Capacidad para confiar en otras personas, incluso extraños & $-4,56$ & 31 \\
\hline 19 & Trabajos seguros, satisfactorios y equitativamente pagados para todos los que quieren trabajar & $-4,52$ & 18 \\
\hline 33 & Una fuerte economía de libre empresa y un gobierno eficiente en sus tareas básicas & $-4,52$ & 28 \\
\hline 3 & Los derechos humanos básicos de todos los ciudadanos están fuertemente protegidos & $-4,50$ & 2 \\
\hline 20 & Fuerte protección social (edad, enfermedad, desempleo, etc.) & $-4,46$ & 11 \\
\hline 10 & Las comunidades locales tienen buena calidad de servicios públicos (transporte, luz, etc.) & $-4,40$ & 16 \\
\hline 17 & Eliminación de la pobreza & $-4,29$ & 20 \\
\hline 16 & Las personas jóvenes son valoradas, y tienen perspectivas de futuro seguras & $-4,27$ & 23 \\
\hline 13 & Las personas se sienten responsables por cada uno de los demás y por la comunidad & $-4,17$ & 29 \\
\hline 6 & Protección del medioambiente, recursos y fauna & $-4,15$ & 17 \\
\hline 27 & Las personas participan en la toma de decisiones de hechos que los afectan & $-4,12$ & 22 \\
\hline 30 & Libertad para hacer lo que nos gusta siempre que no perjudiquemos a otros & $-4,08$ & 10 \\
\hline 11 & Buena atención a las personas vulnerables, disminuidos y de clase baja & $-4,02$ & 14 \\
\hline 25 & Altos niveles de progreso cientifico y tecnológico & $-3,71$ & 21 \\
\hline 14 & Las personas que trabajan duramente pueden tener éxito en la vida & $-3,60$ & 25 \\
\hline 29 & Comunidades y organizaciones locales fuertes & $-3,60$ & 26 \\
\hline
\end{tabular}




\begin{tabular}{|c|c|c|c|}
\hline & & \multirow{3}{*}{\begin{tabular}{|c}
$\begin{array}{c}\text { Discrepancia en } \\
\text { la ciudad de } \\
\text { Ensenada }\end{array}$ \\
Valor \\
$(\mathrm{d}=\mathrm{b}-\mathrm{a})$
\end{tabular}} & \multirow{3}{*}{$\begin{array}{l}\text { Importancia en } \\
\text { la ciudad de } \\
\text { Ensenada } \\
\text { Jerarquía 1-35 } \\
\text { (a') }\end{array}$} \\
\hline & & & \\
\hline Item & Características & & \\
\hline 22 & Ciudad atractiva y bien planificada & $-3,35$ & 32 \\
\hline 15 & Se alienta la vida familiar y los valores de la familia & $-3,31$ & 15 \\
\hline 24 & Relaciones justas, limpias e independientes con otras naciones & $-3,31$ & 24 \\
\hline 26 & Vigorosa libertad de opinión, múltiples opiniones públicas (disensos) & $-3,27$ & 9 \\
\hline 31 & Generosidad en ayudar a regiones perjudicadas & $-2,81$ & 13 \\
\hline 28 & Atomización en la propiedad y control de los medios de comunicación & $-2,71$ & 33 \\
\hline 35 & Las personas tienen valores sociales y estilos de vida similares & $-2,60$ & 34 \\
\hline 7 & Igualdad de oportunidades para hombres y mujeres & $-2,46$ & 7 \\
\hline 34 & Establecer una economía fuerte antes que la equidad y las metas medioambientales & $-1,71$ & 35 \\
\hline \multirow[t]{2}{*}{23} & Protección de la libertad religiosa & $-1,10$ & 27 \\
\hline & Promedio & $-4,04$ & \\
\hline
\end{tabular}

Fuente: Elaboración propia.

Observando la tabla vemos que ninguno de los treinta y cinco (35) aspectos evaluados tiene un desempeño mayor a la importancia que le atribuyen los ciudadanos, con promedio de discrepancia de $-4,04$.

Las cinco (5) características con las mayores discrepancias en valor absoluto están dentro de las ocho (8) de mayor importancia. Estos aspectos en que los desempeños están muy por debajo de sus importancias, con su jerarquía de importancia y los tipos de sociedades con que se relacionan son:

- "Eliminación del crimen y la violencia" con jerarquía uno (1), y sociedades seguras y satisfechas.

- "Altos niveles de honestidad en la política y la vida pública" con jerarquía seis (6), y sociedades éticas y justas.

- "Confianza justificada en que las instituciones públicas actúan con limpieza y justicia" con jerarquía cinco (5), y sociedades éticas.

- "Respeto por, y estricta aplicación de las leyes" con jerarquía ocho (8), y sociedades seguras.

- "Todos son tratados igualitaria y equitativamente por la ley" con jerarquía tres (3), y sociedades éticas, justas, democráticas, y diversas y tolerantes.

En el otro extremo, las cinco (5) características con menor discrepancia, a excepción de "Igualdad de oportunidades para hombres y mujeres" con jerarquía siete (7), se encuentran en el orden veintisiete (27) o posteriores de importancia.

\section{Gravedad Percibida}

La tabla de abajo resume las gravedades percibidas, obtenidas mediante la ponderación de las discrepancias con las importancias de las características analizadas. Esta variable intenta medir la situación de gravedad en que se 
encuentra cada aspecto estudiado según los resultados obtenidos en la encuesta.

Tabla 13

\begin{tabular}{|c|c|c|c|}
\hline \multirow[b]{2}{*}{ Item } & \multirow[b]{2}{*}{ Características } & \multicolumn{2}{|c|}{$\begin{array}{l}\text { Gravedad Percibida en la } \\
\text { ciudad de Ensenada }\end{array}$} \\
\hline & & $\begin{array}{c}\text { Ponderación } \\
\left(g=-d^{*} a\right)\end{array}$ & $\begin{array}{c}\text { Jerarquía 1-35 } \\
\left(g^{\prime}\right)\end{array}$ \\
\hline 5 & Eliminación del crimen y la violencia & 61,85 & 1 \\
\hline 1 & Altos niveles de honestidad en la política y la vida pública & 55,06 & 2 \\
\hline 9 & Confanza justificada en que las instituciones públicas actúan con limpieza y justicia & 53,23 & 3 \\
\hline 2 & Todos son tratados igualitaria y equitativamente por la ley & 51,37 & 4 \\
\hline 18 & Respeto por, y estricta aplicación de las leyes & 51,37 & 4 \\
\hline 32 & No hay grandes diferencias en la riqueza y poder entre las personas & 48,13 & 6 \\
\hline 8 & Todos pagan impuestos equitativamente, acorde con el ingreso y riqueza & 46,27 & 7 \\
\hline 4 & Buena calidad de los servicios básicos (salud, educación, etc.) para todos & 46,17 & 8 \\
\hline 33 & Una fuerte economía de libre empresa y un gobierno eficiente en sus tareas básicas & 44,56 & 9 \\
\hline 3 & Los derechos humanos básicos de todos los ciudadanos están fuertemente protegidos & 44,42 & 10 \\
\hline 12 & Reducción de la contaminación medioambiental, desarrollo de fuentes de energía renovables & 43,96 & 11 \\
\hline 19 & Trabajos seguros, satisfactorios y equitativamente pagados para todos los que quieren trabajar & 42,71 & 12 \\
\hline 20 & Fuerte protección social (edad, enfermedad, desempleo, etc.) & 41,85 & 13 \\
\hline 10 & Las comunidades locales tienen buena calidad de servicios públicos (transporte, luz, etc.) & 41,38 & 14 \\
\hline 21 & Capacidad para confiar en otras personas, incluso extraños & 40,62 & 15 \\
\hline 17 & Eliminación de la pobreza & 40,19 & 16 \\
\hline 16 & Las personas jóvenes son valoradas, y tienen perspectivas de futuro seguras & 39,60 & 17 \\
\hline 30 & Libertad para hacer lo que nos gusta siempre que no perjudiquemos a otros & 39,02 & 18 \\
\hline 6 & Protección del medioambiente, recursos y fauna & 38,98 & 19 \\
\hline 27 & Las personas participan en la toma de decisiones de hechos que los afectan & 38,04 & 20 \\
\hline 11 & Buena atención a las personas vulnerables, disminuidos y de clase baja & 37,60 & 21 \\
\hline 13 & Las personas se sienten responsables por cada uno de los demás y por la comunidad & 37,27 & 22 \\
\hline 25 & Altos niveles de progreso cientifico y tecnológico & 34,85 & 23 \\
\hline 14 & Las personas que trabajan duramente pueden tener éxito en la vida & 33,79 & 24 \\
\hline 29 & Comunidades y organizaciones locales fuertes & 32,90 & 25 \\
\hline 15 & Se alienta la vida familiar y los valores de la familia & 32,54 & 26 \\
\hline 24 & Relaciones justas, limpias e independientes con otras naciones & 31,50 & 27 \\
\hline 26 & Vigorosa libertad de opinión, múltiples opiniones públicas (disensos) & 30,90 & 28 \\
\hline 22 & Ciudad atractiva y bien planificada & 30,48 & 29 \\
\hline 31 & Generosidad en ayudar a regiones perjudicadas & 26,65 & 30 \\
\hline 35 & Las personas tienen valores sociales y estilos de vida similares & 26,13 & 31 \\
\hline 28 & Atomización en la propiedad y control de los medios de comunicación & 25,67 & 32 \\
\hline 7 & Igualdad de oportunidades para hombres y mujeres & 24,04 & 33 \\
\hline 34 & Establecer una economía fuerte antes que la equidad y las metas medioambientales & 20,06 & 34 \\
\hline 23 & Protección de la libertad religiosa & 12,73 & 35 \\
\hline & Promedio & 38,45 & \\
\hline & Desvío estándar & 10,40 & \\
\hline
\end{tabular}

Fuente: Elaboración propia.

Las cinco (5) características con las mayores gravedades percibidas coinciden con las que mayores discrepancias tienen, y se encuentran entre las ocho (8) de mayor importancia.

Los siguientes cinco (5) aspectos incluyen los dos (2) que completan los cinco (5) más importantes y tres (3) que no son considerados tan importantes, pero que al considerar el bajo desempeño que tienen, adquieren una significativa gravedad. Estos aspectos, con su jerarquía de importancia y los tipos de sociedades con que se relacionan son: 
- "No hay grandes diferencias en la riqueza y poder entre las personas" con jerarquía treinta (30), y sociedades justas.

- "Todos pagan impuestos equitativamente, acorde con el ingreso y riqueza" con jerarquía doce (12), y sociedades justas.

- "Buena calidad de los servicios básicos (salud, educación, etc.) para todos" con jerarquía cuatro (4), y sociedades eficientes y con alto nivel de vida.

- "Una fuerte economía de libre empresa y un gobierno eficiente en sus tareas básicas" con jerarquía veintiocho (28), y sociedades eficientes.

- "Los derechos humanos básicos de todos los ciudadanos están fuertemente protegidos" con jerarquía dos (2), y sociedades éticas, democráticas, y comunitariamente inclusivas.

También como con las discrepancias, en el otro extremo, a excepción de "Igualdad de oportunidades para hombres y mujeres" con jerarquía siete (7) de importancia, los otros cuatro (4) aspectos se encuentran en el orden veintisiete (27) o posteriores.

\subsection{Situación comparativa: Ensenada con La Plata y alrededores}

\section{Importancia}

En la próxima tabla se comparan los resultados obtenidos en la encuesta de la variable importancia y su jerarquía en la ciudad de Ensenada, con los resultados en la región de La Plata y alrededores, es decir incluyendo a Berisso y Ensenada. La última columna muestra la diferencia porcentual tomando como base la importancia asignada en la ciudad de Ensenada.

Tabla 14

\begin{tabular}{|c|c|c|c|c|c|c|}
\hline \multirow[b]{2}{*}{ Item } & \multirow[b]{2}{*}{ Caracteristicas } & \multicolumn{2}{|c|}{$\begin{array}{l}\text { Importancia en la } \\
\text { ciudad de Ensenada }\end{array}$} & \multicolumn{2}{|c|}{$\begin{array}{c}\text { Importancia en la } \\
\text { región de La Plata y alrededores }\end{array}$} & \multirow{2}{*}{$\begin{array}{c}\text { Diferencia \% } \\
\text { respecto a la } \\
\text { ciudad de } \\
\text { Ensenada }\end{array}$} \\
\hline & & $\begin{array}{l}\text { Calificación 1-10 } \\
\text { (a) }\end{array}$ & $\begin{array}{c}\text { Jerarquía 1-35 } \\
\text { (a') }\end{array}$ & $\begin{array}{c}\begin{array}{c}\text { Calificación 1-10 } \\
\text { (a) }\end{array} \\
\end{array}$ & $\begin{array}{c}\text { Jerarquía 1-35 } \\
\left(a^{\prime}\right)\end{array}$ & \\
\hline 1 & Altos niveles de honestidad en la pollica y la vida pública & 9,48 & 6 & 9,47 & 5 & $-0,1 \%$ \\
\hline 2 & Todos son tratados igualitaria y equitativamente por la ley & 9,67 & 3 & 9,71 & 1 & $0,4 \%$ \\
\hline 3 & Los derechos humanos básicos de todos los ciudadanos están fuertemente protegidos & 9,71 & 2 & 9,61 & 3 & $-1,0 \%$ \\
\hline 4 & Buena calidad de los servicios básicos (salud, educación, etc.) para todos & 9,65 & 4 & 9,66 & 2 & $0,0 \%$ \\
\hline 5 & Eliminación del crimen y la violencia & 9,75 & 1 & 9,52 & 4 & $-2,4 \%$ \\
\hline 6 & Protección del medioambiente, recursos y fauna & 9,08 & 17 & 9,01 & 18 & $-0,7 \%$ \\
\hline 7 & Igualdad de oportunidades para hombres y mujeres & 9,46 & 7 & 9,33 & 8 & $-1,4 \%$ \\
\hline 8 & Todos pagan impuestos equitativamente, acorde con el ingreso y riqueza & 9,27 & 12 & 8,99 & 19 & $-3,0 \%$ \\
\hline 9 & Confianza justificada en que las instituciones públicas actúan con limpieza y justicia & 9,52 & 5 & 9,42 & 7 & $-1,0 \%$ \\
\hline 10 & Las comunidades locales tienen buena calidad de servicios públicos (transporte, luz, etc.) & 9,10 & 16 & 9,12 & 16 & $0,3 \%$ \\
\hline 11 & Buena atención a las personas vulnerables, disminuidos y de clase baja & 9,15 & 14 & 9,16 & 13 & $0,1 \%$ \\
\hline 12 & Reducción de la contaminación medioambiental, desarrollo de fuentes de energia renovables & 9,04 & 19 & 8,93 & 20 & $-1,2 \%$ \\
\hline 13 & Las personas se sienten responsables por cada uno de los demás y por la comunidad & 8,60 & 29 & 8,50 & 26 & $-1,1 \%$ \\
\hline 14 & Las personas que trabajan duramente pueden tener éxito en la vida & 8,69 & 25 & 8,47 & 27 & $-2,6 \%$ \\
\hline 15 & Se alienta la vida familiar y los valores de la familia & 9,12 & 15 & 9,24 & 10 & $1,3 \%$ \\
\hline 16 & Las personas jóvenes son valoradas, $y$ tienen perspectivas de futuro seguras & 8,87 & 23 & 8,67 & 23 & $-2,2 \%$ \\
\hline 17 & Eliminación de la pobreza & 9,02 & 20 & 9,14 & 14 & $1,3 \%$ \\
\hline 18 & Respeto por, y estricta aplicación de las leyes & 9,44 & 8 & 9,28 & 9 & $-1,7 \%$ \\
\hline 19 & Trabajos seguros, satisfactorios y equitativamente pagados para todos los que quieren trabajar & 9,06 & 18 & 9,07 & 17 & $0,2 \%$ \\
\hline 20 & Fuerte protección social (edad, enfermedad, desempleo, etc.) & 9,29 & 11 & 9,20 & 11 & $-0,9 \%$ \\
\hline
\end{tabular}




\begin{tabular}{|c|c|c|c|c|c|c|}
\hline \multirow[b]{2}{*}{ Item } & \multirow[b]{2}{*}{ Caracteristicas } & \multicolumn{2}{|c|}{$\begin{array}{l}\text { Importancia en la } \\
\text { ciudad de Ensenada }\end{array}$} & \multicolumn{2}{|c|}{$\begin{array}{l}\text { Importancia en la } \\
\text { región de La Plata y alrededores }\end{array}$} & \multirow{2}{*}{$\begin{array}{c}\text { Diferencia \% } \\
\text { respecto a la } \\
\text { ciudad de } \\
\text { Ensenada }\end{array}$} \\
\hline & & $\begin{array}{c}\text { Calificación 1-10 } \\
\text { (a) }\end{array}$ & $\begin{array}{c}\text { Jerarquía 1-35 } \\
\text { (a') }\end{array}$ & $\begin{array}{c}\text { Calificación 1-10 } \\
\text { (a) }\end{array}$ & $\begin{array}{l}\text { Jerarquía 1-35 } \\
\text { (a') }\end{array}$ & \\
\hline 21 & Capacidad para confiar en otras personas, incluso extraños & 8,33 & 31 & 8,22 & 31 & $-1,3 \%$ \\
\hline 22 & Ciudad atractiva y bien planificada & 8,23 & 32 & 8,03 & 32 & $-2,4 \%$ \\
\hline 23 & Protección de la libertad religiosa & 8,63 & 27 & 8,60 & 24 & $-0,4 \%$ \\
\hline 24 & Relaciones justas, limpias e independientes con otras naciones & 8,85 & 24 & 8,56 & 25 & $-3,3 \%$ \\
\hline 25 & Altos niveles de progreso cientifico y tecnológico & 9,00 & 21 & 8,84 & 21 & $-1,8 \%$ \\
\hline 26 & Vigorosa libertad de opinión, múltiples opiniones públicas (disensos) & 9,38 & 9 & 9,43 & 6 & $0,5 \%$ \\
\hline 27 & Las personas participan en la toma de decisiones de hechos que los afectan & 8,88 & 22 & 8,76 & 22 & $-1,4 \%$ \\
\hline 28 & Atomización en la propiedad y control de los medios de comunicación & 7,62 & 33 & 7,55 & 33 & $-0,9 \%$ \\
\hline 29 & Comunidades y organizaciones locales fuertes & 8,65 & 26 & 8,33 & 30 & $-3,7 \%$ \\
\hline 30 & Libertad para hacer lo que nos gusta siempre que no perjudiquemos a otros & 9,37 & 10 & 9,19 & 12 & $-1,9 \%$ \\
\hline 31 & Generosidad en ayudar a regiones perjudicadas & 9,21 & 13 & 9,13 & 15 & $-0,9 \%$ \\
\hline 32 & No hay grandes diferencias en la riqueza y poder entre las personas & 8,50 & 30 & 8,43 & 29 & $-0,8 \%$ \\
\hline 33 & Una fuerte economía de libre empresa y un gobierno eficiente en sus tareas básicas & 8,62 & 28 & 8,46 & 28 & $-1,8 \%$ \\
\hline 34 & Establecer una economía fuerte antes que la equidad y las metas medioambientales & 6,90 & 35 & 6,51 & 35 & $-5,7 \%$ \\
\hline \multirow[t]{2}{*}{35} & Las personas tienen valores sociales y estilos de vida similares & 7,00 & 34 & 6,58 & 34 & $-6,0 \%$ \\
\hline & Promedio & 8,92 & & 8,80 & & $-1,3 \%$ \\
\hline
\end{tabular}

Fuente: Elaboración propia.

Comparando la importancia asignada a las treinta y cinco (35) características, tanto para la ciudad de Ensenada como para la región, todos los atributos tienen gran importancia, siendo el promedio total de 8,92 vs. 8,80 . Al igual que para los ciudadanos de Ensenada, para los de la región sólo tres (3) características no están altamente valoradas, con una importancia menor a ocho (8).

En la siguiente tabla, se extraen las primeras y las últimas diez (10) características ordenadas por la jerarquía de la variable importancia en la ciudad de Ensenada:

Tabla 15

\begin{tabular}{|c|c|c|c|c|c|c|}
\hline \multirow[b]{2}{*}{ Item } & \multirow[b]{2}{*}{ Características } & \multicolumn{2}{|c|}{$\begin{array}{l}\text { Importancia en la } \\
\text { ciudad de Ensenada }\end{array}$} & \multicolumn{2}{|c|}{$\begin{array}{c}\text { Importancia en la } \\
\text { región de La Plata y alrededores }\end{array}$} & \multirow{2}{*}{$\begin{array}{c}\text { Diferencia \% } \\
\text { respecto a la } \\
\text { ciudad de } \\
\text { Ensenada }\end{array}$} \\
\hline & & $\begin{array}{l}\text { Calificación 1-10 } \\
\text { (a) }\end{array}$ & $\begin{array}{c}\text { Jerarquía 1-35 } \\
\text { (a') }\end{array}$ & \begin{tabular}{|l|} 
Calificación 1-10 \\
(a)
\end{tabular} & $\begin{array}{c}\text { Jerarquia 1-35 } \\
\text { (a') }\end{array}$ & \\
\hline 5 & Eliminación del crimen y la violencia & 9,75 & 1 & 9,52 & 4 & $-2,4 \%$ \\
\hline 3 & Los derechos humanos básicos de todos los ciudadanos están fuertemente protegidos & 9,71 & 2 & 9,61 & 3 & $-1,0 \%$ \\
\hline 2 & Todos son tratados igualitaria y equitativamente por la ley & 9,67 & 3 & 9,71 & 1 & $0,4 \%$ \\
\hline 4 & Buena calidad de los servicios básicos (salud, educación, etc.) para todos & 9,65 & 4 & 9,66 & 2 & $0,0 \%$ \\
\hline 9 & Confianza justificada en que las instituciones públicas actúan con limpieza y justicia & 9,52 & 5 & 9,42 & 7 & $-1,0 \%$ \\
\hline 1 & Altos niveles de honestidad en la pollica y la vida pública & 9,48 & 6 & 9,47 & 5 & $-0,1 \%$ \\
\hline 7 & Igualdad de oportunidades para hombres y mujeres & 9,46 & 7 & 9,33 & 8 & $-1,4 \%$ \\
\hline 18 & Respeto por, y estricta aplicación de las leyes & 9,44 & 8 & 9,28 & 9 & $-1,7 \%$ \\
\hline 26 & Vigorosa libertad de opinión, múltiples opiniones públicas (disensos) & 9,38 & 9 & 9,43 & 6 & $0,5 \%$ \\
\hline \multirow[t]{3}{*}{30} & Libertad para hacer lo que nos gusta siempre que no perjudiquemos a otros & 9,37 & 10 & 9,19 & 12 & $-1,9 \%$ \\
\hline & Promedio & 9,54 & & 9,46 & & $-0,9 \%$ \\
\hline & Desvío estándar & 0,14 & & 0,17 & & \\
\hline 29 & Comunidades $\mathrm{y}$ organizaciones locales fuertes & 8,65 & 26 & 8,33 & 30 & $-3,7 \%$ \\
\hline 23 & Protección de la libertad religiosa & 8,63 & 27 & 8,60 & 24 & $-0,4 \%$ \\
\hline 33 & Una fuerte economía de libre empresa y un gobierno eficiente en sus tareas básicas & 8,62 & 28 & 8,46 & 28 & $-1,8 \%$ \\
\hline 13 & Las personas se sienten responsables por cada uno de los demás y por la comunidad & 8,60 & 29 & 8,50 & 26 & $-1,1 \%$ \\
\hline 32 & No hay grandes diferencias en la riqueza y poder entre las personas & 8,50 & 30 & 8,43 & 29 & $-0,8 \%$ \\
\hline 21 & Capacidad para confar en otras personas, incluso extraños & 8,33 & 31 & 8,22 & 31 & $-1,3 \%$ \\
\hline 22 & Ciudad atractiva y bien planificada & 8,23 & 32 & 8,03 & 32 & $-2,4 \%$ \\
\hline 28 & Atomización en la propiedad y control de los medios de comunicación & 7,62 & 33 & 7,55 & 33 & $-0,9 \%$ \\
\hline 35 & Las personas tienen valores sociales y estilos de vida similares & 7,00 & 34 & 6,58 & 34 & $-6,0 \%$ \\
\hline \multirow[t]{3}{*}{34} & Establecer una economia fuerte antes que la equidad y las metas medioambientales & 6,90 & 35 & 6,51 & 35 & $-5,7 \%$ \\
\hline & Promedio & 8,11 & & 7,92 & & $-2,3 \%$ \\
\hline & Desvio estándar & 0,68 & & 0,79 & & \\
\hline
\end{tabular}

Fuente: Elaboración propia. 
De las primeras cinco (5) características por jerarquía de importancia, variando el orden y con pequeñas diferencias en sus promedios, coinciden las cuatro (4) más importantes para los ciudadanos de Ensenada y la región:

- "Eliminación del crimen y la violencia"

- "Los derechos humanos básicos de todos los ciudadanos están fuertemente protegidos"

- "Todos son tratados igualitaria y equitativamente por la ley"

- "Buena calidad de los servicios básicos (salud, educación, etcétera) para todos"

Extendiendo la comparación a las primeras diez (10) características, sólo difieren en una (1), agregándose estas otras cinco (5) como importantes para ambos:

- "Confianza justificada en que las instituciones públicas actúan con limpieza y justicia"

- "Altos niveles de honestidad en la política y la vida pública"

- "Igualdad de oportunidades para hombres y mujeres"

- "Respeto por, y estricta aplicación de las leyes"

- "Vigorosa libertad de opinión, múltiples opiniones públicas (disensos)"

En el otro extremo de jerarquía, las últimas cinco (5) características, incluso en el mismo orden, coinciden en ambos casos:

- "Establecer una economía fuerte antes que la equidad y las metas medioambientales"

- "Las personas tienen valores sociales y estilos de vida similares"

- "Atomización en la propiedad y control de los medios de comunicación"

- "Ciudad atractiva y bien planificada"

- "Capacidad para confiar en otras personas, incluso extraños"

Y ampliando la comparación a las últimas diez (10) características, sólo difieren en una (1), agregándose estas otras cuatro (4) como las menos importantes para ambos:

- "No hay grandes diferencias en la riqueza y poder entre las personas"

- "Las personas se sienten responsables por cada uno de los demás y por la comunidad"

- "Una fuerte economía de libre empresa y un gobierno eficiente en sus tareas básicas"

- "Comunidades y organizaciones locales fuertes"

En conclusión los ciudadanos de Ensenada y los de la región consideran todos los atributos como importantes, y coinciden en la valoración de los que mayor y menor importancia tienen. 


\section{Desempeño}

En la tabla de abajo se comparan los resultados obtenidos de la variable desempeño y su jerarquía en la ciudad de Ensenada y en la región de La Plata y alrededores. La última columna muestra la diferencia porcentual tomando como base el desempeño en la ciudad de Ensenada.

Tabla 16

\begin{tabular}{|c|c|c|c|c|c|c|}
\hline \multirow[b]{2}{*}{ Item } & \multirow[b]{2}{*}{ Caracteristicas } & \multicolumn{2}{|c|}{$\begin{array}{l}\text { Desempeño en la } \\
\text { ciudad de Ensenada }\end{array}$} & \multicolumn{2}{|c|}{$\begin{array}{l}\text { Desempeño en la } \\
\text { región de La Plata y alrededores }\end{array}$} & \multirow{2}{*}{$\begin{array}{c}\text { Diferencia \% } \\
\text { respecto a la } \\
\text { ciudad de } \\
\text { Ensenada }\end{array}$} \\
\hline & & \begin{tabular}{|c|}
$\begin{array}{c}\text { Calificación 1-10 } \\
\text { (b) }\end{array}$ \\
\end{tabular} & $\begin{array}{l}\text { Jerarquía 1-35 } \\
\text { (b') }\end{array}$ & \begin{tabular}{|c|}
$\begin{array}{c}\text { Calificación 1-10 } \\
\text { (b) }\end{array}$ \\
\end{tabular} & $\begin{array}{l}\text { Jerarquía 1-35 } \\
\text { (b') }\end{array}$ & \\
\hline 1 & Altos niveles de honestidad en la pollicca y la vida pública & 3,75 & 33 & 3,68 & 32 & $-2,0 \%$ \\
\hline 2 & Todos son tratados igualitaria y equitativamente por la ley & 4,40 & 25 & 4,32 & 25 & $-2,0 \%$ \\
\hline 3 & Los derechos humanos básicos de todos los ciudadanos están fuertemente protegidos & 5,21 & 9 & 5,01 & 11 & $-3,9 \%$ \\
\hline 4 & Buena calidad de los servicios básicos (salud, educación, etc.) para todos & 4,92 & 14 & 4,98 & 13 & $1,2 \%$ \\
\hline 5 & Eliminación del crimen y la violencia & 3,46 & 34 & 3,52 & 34 & $1,7 \%$ \\
\hline 6 & Protección del medioambiente, recursos y fauna & 4,92 & 14 & 4,70 & 20 & $-4,5 \%$ \\
\hline 7 & Igualdad de oportunidades para hombres y mujeres & 7,00 & 2 & 6,89 & 2 & $-1,5 \%$ \\
\hline 8 & Todos pagan impuestos equitativamente, acorde con el ingreso y riqueza & 4,38 & 27 & 4,34 & 24 & $-0,9 \%$ \\
\hline 9 & Confanza justificada en que las instituciones públicas actúan con limpieza y justicia & 4,04 & 31 & 3,81 & 31 & $-5,7 \%$ \\
\hline 10 & Las comunidades locales tienen buena calidad de servicios públicos (transporte, luz, etc.) & 4,69 & 21 & 4,66 & 21 & $-0,7 \%$ \\
\hline 11 & Buena atención a las personas vulnerables, disminuidos y de clase baja & 5,13 & 11 & 5,00 & 12 & $-2,6 \%$ \\
\hline 12 & Reducción de la contaminación medioambiental, desarrollo de fuentes de energía renovables & 4,31 & 28 & 4,08 & 28 & $-5,3 \%$ \\
\hline 13 & Las personas se sienten responsables por cada uno de los demás y por la comunidad & 4,42 & 24 & 4,23 & 26 & $-4,4 \%$ \\
\hline 14 & Las personas que trabajan duramente pueden tener éxito en la vida & 5,10 & 12 & 4,94 & 14 & $-3,0 \%$ \\
\hline 15 & Se alienta la vida familiar y los valores de la familia & 5,81 & 5 & 5,78 & 5 & $-0,5 \%$ \\
\hline 16 & Las personas jóvenes son valoradas, $\mathrm{y}$ tienen perspectivas de futuro seguras & 4,60 & 22 & 4,79 & 19 & $4,1 \%$ \\
\hline 17 & Eliminación de la pobreza & 4,73 & 20 & 4,47 & 22 & $-5,5 \%$ \\
\hline 18 & Respeto por, y estricta aplicación de las leyes & 4,12 & 29 & 3,89 & 30 & $-5,6 \%$ \\
\hline 19 & Trabajos seguros, satisfactorios y equitativamente pagados para todos los que quieren trabajar & 4,54 & 23 & 4,38 & 23 & $-3,6 \%$ \\
\hline 20 & Fuerte protección social (edad, enfermedad, desempleo, etc.) & 4,83 & 18 & 4,80 & 18 & $-0,6 \%$ \\
\hline 21 & Capacidad para confar en otras personas, incluso extraños & 3,77 & 32 & 3,60 & 33 & $-4,5 \%$ \\
\hline 22 & Ciudad atractiva y bien planificada & 4,88 & 17 & 5,04 & 10 & $3,2 \%$ \\
\hline 23 & Protección de la libertad religiosa & 7,54 & 1 & 7,78 & 1 & $3,2 \%$ \\
\hline 24 & Relaciones justas, limpias e independientes con otras naciones & 5,54 & 6 & 5,48 & 6 & $-1,1 \%$ \\
\hline 25 & Altos niveles de progreso cientifico y tecnológico & 5,29 & 7 & 5,47 & 7 & $3,5 \%$ \\
\hline 26 & Vigorosa libertad de opinión, múltiples opiniones públicas (disensos) & 6,12 & 4 & 6,26 & 4 & $2,4 \%$ \\
\hline 27 & Las personas participan en la toma de decisiones de hechos que los afectan & 4,77 & 19 & 4,82 & 17 & $1,0 \%$ \\
\hline 28 & Atomización en la propiedad y control de los medios de comunicación & 4,90 & 16 & 5,06 & 9 & $3,1 \%$ \\
\hline 29 & Comunidades $\mathrm{y}$ organizaciones locales fuertes & 5,06 & 13 & 4,94 & 14 & $-2,3 \%$ \\
\hline 30 & Libertad para hacer lo que nos gusta siempre que no perjudiquemos a otros & 5,29 & 7 & 5,11 & 8 & $-3,4 \%$ \\
\hline 31 & Generosidad en ayudar a regiones perjudicadas & 6,40 & 3 & 6,58 & 3 & $2,7 \%$ \\
\hline 32 & No hay grandes diferencias en la riqueza y poder entre las personas & 3,29 & 35 & 3,28 & 35 & $-0,3 \%$ \\
\hline 33 & Una fuerte economía de libre empresa y un gobierno eficiente en sus tareas básicas & 4,10 & 30 & 3,96 & 29 & $-3,3 \%$ \\
\hline 34 & Establecer una economia fuerte antes que la equidad y las metas medioambientales & 5,19 & 10 & 4,93 & 16 & $-5,1 \%$ \\
\hline \multirow[t]{3}{*}{35} & Las personas tienen valores sociales $\mathrm{y}$ estilos de vida similares & 4,40 & 25 & 4,10 & 27 & $-7,0 \%$ \\
\hline & Promedio & 4,88 & & 4,82 & & $-1,3 \%$ \\
\hline & Desvío estándar & 0,91 & & 0,97 & & \\
\hline
\end{tabular}

Fuente: Elaboración propia.

Analizando la tabla, al igual que para los ciudadanos de Ensenada, para los de la región, ninguno de los aspectos evaluados puede considerarse con un alto desempeño, ya que ninguno supera el valor ocho (8). Comparando los promedios, el desempeño de los treinta y cinco (35) atributos es muy similar, siendo 4,88 en Ensenada vs. 4,82 en La Plata y alrededores.

En la tabla de abajo un extracto de las primeras y las últimas diez (10) características ordenadas por la jerarquía de la variable desempeño en la ciudad de Ensenada: 


\begin{tabular}{|c|c|c|c|c|c|c|}
\hline \multirow[b]{2}{*}{ Item } & \multirow[b]{2}{*}{ Caracteristicas } & \multicolumn{2}{|c|}{$\begin{array}{l}\text { Desempeño en la } \\
\text { ciudad de Ensenada }\end{array}$} & \multicolumn{2}{|c|}{$\begin{array}{c}\text { Desempeño en la } \\
\text { región de La Plata y alrededores }\end{array}$} & \multirow{2}{*}{$\begin{array}{c}\text { Diferencia \% } \\
\text { respecto a la } \\
\text { ciudad de } \\
\text { Ensenada }\end{array}$} \\
\hline & & $\begin{array}{l}\text { Calificación 1-10 } \\
\text { (b) }\end{array}$ & $\begin{array}{c}\text { Jerarquía 1-35 } \\
\text { (b') }\end{array}$ & $\begin{array}{c}\text { Calificación 1-10 } \\
\text { (b) }\end{array}$ & $\begin{array}{c}\text { Jerarquía 1-35 } \\
\text { (b') }\end{array}$ & \\
\hline 23 & Protección de la libertad religiosa & 7,54 & 1 & 7,78 & 1 & $3,2 \%$ \\
\hline 7 & Igualdad de oportunidades para hombres y mujeres & 7,00 & 2 & 6,89 & 2 & $-1,5 \%$ \\
\hline 31 & Generosidad en ayudar a regiones perjudicadas & 6,40 & 3 & 6,58 & 3 & $2,7 \%$ \\
\hline 26 & Vigorosa libertad de opinión, múltiples opiniones públicas (disensos) & 6,12 & 4 & 6,26 & 4 & $2,4 \%$ \\
\hline 15 & Se alienta la vida familiar y los valores de la familia & 5,81 & 5 & 5,78 & 5 & $-0,5 \%$ \\
\hline 24 & Relaciones justas, limpias e independientes con otras naciones & 5,54 & 6 & 5,48 & 6 & $-1,1 \%$ \\
\hline 25 & Altos niveles de progreso cientifico y tecnológico & 5,29 & 7 & 5,47 & 7 & $3,5 \%$ \\
\hline 30 & Libertad para hacer lo que nos gusta siempre que no perjudiquemos a otros & 5,29 & 7 & 5,11 & 8 & $-3,4 \%$ \\
\hline 3 & Los derechos humanos básicos de todos los ciudadanos están fuertemente protegidos & 5,21 & 9 & 5,01 & 11 & $-3,9 \%$ \\
\hline \multirow[t]{3}{*}{34} & Establecer una economia fuerte antes que la equidad y las metas medioambientales & 5,19 & 10 & 4,93 & 16 & $-5,1 \%$ \\
\hline & Promedio & 5,94 & & 5,93 & & $-0,2 \%$ \\
\hline & Desvío estándar & 0,82 & & 0,93 & & \\
\hline
\end{tabular}

\begin{tabular}{|c|c|c|c|c|c|c|}
\hline 2 & Todos son tratados igualitaria y equitativamente por la ley & 4,40 & 25 & 4,32 & 25 & $-2,0 \%$ \\
\hline 35 & Las personas tienen valores sociales y estilos de vida similares & 4,40 & 25 & 4,10 & 27 & $-7,0 \%$ \\
\hline 8 & Todos pagan impuestos equitativamente, acorde con el ingreso y riqueza & 4,38 & 27 & 4,34 & 24 & $-0,9 \%$ \\
\hline 12 & Reducción de la contaminación medioambiental, desarrollo de fuentes de energía renovables & 4,31 & 28 & 4,08 & 28 & $-5,3 \%$ \\
\hline 18 & Respeto por, y estricta aplicación de las leyes & 4,12 & 29 & 3,89 & 30 & $-5,6 \%$ \\
\hline 33 & Una fuerte economía de libre empresa y un gobierno eficiente en sus tareas básicas & 4,10 & 30 & 3,96 & 29 & $-3,3 \%$ \\
\hline 9 & Confianza justificada en que las instituciones públicas actúan con limpieza y justicia & 4,04 & 31 & 3,81 & 31 & $-5,7 \%$ \\
\hline 21 & Capacidad para confiar en otras personas, incluso extraños & 3,77 & 32 & 3,60 & 33 & $-4,5 \%$ \\
\hline 1 & Altos niveles de honestidad en la politica y la vida pública & 3,75 & 33 & 3,68 & 32 & $-2,0 \%$ \\
\hline 5 & Eliminación del crimen y la violencia & 3,46 & 34 & 3,52 & 34 & $1,7 \%$ \\
\hline \multirow[t]{3}{*}{32} & No hay grandes diferencias en la riqueza y poder entre las personas & 3,29 & 35 & 3,28 & 35 & $-0,3 \%$ \\
\hline & Promedio & 4,00 & & 3,87 & & $-3,3 \%$ \\
\hline & Desvío estándar & 0,39 & & 0,33 & & \\
\hline
\end{tabular}

Fuente: Elaboración propia.

Las primeras siete (7) características por jerarquía de desempeño, en el mismo orden, pero con diferencias en el promedio de la variable, coinciden en ambos casos:

- "Protección de la libertad religiosa"

- " "Igualdad de oportunidades para hombres y mujeres"

- "Generosidad en ayudar a regiones perjudicadas"

- "Vigorosa libertad de opinión, múltiples opiniones públicas (disensos)"

- "Se alienta la vida familiar y los valores de la familia"

- "Relaciones justas, limpias e independientes con otras naciones"

- "Altos niveles de progreso científico y tecnológico"

De estas características con mayor desempeño, sólo tres (3) están dentro de las diez (10) primeras por jerarquía de importancia:

- "Igualdad de oportunidades para hombres y mujeres" con jerarquía siete (7) en Ensenada y jerarquía ocho (8) en la región.

- "Vigorosa libertad de opinión, múltiples opiniones públicas (disensos)" con jerarquía nueve (9) en Ensenada y jerarquía seis (6) en la región.

- "Los derechos humanos básicos de todos los ciudadanos están fuertemente protegidos" con jerarquía dos (2) en Ensenada y jerarquía tres (3) en la región.

En el otro extremo, las cinco (5) características con menor desempeño coinciden en ambos casos: 
- "No hay grandes diferencias en la riqueza y poder entre las personas"

- "Eliminación del crimen y la violencia"

- "Altos niveles de honestidad en la política y la vida pública"

- "Capacidad para confiar en otras personas, incluso extraños"

- "Confianza justificada en que las instituciones públicas actúan con limpieza y justicia"

Extendiendo la comparación a las últimas diez (10) características, sólo difieren en una (1), agregándose estos otros atributos como los de menor desempeño para ambos:

- "Una fuerte economía de libre empresa y un gobierno eficiente en sus tareas básicas"

- "Respeto por, y estricta aplicación de las leyes"

- "Reducción de la contaminación medioambiental, desarrollo de fuentes de energía renovables"

- "Las personas tienen valores sociales y estilos de vida similares"

- "Todos son tratados igualitaria y equitativamente por la ley"

De estas características con el menor desempeño, hay cinco (5) que están dentro de las diez (10) primeras por jerarquía de importancia:

- "Eliminación del crimen y la violencia" con jerarquía uno (1) en Ensenada y jerarquía cuatro (4) en la región.

- "Altos niveles de honestidad en la política y la vida pública" con jerarquía seis (6) en Ensenada y jerarquía cinco (5) en la región.

- "Confianza justificada en que las instituciones públicas actúan con limpieza y justicia" con jerarquía cinco (5) en Ensenada y jerarquía siete (7) en la región.

- "Respeto por, y estricta aplicación de las leyes" con jerarquía ocho (8) en Ensenada y jerarquía nueve (9) en la región.

- "Todos son tratados igualitaria y equitativamente por la ley" con jerarquía tres (3) en Ensenada y jerarquía uno (1) en la región.

Resumiendo, la valoración que hacen los ciudadanos de Ensenada y de la región del desempeño que presentan estos atributos es muy similar, compartiendo los que consideran con mayores y menores desempeños, que en general son los menos y más importantes respectivamente.

\section{Discrepancia}

En la siguiente tabla se comparan los resultados de la variable discrepancia y su jerarquía de importancia en la ciudad de Ensenada con los resultados en la región de La Plata y alrededores. La última columna muestra la diferencia porcentual tomando como base la discrepancia en la ciudad de Ensenada. 


\begin{tabular}{|c|c|c|c|c|c|c|}
\hline & \multirow{2}{*}{\multicolumn{2}{|c|}{$\begin{array}{l}\text { Discrepancia y jerarquía de } \\
\text { Importancia en la } \\
\text { ciudad de Ensenada }\end{array}$}} & \multirow{2}{*}{\multicolumn{2}{|c|}{$\begin{array}{c}\text { Discrepancia y jerarquia de } \\
\text { Importancia en la } \\
\text { región de La Plata y alrededores }\end{array}$}} & \multirow{3}{*}{$\begin{array}{c}\text { Diferencia \% } \\
\text { respecto a la } \\
\text { ciudad de } \\
\text { Ensenada }\end{array}$} \\
\hline & & & & & & \\
\hline Item & Características & $\begin{array}{c}\text { Valor } \\
(d=c-a)\end{array}$ & $\begin{array}{c}\text { Jerarquía 1-35 } \\
\left(a^{\prime}\right)\end{array}$ & $\begin{array}{c}\text { Valor } \\
(d=c-a)\end{array}$ & $\begin{array}{c}\text { Jerarquía 1-35 } \\
\text { (a') }\end{array}$ & \\
\hline 1 & Altos niveles de honestidad en la pollica y la vida pública & $-5,73$ & 6 & $-5,80$ & 5 & $-1,1 \%$ \\
\hline 2 & Todos son tratados igualitaria y equitativamente por la ley & $-5,27$ & 3 & $-5,39$ & 1 & $-2,4 \%$ \\
\hline 3 & Los derechos humanos básicos de todos los ciudadanos están fuertemente protegidos & $-4,50$ & 2 & $-4,60$ & 3 & $-2,3 \%$ \\
\hline 4 & Buena calidad de los servicios básicos (salud, educación, etc.) para todos & $-4,73$ & 4 & $-4,68$ & 2 & $1,1 \%$ \\
\hline 5 & Eliminación del crimen y la violencia & $-6,29$ & 1 & $-6,00$ & 4 & $4,6 \%$ \\
\hline 6 & Protección del medioambiente, recursos $\mathrm{y}$ fauna & $-4,15$ & 17 & $-4,31$ & 18 & $-3,8 \%$ \\
\hline 7 & Igualdad de oportunidades para hombres y mujeres & $-2,46$ & 7 & $-2,43$ & 8 & $1,1 \%$ \\
\hline 8 & Todos pagan impuestos equitativamente, acorde con el ingreso y riqueza & $-4,88$ & 12 & $-4,64$ & 19 & $4,9 \%$ \\
\hline 9 & Confianza justificada en que las instituciones públicas actúan con limpieza y justicia & $-5,48$ & 5 & $-5,61$ & 7 & $-2,4 \%$ \\
\hline 10 & Las comunidades locales tienen buena calidad de servicios públicos (transporte, luz, etc.) & $-4,40$ & 16 & $-4,46$ & 16 & $-1,4 \%$ \\
\hline 11 & Buena atención a las personas vulnerables, disminuidos y de clase baja & $-4,02$ & 14 & $-4,16$ & 13 & $-3,6 \%$ \\
\hline 12 & Reducción de la contaminación medioambiental, desarrollo de fuentes de energía renovables & $-4,73$ & 19 & $-4,85$ & 20 & $-2,5 \%$ \\
\hline 13 & Las personas se sienten responsables por cada uno de los demás y por la comunidad & $-4,17$ & 29 & $-4,27$ & 26 & $-2,4 \%$ \\
\hline 14 & Las personas que trabajan duramente pueden tener éxito en la vida & $-3,60$ & 25 & $-3,53$ & 27 & $1,9 \%$ \\
\hline 15 & Se alienta la vida familiar y los valores de la familia & $-3,31$ & 15 & $-3,46$ & 10 & $-4,5 \%$ \\
\hline 16 & Las personas jóvenes son valoradas, $y$ teenen perspectivas de futuro seguras & $-4,27$ & 23 & $-3,89$ & 23 & $9,0 \%$ \\
\hline 17 & Eliminación de la pobreza & $-4,29$ & 20 & $-4,67$ & 14 & $-8,9 \%$ \\
\hline 18 & Respeto por, y estricta aplicación de las leyes & $-5,33$ & 8 & $-5,39$ & 9 & $-1,2 \%$ \\
\hline 19 & Trabajos seguros, satisfactorios y equitativamente pagados para todos los que quieren trabajar & $-4,52$ & 18 & $-4,70$ & 17 & $-3,9 \%$ \\
\hline 20 & Fuerte protección social (edad, enfermedad, desempleo, etc.) & $-4,46$ & 11 & $-4,41$ & 11 & $1,2 \%$ \\
\hline 21 & Capacidad para confar en otras personas, incluso extraños & $-4,56$ & 31 & $-4,62$ & 31 & $-1,3 \%$ \\
\hline 22 & Ciudad atractiva y bien planificada & $-3,35$ & 32 & $-2,99$ & 32 & $10,6 \%$ \\
\hline 23 & Protección de la libertad religiosa & $-1,10$ & 27 & $-0,82$ & 24 & $24,9 \%$ \\
\hline 24 & Relaciones justas, limpias e independientes con otras naciones & $-3,31$ & 24 & $-3,08$ & 25 & $6,9 \%$ \\
\hline 25 & Altos niveles de progreso cientifico y tecnológico & $-3,71$ & 21 & $-3,37$ & 21 & $9,3 \%$ \\
\hline 26 & Vigorosa libertad de opinión, múltiples opiniones públicas (disensos) & $-3,27$ & 9 & $-3,17$ & 6 & $3,0 \%$ \\
\hline 27 & Las personas participan en la toma de decisiones de hechos que los afectan & $-4,12$ & 22 & $-3,95$ & 22 & $4,1 \%$ \\
\hline 28 & Atomización en la propiedad y control de los medios de comunicación & $-2,71$ & 33 & $-2,49$ & 33 & $8,0 \%$ \\
\hline 29 & Comunidades $\mathrm{y}$ organizaciones locales fuertes & $-3,60$ & 26 & $-3,39$ & 30 & $5,7 \%$ \\
\hline 30 & Libertad para hacer lo que nos gusta siempre que no perjudiquemos a otros & $-4,08$ & 10 & $-4,08$ & 12 & $-0,2 \%$ \\
\hline 31 & Generosidad en ayudar a regiones perjudicadas & $-2,81$ & 13 & $-2,55$ & 15 & $9,1 \%$ \\
\hline 32 & No hay grandes diferencias en la riqueza y poder entre las personas & $-5,21$ & 30 & $-5,15$ & 29 & $1,2 \%$ \\
\hline 33 & Una fuerte economía de libre empresa y un gobierno eficiente en sus tareas básicas & $-4,52$ & 28 & $-4,50$ & 28 & $0,5 \%$ \\
\hline 34 & Establecer una economía fuerte antes que la equidad y las metas medioambientales & $-1,71$ & 35 & $-1,58$ & 35 & $7,7 \%$ \\
\hline \multirow[t]{3}{*}{35} & \begin{tabular}{|l|l|} 
Las personas tienen valores sociales y estilos de vida similares \\
\end{tabular} & $-2,60$ & 34 & $-2,48$ & 34 & $4,5 \%$ \\
\hline & Promedio & $-4,04$ & & $-3,99$ & & $1,2 \%$ \\
\hline & Desvío estándar & 1,11 & & 1,19 & & \\
\hline
\end{tabular}

Fuente: Elaboración propia.

Observando la tabla vemos que para los ciudadanos de Ensenada, al igual que para los de La Plata y alrededores, ninguno de los treinta y cinco (35) atributos evaluados tiene un desempeño mayor a la importancia que les atribuyen, siendo el promedio de discrepancia muy similar: $-4,04$ vs. $-3,99$.

En la tabla de abajo se muestran las diez (10) características con las menores y mayores discrepancias en la ciudad de Ensenada junto con las jerarquías de importancia:

Tabla 19

\begin{tabular}{|c|c|c|c|c|c|c|}
\hline \multirow[b]{2}{*}{ Item } & \multirow[b]{2}{*}{ Caracteristicas } & \multicolumn{2}{|c|}{$\begin{array}{l}\text { Discrepancia y jerarquia de } \\
\text { Importancia en la } \\
\text { ciudad de Ensenada }\end{array}$} & \multicolumn{2}{|c|}{$\begin{array}{l}\text { Discrepancia y jerarquía de } \\
\text { Importancia en la } \\
\text { región de La Plata y alrededores }\end{array}$} & \multirow{2}{*}{$\begin{array}{c}\text { Diferencia \% } \\
\text { respecto a la } \\
\text { ciudad de } \\
\text { Ensenada }\end{array}$} \\
\hline & & $\begin{array}{c}\text { Valor } \\
(d=c-a)\end{array}$ & $\begin{array}{c}\text { Jerarquía 1-35 } \\
\text { (a') }\end{array}$ & $\begin{array}{c}\text { Valor } \\
(\mathrm{d}=\mathrm{c}-\mathrm{a})\end{array}$ & $\begin{array}{c}\text { Jerarquia 1-35 } \\
\text { (a') }\end{array}$ & \\
\hline 5 & Eliminación del crimen y la violencia & $-6,29$ & 1 & $-6,00$ & 4 & $4,6 \%$ \\
\hline 1 & Allos niveles de honestidad en la politica y la vida pública & $-5,73$ & 6 & $-5,80$ & 5 & $-1,1 \%$ \\
\hline 9 & Confianza justificada en que las instituciones públicas actían con limpieza y justicia & $-5,48$ & 5 & $-5,61$ & 7 & $-2,4 \%$ \\
\hline 18 & Respeto por, y estricta aplicación de las leyes & $-5,33$ & 8 & $-5,39$ & 9 & $-1,2 \%$ \\
\hline 2 & Todos son tratados igualitiria y equitativamente por la ley & $-5,27$ & 3 & $-5,39$ & 1 & $-2,4 \%$ \\
\hline 32 & No hay grandes difierencias en la riqueza y poder ente las personas & $-5,21$ & 30 & $-5,15$ & 29 & $1,2 \%$ \\
\hline 8 & Todos pagan impuestos equitativamente, acorde con el ingreso y riqueza & $-4,88$ & 12 & $-4,64$ & 19 & $4,9 \%$ \\
\hline 4 & Buena calidad de los servicios básicos (salud, educación, etc.) para todos & $-4,73$ & 4 & $-4,68$ & 2 & $1,1 \%$ \\
\hline 12 & Reducción de la contaminación medioambiental, desarrollo de fuentes de energía renovables & $-4,73$ & 19 & $-4,85$ & 20 & $-2,5 \%$ \\
\hline \multirow{3}{*}{21} & Capacidad para confar en otras personas, incluso extaños & $-4,56$ & 31 & $-4,62$ & 31 & $-1,3 \%$ \\
\hline & Promedio & $-5,22$ & & $-5,21$ & & $0,1 \%$ \\
\hline & Desvio estándar & 0,53 & & 0,50 & & \\
\hline
\end{tabular}




\begin{tabular}{|c|c|c|c|c|c|c|}
\hline 22 & Ciudad atractiva y bien planificada & $-3,35$ & 32 & $-2,99$ & 32 & $10,6 \%$ \\
\hline 15 & Se alienta la vida familiar y los valores de la familia & $-3,31$ & 15 & $-3,46$ & 10 & $-4,5 \%$ \\
\hline 24 & Relaciones justas, limpias e independientes con otras naciones & $-3,31$ & 24 & $-3,08$ & 25 & $6,9 \%$ \\
\hline 26 & Vigorosa libertad de opinión, múltiples opiniones públicas (disensos) & $-3,27$ & 9 & $-3,17$ & 6 & $3,0 \%$ \\
\hline 31 & Generosidad en ayudar a regiones perjudicadas & $-2,81$ & 13 & $-2,55$ & 15 & $9,1 \%$ \\
\hline 28 & Atomización en la propiedad y control de los medios de comunicación & $-2,71$ & 33 & $-2,49$ & 33 & $8,0 \%$ \\
\hline 35 & Las personas tienen valores sociales y estilos de vida similares & $-2,60$ & 34 & $-2,48$ & 34 & $4,5 \%$ \\
\hline 7 & Igualdad de oportunidades para hombres y mujeres & $-2,46$ & 7 & $-2,43$ & 8 & $1,1 \%$ \\
\hline 34 & Establecer una economía fuerte antes que la equidad y las metas medioambientales & $-1,71$ & 35 & $-1,58$ & 35 & $7,7 \%$ \\
\hline 23 & Protección de la libertad religiosa & $-1,10$ & 27 & $-0,82$ & 24 & $24,9 \%$ \\
\hline & Promedio & $-2,66$ & & $-2,51$ & & $5,8 \%$ \\
\hline
\end{tabular}

Fuente: Elaboración propia.

Considerando los diez (10) atributos con las mayores discrepancias en valor absoluto para los ciudadanos de Ensenada, y comparándolos con las discrepancias de esos atributos en la región, las diferencias son muy bajas, siendo el promedio prácticamente igual. En este grupo hay seis (6) atributos que están dentro de los diez (10) más importantes para ambos.

En el lado opuesto de la tabla, los diez (10) atributos con las menores discrepancias en valor absoluto para los ciudadanos de Ensenada, las diferencias son más grandes, siendo el promedio casi seis (6) puntos porcentuales mayor en Ensenada que en la región. En este grupo se encuentran los cuatro (4) atributos menos importantes para ambos.

Esto significa que en ambos casos la mayoría de las características más importantes son las que menor desempeño tienen y viceversa. Para los atributos más importantes el desempeño es similar tanto en Ensenada como en la región, pero en los atributos con menor importancia el desempeño es un poco mejor en la región.

\section{Gravedad Percibida}

En la próxima tabla se comparan los resultados de la variable gravedad percibida y su jerarquía en la ciudad de Ensenada con los resultados en la región de La Plata y alrededores. La última columna muestra la diferencia porcentual tomando como base la discrepancia en la ciudad de Ensenada.

Tabla 20

\begin{tabular}{|c|c|c|c|c|c|c|}
\hline \multirow[b]{2}{*}{ Item } & \multirow[b]{2}{*}{ Caracteristicas } & \multicolumn{2}{|c|}{$\begin{array}{l}\text { Gravedad Percibida en la } \\
\text { ciudad de Ensenada }\end{array}$} & \multicolumn{2}{|c|}{$\begin{array}{l}\text { Gravedad Percibida en la } \\
\text { región de La Plata y alrededores }\end{array}$} & \multirow{2}{*}{$\begin{array}{c}\text { Diferencia \% } \\
\text { respecto a la } \\
\text { ciudad de } \\
\text { Ensenada }\end{array}$} \\
\hline & & $\begin{array}{c}\text { Ponderación } \\
\left(g=-d^{*} a\right)\end{array}$ & $\begin{array}{c}\text { Jerarquía 1-35 } \\
\text { (g') }\end{array}$ & $\begin{array}{c}\text { Ponderación } \\
\left(g=-d^{*} a\right)\end{array}$ & $\begin{array}{c}\text { Jerarquía 1-35 } \\
\left(g^{\prime}\right)\end{array}$ & \\
\hline 1 & Altos niveles de honestidad en la politica y la vida pública & 55,06 & 2 & 55,73 & 2 & $1,2 \%$ \\
\hline 2 & Todos son tratados igualitaria y equitativamente por la ley & 51,37 & 4 & 52,77 & 4 & $2,7 \%$ \\
\hline 3 & Los derechos humanos básicos de todos los ciudadanos están fuertemente protegidos & 44,42 & 10 & 44,99 & 8 & $1,3 \%$ \\
\hline 4 & Buena calidad de los servicios básicos (salud, educación, etc.) para todos & 46,17 & 8 & 45,73 & 7 & $-1,0 \%$ \\
\hline 5 & Eliminación del crimen y la violencia & 61,85 & 1 & 58,29 & 1 & $-5,8 \%$ \\
\hline 6 & Protección del medioambiente, recursos y fauna & 38,98 & 19 & 40,58 & 16 & $4,1 \%$ \\
\hline 7 & Igualdad de oportunidades para hombres y mujeres & 24,04 & 33 & 23,86 & 32 & $-0,7 \%$ \\
\hline 8 & Todos pagan impuestos equitativamente, acorde con el ingreso y riqueza & 46,27 & 7 & 44,08 & 11 & $-4,7 \%$ \\
\hline 9 & Confianza justificada en que las instituciones públicas actúan con limpieza y justicia & 53,23 & 3 & 53,89 & 3 & $1,2 \%$ \\
\hline 10 & Las comunidades locales tienen buena calidad de servicios públicos (transporte, luz, etc.) & 41,38 & 14 & 41,93 & 14 & $1,3 \%$ \\
\hline 11 & Buena atención a las personas vulnerables, disminuidos y de clase baja & 37,60 & 21 & 39,46 & 18 & $5,0 \%$ \\
\hline 12 & Reducción de la contaminación medioambiental, desarrollo de fuentes de energía renovables & 43,96 & 11 & 44,93 & 9 & $2,2 \%$ \\
\hline 13 & Las personas se sienten responsables por cada uno de los demás y por la comunidad & 37,27 & 22 & 38,13 & 20 & $2,3 \%$ \\
\hline 14 & Las personas que trabajan duramente pueden tener éxito en la vida & 33,79 & 24 & 32,37 & 24 & $-4,2 \%$ \\
\hline 15 & Se alienta la vida familiar y los valores de la familia & 32,54 & 26 & 34,21 & 23 & $5,1 \%$ \\
\hline
\end{tabular}




\begin{tabular}{|c|c|c|c|c|c|c|}
\hline \multirow[b]{2}{*}{ Item } & \multirow[b]{2}{*}{ Caracteristicas } & \multicolumn{2}{|c|}{$\begin{array}{l}\text { Gravedad Percibida en la } \\
\text { ciudad de Ensenada }\end{array}$} & \multicolumn{2}{|c|}{$\begin{array}{l}\text { Gravedad Percibida en la } \\
\text { región de La Plata y alrededores }\end{array}$} & \multirow{2}{*}{$\begin{array}{c}\text { Diferencia \% } \\
\text { respecto a la } \\
\text { ciudad de } \\
\text { Ensenada }\end{array}$} \\
\hline & & $\begin{array}{c}\text { Ponderación } \\
\left(g=-d^{*} a\right)\end{array}$ & $\begin{array}{c}\text { Jerarquía 1-35 } \\
\left(\mathrm{g}^{\prime}\right)\end{array}$ & $\begin{array}{c}\text { Ponderación } \\
(g=-d * a)\end{array}$ & $\begin{array}{c}\text { Jerarquía 1-35 } \\
\left(\mathrm{g}^{\prime}\right)\end{array}$ & \\
\hline 16 & Las personas jóvenes son valoradas, y tienen perspectivas de futuro seguras & 39,60 & 17 & 35,78 & 22 & $-9,6 \%$ \\
\hline 17 & Eliminación de la pobreza & 40,19 & 16 & 43,83 & 12 & $9,0 \%$ \\
\hline 18 & Respeto por, y estricta aplicación de las leyes & 51,37 & 4 & 51,48 & 5 & $0,2 \%$ \\
\hline 19 & Trabajos seguros, satisfactorios y equitativamente pagados para todos los que quieren trabajar & 42,71 & 12 & 44,32 & 10 & $3,8 \%$ \\
\hline 20 & Fuerte protección social (edad, enfermedad, desempleo, etc.) & 41,85 & 13 & 41,62 & 15 & $-0,5 \%$ \\
\hline 21 & Capacidad para confar en otras personas, incluso extraños & 40,62 & 15 & 40,46 & 17 & $-0,4 \%$ \\
\hline 22 & Ciudad atractiva y bien planificada & 30,48 & 29 & 27,41 & 29 & $-10,1 \%$ \\
\hline 23 & Protección de la libertad religiosa & 12,73 & 35 & 10,63 & 35 & $-16,5 \%$ \\
\hline 24 & Relaciones justas, limpias e independientes con otras naciones & 31,50 & 27 & 28,75 & 28 & $-8,7 \%$ \\
\hline 25 & Altos niveles de progreso cientifico y tecnológico & 34,85 & 23 & 31,48 & 25 & $-9,7 \%$ \\
\hline 26 & Vigorosa libertad de opinión, múltiples opiniones públicas (disensos) & 30,90 & 28 & 30,45 & 27 & $-1,5 \%$ \\
\hline 27 & Las personas participan en la toma de decisiones de hechos que los afectan & 38,04 & 20 & 36,20 & 21 & $-4,8 \%$ \\
\hline 28 & Atomización en la propiedad y control de los medios de comunicación & 25,67 & 32 & 23,80 & 33 & $-7,3 \%$ \\
\hline 29 & Comunidades y organizaciones locales fuertes & 32,90 & 25 & 30,67 & 26 & $-6,8 \%$ \\
\hline 30 & Libertad para hacer lo que nos gusta siempre que no perjudiquemos a otros & 39,02 & 18 & 38,87 & 19 & $-0,4 \%$ \\
\hline 31 & Generosidad en ayudar a regiones perjudicadas & 26,65 & 30 & 24,23 & 31 & $-9,1 \%$ \\
\hline 32 & No hay grandes diferencias en la riqueza y poder entre las personas & 48,13 & 6 & 47,30 & 6 & $-1,7 \%$ \\
\hline 33 & Una fuerte economia de libre empresa y un gobierno eficiente en sus tareas básicas & 44,56 & 9 & 43,31 & 13 & $-2,8 \%$ \\
\hline 34 & Establecer una economía fuerte antes que la equidad y las metas medioambientales & 20,06 & 34 & 18,95 & 34 & $-5,5 \%$ \\
\hline \multirow[t]{2}{*}{35} & Las personas tienen valores sociales y estilos de vida similares & 26,13 & 31 & 24,52 & 30 & $-6,2 \%$ \\
\hline & Promedio & 38,45 & & 37,86 & & $-1,6 \%$ \\
\hline
\end{tabular}

Fuente: Elaboración propia.

Al analizar la tabla se aprecia que la gravedad percibida promedio tanto en la ciudad de Ensenada como en la región de La Plata y alrededores es muy similar: 38,45 vs. 37,86 .

En la tabla de abajo se muestran las gravedades de las primeras y las últimas diez (10) características ordenadas por su jerarquía de gravedad percibida en la ciudad de Ensenada:

Tabla 21

\begin{tabular}{|c|c|c|c|c|c|c|}
\hline \multirow[b]{2}{*}{ Item } & \multirow[b]{2}{*}{ Caracteristicas } & \multicolumn{2}{|c|}{$\begin{array}{l}\text { Gravedad Percibida en la } \\
\text { ciudad de Ensenada }\end{array}$} & \multicolumn{2}{|c|}{$\begin{array}{l}\text { Gravedad Percibida en la } \\
\text { región de La Plata y alrededores }\end{array}$} & \multirow{2}{*}{$\begin{array}{c}\text { Diferencia \% } \\
\text { respecto a la } \\
\text { ciudad de } \\
\text { Ensenada }\end{array}$} \\
\hline & & $\begin{array}{c}\begin{array}{c}\text { Ponderación } \\
\left(g=-d^{*} a\right)\end{array}\end{array}$ & $\begin{array}{l}\text { Jerarquía 1-35 } \\
\left(\mathrm{g}^{\prime}\right)\end{array}$ & $\begin{array}{c}\begin{array}{c}\text { Ponderación } \\
(g=-d * a)\end{array}\end{array}$ & $\begin{array}{l}\text { Jerarquia 1-35 } \\
\text { (g') }\end{array}$ & \\
\hline 5 & Eliminación del crimen y la violencia & 61,85 & 1 & 58,29 & 1 & $-5,8 \%$ \\
\hline 1 & Altos niveles de honestidad en la politica y la vida pública & 55,06 & 2 & 55,73 & 2 & $1,2 \%$ \\
\hline 9 & Confianza justificada en que las instituciones públicas actúan con limpieza y justicia & 53,23 & 3 & 53,89 & 3 & $1,2 \%$ \\
\hline 2 & Todos son tratados igualitaria y equitativamente por la ley & 51,37 & 4 & 52,77 & 4 & $2,7 \%$ \\
\hline 18 & Respeto por, y estricta aplicación de las leyes & 51,37 & 4 & 51,48 & 5 & $0,2 \%$ \\
\hline 32 & No hay grandes diferencias en la riqueza y poder entre las personas & 48,13 & 6 & 47,30 & 6 & $-1,7 \%$ \\
\hline 8 & Todos pagan impuestos equitativamente, acorde con el ingreso y riqueza & 46,27 & 7 & 44,08 & 11 & $-4,7 \%$ \\
\hline 4 & Buena calidad de los servicios básicos (salud, educación, etc.) para todos & 46,17 & 8 & 45,73 & 7 & $-1,0 \%$ \\
\hline 33 & Una fuerte economia de libre empresa y un gobierno eficiente en sus tareas básicas & 44,56 & 9 & 43,31 & 13 & $-2,8 \%$ \\
\hline \multirow[t]{3}{*}{3} & Los derechos humanos básicos de todos los ciudadanos están fuertemente protegidos & 44,42 & 10 & 44,99 & 8 & $1,3 \%$ \\
\hline & Promedio & 50,24 & & 49,76 & & $-1,0 \%$ \\
\hline & Desvío estándar & 5,50 & & 5,34 & & \\
\hline
\end{tabular}

\begin{tabular}{|c|c|c|c|c|c|c|}
\hline 15 & Se alienta la vida familiar y los valores de la familia & 32,54 & 26 & 34,21 & 23 & $5,1 \%$ \\
\hline 24 & Relaciones justas, limpias e independientes con otras naciones & 31,50 & 27 & 28,75 & 28 & $-8,7 \%$ \\
\hline 26 & Vigorosa libertad de opinión, múltiples opiniones públicas (disensos) & 30,90 & 28 & 30,45 & 27 & $-1,5 \%$ \\
\hline 22 & Ciudad atactiva y bien planificada & 30,48 & 29 & 27,41 & 29 & $-10,1 \%$ \\
\hline 31 & Generosidad en ayudar a regiones perjudicadas & 26,65 & 30 & 24,23 & 31 & $-9,1 \%$ \\
\hline 35 & Las personas tienen valores sociales $y$ estilos de vida similares & 26,13 & 31 & 24,52 & 30 & $-6,2 \%$ \\
\hline 28 & Atomización en la propiedad y control de los medios de comunicación & 25,67 & 32 & 23,80 & 33 & $-7,3 \%$ \\
\hline 7 & Igualdad de oportunidades para hombres y mujeres & 24,04 & 33 & 23,86 & 32 & $-0,7 \%$ \\
\hline 34 & Establecer una economia fuerte antes que la equidad y las metas medioambientales & 20,06 & 34 & 18,95 & 34 & $-5,5 \%$ \\
\hline \multirow[t]{3}{*}{23} & Protección de la libertad religiosa & 12,73 & 35 & 10,63 & 35 & $-16,5 \%$ \\
\hline & Promedio & 26,07 & & 24,68 & & $-5,3 \%$ \\
\hline & Desvio estándar & 6,08 & & 6,50 & & \\
\hline
\end{tabular}

Fuente: Elaboración propia. 
Las cinco (5) características con las mayores gravedades percibidas coinciden tanto en Ensenada como en la región, siendo estos aspectos considerados por sus ciudadanos dentro de los diez (10) de mayor importancia:

- "Eliminación del crimen y la violencia" con jerarquía uno (1) en Ensenada y jerarquía cuatro (4) en la región.

- "Altos niveles de honestidad en la política y la vida pública" con jerarquía seis (6) en Ensenada y jerarquía cinco (5) en la región.

- "Confianza justificada en que las instituciones públicas actúan con limpieza y justicia" con jerarquía cinco (5) en Ensenada y jerarquía siete (7) en la región.

- "Todos son tratados igualitaria y equitativamente por la ley" con jerarquía tres (3) en Ensenada y jerarquía uno (1) en la región.

- "Respeto por, y estricta aplicación de las leyes" con jerarquía ocho (8) en Ensenada y jerarquía nueve (9) en la región.

En las siguientes características por orden de gravedad percibida aparecen algunos aspectos no considerados tan importantes, pero que tienen gran discrepancia:

- "No hay grandes diferencias en la riqueza y poder entre las personas" con jerarquía treinta (30) en Ensenada y jerarquía veintinueve (29) en la región.

- "Todos pagan impuestos equitativamente, acorde con el ingreso y riqueza" con jerarquía doce (12) en Ensenada y jerarquía diecinueve (19) en la región.

- "Una fuerte economía de libre empresa y un gobierno eficiente en sus tareas básicas" con jerarquía veintiocho (28) en Ensenada y jerarquía veintiocho (28) en la región.

Para las primeras diez (10) características por su jerarquía para la ciudad de Ensenada, la gravedad percibida es un (1) punto porcentual mayor que en esas características para la región de La Plata y alrededores. Para las últimas diez (10) la diferencia porcentual es considerablemente mayor, superando los cinco (5) puntos.

Entre estas últimas por gravedad percibida, coinciden en nueve (9), siendo que dos (2) están entre las diez (10) de mayor importancia para ambos, pero debido a que la discrepancia no es tan grande pierden peso al analizar esta variable:

- "Igualdad de oportunidades para hombres y mujeres" con jerarquía siete (7) en Ensenada y jerarquía ocho (8) en la región.

- "Vigorosa libertad de opinión, múltiples opiniones públicas (disensos)" con jerarquía nueve (9) en Ensenada y jerarquía seis (6) en la región. 
Esto significa que tanto los ciudadanos de Ensenada como los de la región coinciden en que la mayoría de los atributos más importantes también son los percibidos con mayor gravedad. Sólo tres (3) aspectos no tan importantes tienen una alta jerarquía por gravedad percibida y dos (2) de gran importancia tienen una baja jerarquía por gravedad.

\subsection{Situación comparativa: Ensenada con Australia}

\section{Importancia}

En la tabla de abajo se comparan los resultados obtenidos para la variable importancia y su jerarquía en la ciudad de Ensenada, con los resultados de la encuesta en Australia. La última columna muestra la diferencia porcentual tomando como base la importancia asignada en la ciudad de Ensenada.

Tabla 22

\begin{tabular}{|c|c|c|c|c|c|c|}
\hline \multirow[b]{2}{*}{ Item } & \multirow[b]{2}{*}{ Caracteristicas } & \multicolumn{2}{|c|}{$\begin{array}{l}\text { Importancia en la } \\
\text { ciudad de Ensenada }\end{array}$} & \multicolumn{2}{|c|}{$\begin{array}{l}\text { Importancia en } \\
\text { Australia }\end{array}$} & \multirow{2}{*}{$\begin{array}{c}\text { Diferencia \% } \\
\text { respecto a la } \\
\text { ciudad de } \\
\text { Ensenada }\end{array}$} \\
\hline & & $\begin{array}{c}\text { Calificación 1-10 } \\
\text { (a) }\end{array}$ & $\begin{array}{c}\text { Jerarquía 1-35 } \\
\left(a^{\prime}\right)\end{array}$ & \begin{tabular}{|c|} 
Calificación 1-10 \\
(a)
\end{tabular} & $\begin{array}{c}\text { Jerarquia 1-35 } \\
\left(a^{\prime}\right)\end{array}$ & \\
\hline 1 & Altos niveles de honestidad en la politica y la vida pública & 9,48 & 6 & 9,30 & 1 & $-1,9 \%$ \\
\hline 2 & Todos son tratados igualitaria y equitativamente por la ley & 9,67 & 3 & 9,30 & 2 & $-3,9 \%$ \\
\hline 3 & Los derechos humanos básicos de todos los ciudadanos están fuertemente protegidos & 9,71 & 2 & 9,10 & 3 & $-6,3 \%$ \\
\hline 4 & Buena calidad de los servicios básicos (salud, educación, etc.) para todos & 9,65 & 4 & 9,10 & 4 & $-5,7 \%$ \\
\hline 5 & Eliminación del crimen y la violencia & 9,75 & 1 & 9,10 & 5 & $-6,7 \%$ \\
\hline 6 & Protección del medioambiente, recursos y fauna & 9,08 & 17 & 9,10 & 6 & $0,3 \%$ \\
\hline 7 & Igualdad de oportunidades para hombres y mujeres & 9,46 & 7 & 9,00 & 7 & $-4,9 \%$ \\
\hline 8 & Todos pagan impuestos equitativamente, acorde con el ingreso y riqueza & 9,27 & 12 & 9,00 & 8 & $-2,9 \%$ \\
\hline 9 & Confianza justificada en que las instituciones públicas actuan con limpieza y justicia & 9,52 & 5 & 9,00 & 9 & $-5,5 \%$ \\
\hline 10 & Las comunidades locales tienen buena calidad de servicios públicos (transporte, luz, etc.) & 9,10 & 16 & 9,00 & 10 & $-1,1 \%$ \\
\hline 11 & Buena atención a las personas vulnerables, disminuidos y de clase baja & 9,15 & 14 & 8,80 & 11 & $-3,9 \%$ \\
\hline 12 & Reducción de la contaminación medioambiental, desarrollo de fuentes de energía renovables & 9,04 & 19 & 8,80 & 12 & $-2,6 \%$ \\
\hline 13 & Las personas se sienten responsables por cada uno de los demás y por la comunidad & 8,60 & 29 & 8,70 & 13 & $1,2 \%$ \\
\hline 14 & Las personas que trabajan duramente pueden tener éxito en la vida & 8,69 & 25 & 8,60 & 14 & $-1,1 \%$ \\
\hline 15 & Se alienta la vida familiar y los valores de la familia & 9,12 & 15 & 8,60 & 15 & $-5,7 \%$ \\
\hline 16 & Las personas jóvenes son valoradas, $\mathrm{y}$ fienen perspectivas de futuro seguras & 8,87 & 23 & 8,60 & 16 & $-3,0 \%$ \\
\hline 17 & Eliminación de la pobreza & 9,02 & 20 & 8,60 & 17 & $-4,6 \%$ \\
\hline 18 & Respeto por, y estricta aplicación de las leyes & 9,44 & 8 & 8,60 & 18 & $-8,9 \%$ \\
\hline 19 & Trabajos seguros, satisfactorios y equitativamente pagados para todos los que quieren trabajar & 9,06 & 18 & 8,60 & 19 & $-5,1 \%$ \\
\hline 20 & Fuerte protección social (edad, enfermedad, desempleo, etc.) & 9,29 & 11 & 8,50 & 20 & $-8,5 \%$ \\
\hline 21 & Capacidad para confiar en otras personas, incluso extraños & 8,33 & 31 & 8,40 & 21 & $0,9 \%$ \\
\hline 22 & Ciudad atractiva y bien planificada & 8,23 & 32 & 8,30 & 22 & $0,8 \%$ \\
\hline 23 & Protección de la libertad religiosa & 8,63 & 27 & 8,20 & 23 & $-5,0 \%$ \\
\hline 24 & Relaciones justas, limpias e independientes con otras naciones & 8,85 & 24 & 8,20 & 24 & $-7,3 \%$ \\
\hline 25 & Altos niveles de progreso cientifico y tecnológico & 9,00 & 21 & 8,10 & 25 & $-10,0 \%$ \\
\hline 26 & Vigorosa libertad de opinión, múltiples opiniones públicas (disensos) & 9,38 & 9 & 8,10 & 26 & $-13,7 \%$ \\
\hline 27 & Las personas participan en la toma de decisiones de hechos que los afectan & 8,88 & 22 & 8,10 & 27 & $-8,8 \%$ \\
\hline 28 & Atomización en la propiedad y control de los medios de comunicación & 7,62 & 33 & 7,90 & 28 & $3,7 \%$ \\
\hline 29 & Comunidades y organizaciones locales fuertes & 8,65 & 26 & 7,80 & 29 & $-9,9 \%$ \\
\hline 30 & Libertad para hacer lo que nos gusta siempre que no perjudiquemos a otros & 9,37 & 10 & 7,40 & 30 & $-21,0 \%$ \\
\hline 31 & Generosidad en ayudar a regiones perjudicadas & 9,21 & 13 & 7,00 & 31 & $-24,0 \%$ \\
\hline 32 & No hay grandes diferencias en la riqueza y poder entre las personas & 8,50 & 30 & 6,80 & 32 & $-20,0 \%$ \\
\hline 33 & Una fuerte economia de libre empresa y un gobierno eficiente en sus tareas básicas & 8,62 & 28 & 6,70 & 33 & $-22,2 \%$ \\
\hline 34 & Establecer una economía fuerte antes que la equidad y las metas medioambientales & 6,90 & 35 & 5,20 & 34 & $-24,7 \%$ \\
\hline \multirow[t]{3}{*}{35} & Las personas tenen valores sociales $\mathrm{y}$ estilos de vida similares & 7,00 & 34 & 4,50 & 35 & $-35,7 \%$ \\
\hline & Promedio & 8,92 & & 8,23 & & $-7,7 \%$ \\
\hline & Desvío estándar & 0,67 & & 1,08 & & \\
\hline
\end{tabular}

Fuente: Elaboración propia.

Comparando la importancia asignada a las treinta y cinco (35) características, el promedio total para Ensenada es significativamente mayor, 
casi ocho (8) puntos porcentuales, que para Australia: 8,92 vs. 8,23. Mientras en Ensenada son sólo tres (3) los atributos con una importancia menor a ocho (8), es decir que no son altamente valorados, en Australia son ocho (8) con esta apreciación, incluyendo dos (2) atributos que no son considerados de gran importancia, con valores de importancia menor a seis (6).

A continuación las primeras y las últimas diez (10) características ordenadas por la jerarquía de la variable en la ciudad de Ensenada:

Tabla 23

\begin{tabular}{|c|c|c|c|c|c|c|}
\hline \multirow[b]{2}{*}{ Item } & \multirow[b]{2}{*}{ Caracteristicas } & \multicolumn{2}{|c|}{$\begin{array}{l}\text { Importancia en la } \\
\text { ciudad de Ensenada }\end{array}$} & \multicolumn{2}{|c|}{$\begin{array}{l}\text { Importancia en } \\
\text { Australia }\end{array}$} & \multirow{2}{*}{$\begin{array}{c}\text { Diferencia \% } \\
\text { respecto a la } \\
\text { ciudad de } \\
\text { Ensenada }\end{array}$} \\
\hline & & $\begin{array}{l}\text { Calificación 1-10 } \\
\text { (a) }\end{array}$ & $\begin{array}{c}\text { Jerarquía 1-35 } \\
\text { (a') }\end{array}$ & $\begin{array}{l}\text { Calificación 1-10 } \\
\text { (a) }\end{array}$ & $\begin{array}{l}\text { Jerarquía 1-35 } \\
\text { (a') }\end{array}$ & \\
\hline 5 & Eliminación del crimen y la violencia & 9,75 & 1 & 9,10 & 5 & $-6,7 \%$ \\
\hline 3 & Los derechos humanos básicos de todos los ciudadanos están fuertemente protegidos & 9,71 & 2 & 9,10 & 3 & $-6,3 \%$ \\
\hline 2 & Todos son tratados igualitaria y equitativamente por la ley & 9,67 & 3 & 9,30 & 2 & $-3,9 \%$ \\
\hline 4 & Buena calidad de los servicios básicos (salud, educación, etc.) para todos & 9,65 & 4 & 9,10 & 4 & $-5,7 \%$ \\
\hline 9 & Confianza justificada en que las instituciones públicas actúan con limpieza y justicia & 9,52 & 5 & 9,00 & 9 & $-5,5 \%$ \\
\hline 1 & Altos niveles de honestidad en la pollitca y la vida pública & 9,48 & 6 & 9,30 & 1 & $-1,9 \%$ \\
\hline 7 & Igualdad de oportunidades para hombres y mujeres & 9,46 & 7 & 9,00 & 7 & $-4,9 \%$ \\
\hline 18 & Respeto por, y estricta aplicación de las leyes & 9,44 & 8 & 8,60 & 18 & $-8,9 \%$ \\
\hline 26 & Vigorosa libertad de opinión, múltiples opiniones públicas (disensos) & 9,38 & 9 & 8,10 & 26 & $-13,7 \%$ \\
\hline \multirow[t]{3}{*}{30} & Libertad para hacer lo que nos gusta siempre que no perjudiquemos a otros & 9,37 & 10 & 7,40 & 30 & $-21,0 \%$ \\
\hline & Promedio & 9,54 & & 8,80 & & $-7,8 \%$ \\
\hline & Desvio estándar & 0,14 & & 0,61 & & \\
\hline
\end{tabular}

\begin{tabular}{|c|c|c|c|c|c|c|}
\hline 29 & Comunidades y organizaciones locales fuertes & 8,65 & 26 & 7,80 & 29 & $-9,9 \%$ \\
\hline 23 & Protección de la libertad religiosa & 8,63 & 27 & 8,20 & 23 & $-5,0 \%$ \\
\hline 33 & Una fuerte economía de libre empresa y un gobierno eficiente en sus tareas básicas & 8,62 & 28 & 6,70 & 33 & $-22,2 \%$ \\
\hline 13 & Las personas se sienten responsables por cada uno de los demás y por la comunidad & 8,60 & 29 & 8,70 & 13 & $1,2 \%$ \\
\hline 32 & No hay grandes diferencias en la riqueza y poder entre las personas & 8,50 & 30 & 6,80 & 32 & $-20,0 \%$ \\
\hline 21 & Capacidad para confiar en otras personas, incluso extraños & 8,33 & 31 & 8,40 & 21 & $0,9 \%$ \\
\hline 22 & Ciudad atractiva y bien planificada & 8,23 & 32 & 8,30 & 22 & $0,8 \%$ \\
\hline 28 & Atomización en la propiedad y control de los medios de comunicación & 7,62 & 33 & 7,90 & 28 & $3,7 \%$ \\
\hline 35 & Las personas tienen valores sociales $\mathrm{y}$ estilos de vida similares & 7,00 & 34 & 4,50 & 35 & $-35,7 \%$ \\
\hline \multirow[t]{3}{*}{34} & Establecer una economia fuerte antes que la equidad y las metas medioambientales & 6,90 & 35 & 5,20 & 34 & $-24,7 \%$ \\
\hline & Promedio & 8,11 & & 7,25 & & $-10,6 \%$ \\
\hline & Desvío estándar & 0,68 & & 1,43 & & \\
\hline
\end{tabular}

Fuente: Elaboración propia.

De las primeras cinco (5) características por jerarquía de importancia, aunque en distinto orden y con promedios considerablemente mayores de importancia para Ensenada, coinciden en cuatro (4):

- "Eliminación del crimen y la violencia"

- "Los derechos humanos básicos de todos los ciudadanos están fuertemente protegidos"

- "Todos son tratados igualitaria y equitativamente por la ley"

- "Buena calidad de los servicios básicos (salud, educación, etcétera) para todos"

Extendiendo la comparación a las primeras diez (10) características, en total difieren en tres (3), agregándose estas otras tres (3) como importantes tanto para Ensenada como para Australia:

- "Confianza justificada en que las instituciones públicas actúan con limpieza y justicia" 
- "Altos niveles de honestidad en la política y la vida pública"

- "Igualdad de oportunidades para hombres y mujeres"

De las últimas cinco (5) características por jerarquía de importancia se repiten sólo las dos (2) últimas:

- "Establecer una economía fuerte antes que la equidad y las metas medioambientales"

- "Las personas tienen valores sociales y estilos de vida similares"

Y ampliando la comparación a las últimas diez (10) características, se repiten cuatro (4) más en ambos casos:

- "Atomización en la propiedad y control de los medios de comunicación"

- "No hay grandes diferencias en la riqueza y poder entre las personas"

- "Una fuerte economía de libre empresa y un gobierno eficiente en sus tareas básicas"

- "Comunidades y organizaciones locales fuertes"

En conclusión los ciudadanos de Ensenada y los de Australia coinciden en varios de los atributos identificados como los más importantes, siendo un número menor que la cantidad de coincidencias de Ensenada con la región. Además el valor de importancia que le dan los ciudadanos de Ensenada es significativamente superior al que le dan los de Australia.

\section{Desempeño}

En la tabla de abajo se comparan los resultados de la variable desempeño y su jerarquía en la ciudad de Ensenada, con los de la encuesta en Australia. La última columna muestra la diferencia porcentual tomando como base el desempeño en la ciudad de Ensenada.

Tabla 24

\begin{tabular}{|c|c|c|c|c|c|c|}
\hline \multirow[b]{2}{*}{ Item } & \multirow[b]{2}{*}{ Características } & \multicolumn{2}{|c|}{$\begin{array}{l}\text { Desempeño en la } \\
\text { ciudad de Ensenada }\end{array}$} & \multicolumn{2}{|c|}{$\begin{array}{l}\text { Desempeño en } \\
\text { Australia }\end{array}$} & \multirow{2}{*}{$\begin{array}{c}\text { Diferencia \% } \\
\text { respecto a la } \\
\text { ciudad de } \\
\text { Ensenada }\end{array}$} \\
\hline & & \begin{tabular}{|c|}
$\begin{array}{c}\text { Calificación 1-10 } \\
\text { (b) }\end{array}$ \\
\end{tabular} & $\begin{array}{c}\text { Jerarquía 1-35 } \\
\left(b^{\prime}\right)\end{array}$ & \begin{tabular}{|c|} 
Calificación 1-10 \\
(b)
\end{tabular} & $\begin{array}{c}\text { Jerarquía 1-35 } \\
\left(b^{\prime}\right)\end{array}$ & \\
\hline 1 & Altos niveles de honestidad en la pollica y la vida pública & 3,75 & 33 & 4,30 & 27 & $14,7 \%$ \\
\hline 2 & Todos son tratados igualitaria y equitativamente por la ley & 4,40 & 25 & 5,40 & 19 & $22,6 \%$ \\
\hline 3 & Los derechos humanos básicos de todos los ciudadanos están fuertemente protegidos & 5,21 & 9 & 6,60 & 6 & $26,6 \%$ \\
\hline 4 & Buena calidad de los servicios básicos (salud, educación, etc.) para todos & 4,92 & 14 & 5,50 & 17 & $11,7 \%$ \\
\hline 5 & Eliminación del crimen y la violencia & 3,46 & 34 & 3,40 & 33 & $-1,8 \%$ \\
\hline 6 & Protección del medioambiente, recursos y fauna & 4,92 & 14 & 5,60 & 15 & $13,8 \%$ \\
\hline 7 & Igualdad de oportunidades para hombres y mujeres & 7,00 & 2 & 6,40 & 8 & $-8,6 \%$ \\
\hline 8 & Todos pagan impuestos equitativamente, acorde con el ingreso y riqueza & 4,38 & 27 & 3,40 & 33 & $-22,5 \%$ \\
\hline 9 & Confianza justificada en que las instituciones públicas actúan con limpieza y justicia & 4,04 & 31 & 5,10 & 21 & $26,3 \%$ \\
\hline 10 & Las comunidades locales tienen buena calidad de servicios públicos (transporte, luz, etc.) & 4,69 & 21 & 4,80 & 24 & $2,3 \%$ \\
\hline 11 & Buena atención a las personas vulnerables, disminuidos y de clase baja & 5,13 & 11 & 5,60 & 15 & $9,1 \%$ \\
\hline 12 & Reducción de la contaminación medioambiental, desarrollo de fuentes de energía renovables & 4,31 & 28 & 4,80 & 24 & $11,4 \%$ \\
\hline 13 & Las personas se sienten responsables por cada uno de los demás y por la comunidad & 4,42 & 24 & 5,10 & 21 & $15,3 \%$ \\
\hline 14 & Las personas que trabajan duramente pueden tener éxito en la vida & 5,10 & 12 & 6,80 & 3 & $33,4 \%$ \\
\hline 15 & Se alienta la vida familiar y los valores de la familia & 5,81 & 5 & 5,80 & 14 & $-0,1 \%$ \\
\hline
\end{tabular}




\begin{tabular}{|c|c|c|c|c|c|c|}
\hline \multirow[b]{3}{*}{ Item } & \multirow[b]{3}{*}{ Características } & \multirow{2}{*}{\multicolumn{2}{|c|}{$\begin{array}{l}\text { Desempeño en la } \\
\text { ciudad de Ensenada }\end{array}$}} & & & \\
\hline & & & & \multicolumn{2}{|c|}{$\begin{array}{l}\text { Desempeño en } \\
\text { Australia }\end{array}$} & \multirow{2}{*}{$\begin{array}{c}\text { Diferencia \% } \\
\text { respecto a la } \\
\text { ciudad de } \\
\text { Ensenada }\end{array}$} \\
\hline & & $\begin{array}{l}\text { Calificación 1-10 } \\
\text { (b) }\end{array}$ & $\begin{array}{c}\text { Jerarquía 1-35 } \\
\text { (b') }\end{array}$ & \begin{tabular}{|c|} 
Calificación 1-10 \\
(b)
\end{tabular} & $\begin{array}{c}\text { Jerarquia 1-35 } \\
\text { (b') }\end{array}$ & \\
\hline 16 & Las personas jóvenes son valoradas, y tenen perspectivas de futuro seguras & 4,60 & 22 & 4,30 & 27 & $-6,4 \%$ \\
\hline 17 & Eliminación de la pobreza & 4,73 & 20 & 3,80 & 31 & $-19,7 \%$ \\
\hline 18 & Respeto por, y estricta aplicación de las leyes & 4,12 & 29 & 5,50 & 17 & $33,6 \%$ \\
\hline 19 & Trabajos seguros, satisfactorios y equitativamente pagados para todos los que quieren trabajar & 4,54 & 23 & 4,20 & 29 & $-7,5 \%$ \\
\hline 20 & Fuerte protección social (edad, enfermedad, desempleo, etc.) & 4,83 & 18 & 5,40 & 19 & $11,9 \%$ \\
\hline 21 & Capacidad para confar en otras personas, incluso extraños & 3,77 & 32 & 3,90 & 30 & $3,5 \%$ \\
\hline 22 & Ciudad atractiva y bien planificada & 4,88 & 17 & 6,60 & 6 & $35,1 \%$ \\
\hline 23 & Protección de la libertad religiosa & 7,54 & 1 & 7,50 & 1 & $-0,5 \%$ \\
\hline 24 & Relaciones justas, limpias e independientes con otras naciones & 5,54 & 6 & 6,10 & 11 & $10,1 \%$ \\
\hline 25 & Altos niveles de progreso cientifico y tecnológico & 5,29 & 7 & 6,80 & 3 & $28,6 \%$ \\
\hline 26 & Vigorosa libertad de opinión, múltiples opiniones públicas (disensos) & 6,12 & 4 & 6,30 & 9 & $3,0 \%$ \\
\hline 27 & Las personas participan en la toma de decisiones de hechos que los afectan & 4,77 & 19 & 5,10 & 21 & $6,9 \%$ \\
\hline 28 & Atomización en la propiedad y control de los medios de comunicación & 4,90 & 16 & 3,70 & 32 & $-24,5 \%$ \\
\hline 29 & Comunidades y organizaciones locales fuertes & 5,06 & 13 & 6,00 & 13 & $18,6 \%$ \\
\hline 30 & Libertad para hacer lo que nos gusta siempre que no perjudiquemos a otros & 5,29 & 7 & 7,10 & 2 & $34,3 \%$ \\
\hline 31 & Generosidad en ayudar a regiones periudicadas & 6,40 & 3 & 6,20 & 10 & $-3,2 \%$ \\
\hline 32 & No hay grandes diferencias en la riqueza y poder entre las personas & 3,29 & 35 & 3,30 & 35 & $0,4 \%$ \\
\hline 33 & Una fuerte economia de libre empresa y un gobierno eficiente en sus tareas básicas & 4,10 & 30 & 6,10 & 11 & $48,9 \%$ \\
\hline 34 & Establecer una economia fuerte antes que la equidad y las metas medioambientales & 5,19 & 10 & 6,80 & 3 & $31,0 \%$ \\
\hline \multirow[t]{2}{*}{35} & Las personas tienen valores sociales y estilos de vida similares & 4,40 & 25 & 4,60 & 26 & $4,5 \%$ \\
\hline & Promedio & 4,88 & & 5,37 & & $9,9 \%$ \\
\hline
\end{tabular}

Fuente: Elaboración propia.

Analizando la tabla, al igual que para los ciudadanos de Ensenada, para los de Australia, ninguno de los aspectos evaluados puede considerarse con un alto desempeño, ya que no superan el valor ocho (8). Comparando los promedios, el desempeño en la ciudad de Ensenada es significativamente menor, casi diez (10) puntos porcentuales, siendo 4,88 en Ensenada vs. 5,37 en Australia.

Abajo el extracto de las primeras y las últimas diez (10) características ordenadas por la jerarquía de la variable desempeño en la ciudad de Ensenada:

Tabla 25

\begin{tabular}{|c|c|c|c|c|c|c|}
\hline \multirow[b]{2}{*}{ Item } & \multirow[b]{2}{*}{ Características } & \multicolumn{2}{|c|}{$\begin{array}{l}\text { Desempeño en la } \\
\text { ciudad de Ensenada }\end{array}$} & \multicolumn{2}{|c|}{$\begin{array}{l}\text { Desempeño en } \\
\text { Australia }\end{array}$} & \multirow{2}{*}{$\begin{array}{c}\text { Diferencia \% } \\
\text { respecto a la } \\
\text { ciudad de } \\
\text { Ensenada }\end{array}$} \\
\hline & & $\begin{array}{l}\text { Calificación 1-10 } \\
\text { (b) }\end{array}$ & $\begin{array}{c}\text { Jerarquía 1-35 } \\
\text { (b') }\end{array}$ & \begin{tabular}{|c|}
$\begin{array}{c}\text { Calificación 1-10 } \\
\text { (b) }\end{array}$ \\
\end{tabular} & $\begin{array}{l}\text { Jerarquía 1-35 } \\
\left(b^{\prime}\right)\end{array}$ & \\
\hline 23 & Protección de la libertad religiosa & 7,54 & 1 & 7,50 & 1 & $-0,5 \%$ \\
\hline 7 & Igualdad de oportunidades para hombres y mujeres & 7,00 & 2 & 6,40 & 8 & $-8,6 \%$ \\
\hline 31 & Generosidad en ayudar a regiones perjudicadas & 6,40 & 3 & 6,20 & 10 & $-3,2 \%$ \\
\hline 26 & Vigorosa libertad de opinión, múltiples opiniones públicas (disensos) & 6,12 & 4 & 6,30 & 9 & $3,0 \%$ \\
\hline 15 & Se alienta la vida familiar y los valores de la familia & 5,81 & 5 & 5,80 & 14 & $-0,1 \%$ \\
\hline 24 & Relaciones justas, limpias e independientes con otras naciones & 5,54 & 6 & 6,10 & 11 & $10,1 \%$ \\
\hline 25 & Altos niveles de progreso cientifico y tecnológico & 5,29 & 7 & 6,80 & 3 & $28,6 \%$ \\
\hline 30 & Libertad para hacer lo que nos gusta siempre que no perjudiquemos a otros & 5,29 & 7 & 7,10 & 2 & $34,3 \%$ \\
\hline 3 & Los derechos humanos básicos de todos los ciudadanos están fuertemente protegidos & 5,21 & 9 & 6,60 & 6 & $26,6 \%$ \\
\hline \multirow[t]{3}{*}{34} & Establecer una economia fuerte antes que la equidad y las metas medioambientales & 5,19 & 10 & 6,80 & 3 & $31,0 \%$ \\
\hline & Promedio & 5,94 & & 6,56 & & $10,5 \%$ \\
\hline & Desvio estándar & 0,82 & & 0,51 & & \\
\hline
\end{tabular}




\begin{tabular}{|c|c|c|c|c|c|c|}
\hline 2 & Todos son tratados igualitaria y equitaivamente por la ley & 4,40 & 25 & 5,40 & 19 & $22,6 \%$ \\
\hline 35 & Las personas tienen valores sociales y estilos de vida similares & 4,40 & 25 & 4,60 & 26 & $4,5 \%$ \\
\hline 8 & Todos pagan impuestos equitativamente, acorde con el ingreso y riqueza & 4,38 & 27 & 3,40 & 33 & $-22,5 \%$ \\
\hline 12 & Reducción de la contaminación medioambiental, desarrollo de fuentes de energía renovables & 4,31 & 28 & 4,80 & 24 & $11,4 \%$ \\
\hline 18 & Respeto por, y estricta aplicación de las leyes & 4,12 & 29 & 5,50 & 17 & $33,6 \%$ \\
\hline 33 & Una fuerte economia de libre empresa y un gobierno eficiente en sus tareas básicas & 4,10 & 30 & 6,10 & 11 & $48,9 \%$ \\
\hline 9 & Confianza justificada en que las instituciones públicas actúan con limpieza y justicia & 4,04 & 31 & 5,10 & 21 & $26,3 \%$ \\
\hline 21 & Capacidad para confiar en otras personas, incluso extraños & 3,77 & 32 & 3,90 & 30 & $3,5 \%$ \\
\hline 1 & Altos niveles de honestidad en la politica y la vida pública & 3,75 & 33 & 4,30 & 27 & $14,7 \%$ \\
\hline 5 & Eliminación del crimen y la violencia & 3,46 & 34 & 3,40 & 33 & $-1,8 \%$ \\
\hline 32 & No hay grandes differencias en la riqueza y poder entre las personas & 3,29 & 35 & 3,30 & 35 & $0,4 \%$ \\
\hline & Promedio & 4,00 & & 4,53 & & $13,1 \%$ \\
\hline
\end{tabular}

Fuente: Elaboración propia.

La característica con mayor desempeño coincide tanto para Ensenada como para Australia: "Protección de la libertad religiosa", teniendo una valoración prácticamente igual en ambos casos.

De las siguientes nueve (9) características por jerarquía de desempeño, los ciudadanos de Ensenada y Australia coinciden en otras siete (7):

- "Igualdad de oportunidades para hombres y mujeres"

- "Generosidad en ayudar a regiones perjudicadas"

- "Vigorosa libertad de opinión, múltiples opiniones públicas (disensos)"

- "Altos niveles de progreso científico y tecnológico"

- "Libertad para hacer lo que nos gusta siempre que no perjudiquemos a otros"

- "Los derechos humanos básicos de todos los ciudadanos están fuertemente protegidos"

- "Establecer una economía fuerte antes que la equidad y las metas medioambientales"

De estas características con mayor desempeño, sólo dos (2) están para ambos casos dentro de las diez (10) primeras por jerarquía de importancia:

- "Igualdad de oportunidades para hombres y mujeres" con jerarquía siete (7) en Ensenada y jerarquía siete (7) en Australia.

- "Los derechos humanos básicos de todos los ciudadanos están fuertemente protegidos" con jerarquía dos (2) en Ensenada y jerarquía tres (3) en Australia.

En el otro extremo, de las características con el menor desempeño, ambas sociedades coinciden en seis (6):

- "No hay grandes diferencias en la riqueza y poder entre las personas"

- "Eliminación del crimen y la violencia"

- "Altos niveles de honestidad en la política y la vida pública"

- "Capacidad para confiar en otras personas, incluso extraños"

- "Todos pagan impuestos equitativamente, acorde con el ingreso y riqueza"

- "Las personas tienen valores sociales y estilos de vida similares" 
De estas características con el menor desempeño, hay cuatro (4) que son consideradas por ambas sociedades dentro de las diez (10) primeras por jerarquía de importancia:

- "Eliminación del crimen y la violencia" con jerarquía uno (1) en Ensenada y jerarquía cinco (5) en Australia.

- "Altos niveles de honestidad en la política y la vida pública" con jerarquía seis (6) en Ensenada y jerarquía uno (1) en Australia.

- "Confianza justificada en que las instituciones públicas actúan con limpieza y justicia" con jerarquía cinco (5) en Ensenada y jerarquía nueve (9) en Australia.

- "Todos son tratados igualitaria y equitativamente por la ley" con jerarquía tres (3) en Ensenada y jerarquía dos (2) en Australia.

Resumiendo, entre los ciudadanos de Ensenada y Australia hay varias coincidencias entre los atributos con mayor y menor desempeño, aunque menos que las que tienen los ensenadenses con los de la región de La Plata y alrededores. El desempeño promedio de los treinta y cinco (35) atributos es bastante inferior en Ensenada en comparación con Australia.

\section{Discrepancia}

La tabla de abajo compara los resultados de la variable discrepancia y su jerarquía de importancia en la ciudad de Ensenada con los resultados en Australia. La última columna muestra la diferencia porcentual tomando como base la discrepancia en la ciudad de Ensenada.

Tabla 26

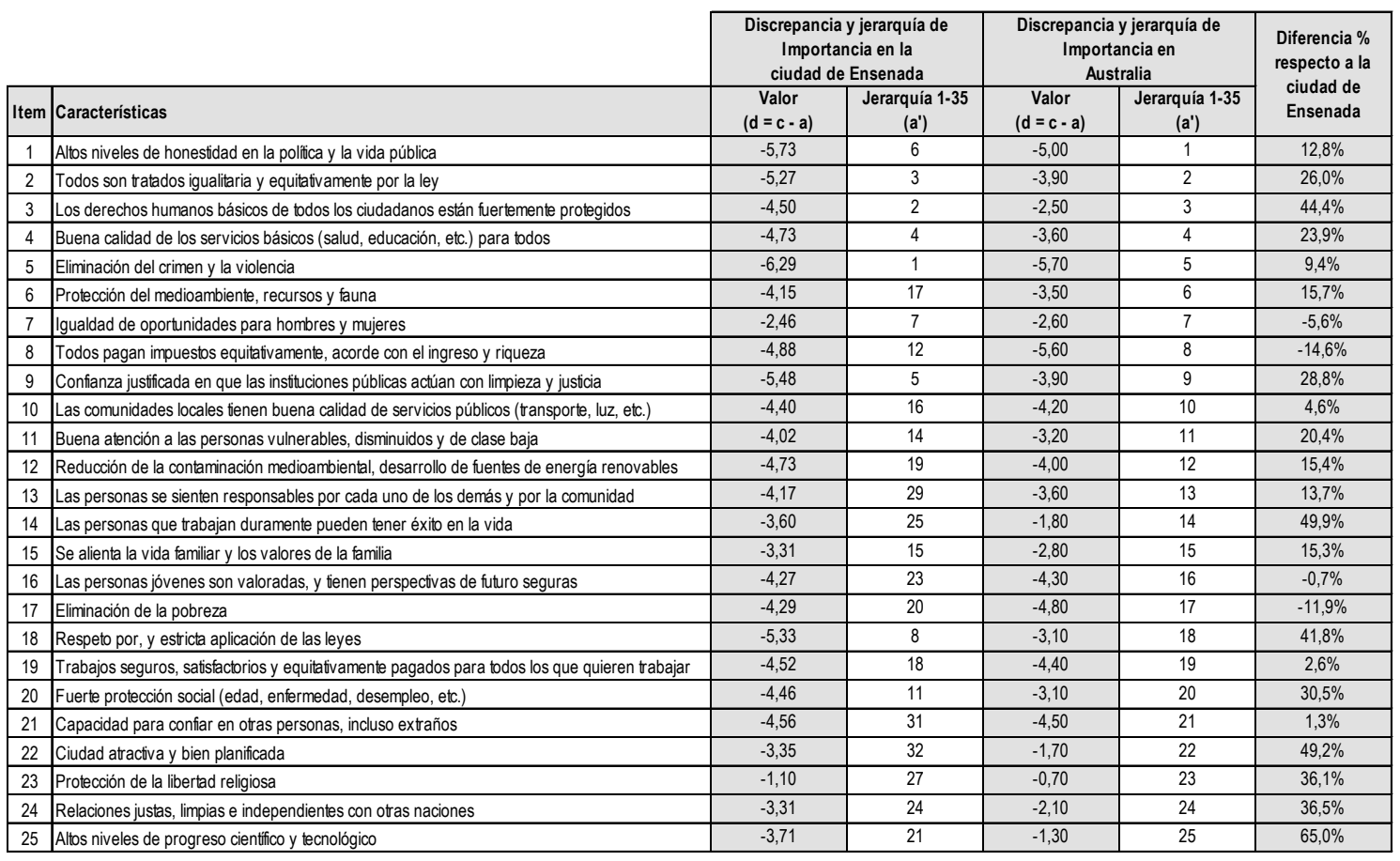




\begin{tabular}{|c|c|c|c|c|c|c|}
\hline \multirow[b]{3}{*}{ Item } & \multirow[b]{3}{*}{ Características } & \multirow{2}{*}{\multicolumn{2}{|c|}{$\begin{array}{l}\text { Discrepancia y jerarquía de } \\
\text { Importancia en la } \\
\text { ciudad de Ensenada }\end{array}$}} & \multirow{2}{*}{\multicolumn{2}{|c|}{$\begin{array}{l}\text { Discrepancia y jerarquía de } \\
\text { Importancia en } \\
\text { Australia } \\
\end{array}$}} & \multirow{3}{*}{$\begin{array}{c}\text { Diferencia \% } \\
\text { respecto a la } \\
\text { ciudad de } \\
\text { Ensenada }\end{array}$} \\
\hline & & & & & & \\
\hline & & $\begin{array}{c}\text { Valor } \\
(d=c-a)\end{array}$ & $\begin{array}{c}\text { Jerarquía 1-35 } \\
\left(a^{\prime}\right)\end{array}$ & $\begin{array}{c}\text { Valor } \\
(d=c-a)\end{array}$ & $\begin{array}{c}\text { Jerarquía 1-35 } \\
\text { (a') }\end{array}$ & \\
\hline 26 & Vigorosa libertad de opinión, múltiples opiniones públicas (disensos) & $-3,27$ & 9 & $-1,80$ & 26 & $44,9 \%$ \\
\hline 27 & Las personas participan en la toma de decisiones de hechos que los afectan & $-4,12$ & 22 & $-3,00$ & 27 & $27,1 \%$ \\
\hline 28 & Atomización en la propiedad y control de los medios de comunicación & $-2,71$ & 33 & $-4,20$ & 28 & $-54,9 \%$ \\
\hline 29 & Comunidades y organizaciones locales fuertes & $-3,60$ & 26 & $-1,80$ & 29 & $49,9 \%$ \\
\hline 30 & Libertad para hacer lo que nos gusta siempre que no perjudiquemos a otros & $-4,08$ & 10 & $-0,30$ & 30 & $92,6 \%$ \\
\hline 31 & Generosidad en ayudar a regiones perjudicadas & $-2,81$ & 13 & $-0,80$ & 31 & $71,5 \%$ \\
\hline 32 & No hay grandes diferencias en la riqueza y poder entre las personas & $-5,21$ & 30 & $-3,50$ & 32 & $32,8 \%$ \\
\hline 33 & Una fuerte economia de libre empresa y un gobierno eficiente en sus tareas básicas & $-4,52$ & 28 & $-0,60$ & 33 & $86,7 \%$ \\
\hline 34 & Establecer una economia fuerte antes que la equidad y las metas medioambientales & $-1,71$ & 35 & 1,60 & 34 & $193,5 \%$ \\
\hline \multirow{2}{*}{35} & Las personas tienen valores sociales y estilos de vida similares & $-2,60$ & 34 & 0,10 & 35 & $103,9 \%$ \\
\hline & Promedio & $\begin{array}{l}-4,04 \\
\end{array}$ & & $-2,86$ & & $29,1 \%$ \\
\hline
\end{tabular}

Fuente: Elaboración propia.

Observando la tabla vemos que mientras que para los ciudadanos de Ensenada ninguno de los treinta y cinco (35) atributos tiene mayor desempeño que la importancia atribuida, para los ciudadanos de Australia hay dos (2) atributos que tienen esa cualidad. Considerando el promedio total, la discrepancia en valor absoluto en Ensenada es muy superior que en Australia, casi treinta (30) puntos porcentuales: 4,04 vs. 2,86. Esto significa que la brecha entre lo que quieren y perciben los ciudadanos de Ensenada es mucho mayor que la existe para los australianos.

En la siguiente tabla se muestran las diez (10) características con las menores y mayores discrepancias en la ciudad de Ensenada junto con las jerarquías de importancia:

Tabla 27

\begin{tabular}{|c|c|c|c|c|c|c|}
\hline \multirow[b]{2}{*}{ Item } & \multirow[b]{2}{*}{ Caracteristicas } & \multicolumn{2}{|c|}{$\begin{array}{l}\text { Discrepancia y jerarquía de } \\
\text { Importancia en la } \\
\text { ciudad de Ensenada }\end{array}$} & \multicolumn{2}{|c|}{$\begin{array}{l}\text { Discrepancia y jerarquía de } \\
\text { Importancia en } \\
\text { Australia }\end{array}$} & \multirow{2}{*}{$\begin{array}{c}\text { Diferencia \% } \\
\text { respecto a la } \\
\text { ciudad de } \\
\text { Ensenada }\end{array}$} \\
\hline & & $\begin{array}{c}\text { Valor } \\
(d=c-a)\end{array}$ & $\begin{array}{c}\text { Jerarquía 1-35 } \\
\left(\mathrm{a}^{\prime}\right)\end{array}$ & $\begin{array}{c}\text { Valor } \\
(d=c-a)\end{array}$ & $\begin{array}{c}\text { Jerarquía 1-35 } \\
\text { (a') }\end{array}$ & \\
\hline 5 & Eliminación del crimen y la violencia & $-6,29$ & 1 & $-5,70$ & 5 & $9,4 \%$ \\
\hline 1 & Altos niveles de honestidad en la politica y la vida pública & $-5,73$ & 6 & $-5,00$ & 1 & $12,8 \%$ \\
\hline 9 & Confianza justificada en que las instituciones públicas actúan con limpieza y justicia & $-5,48$ & 5 & $-3,90$ & 9 & $28,8 \%$ \\
\hline 18 & Respeto por, y estricta aplicación de las leyes & $-5,33$ & 8 & $-3,10$ & 18 & $41,8 \%$ \\
\hline 2 & Todos son tratados igualitaria y equitativamente por la ley & $-5,27$ & 3 & $-3,90$ & 2 & $26,0 \%$ \\
\hline 32 & No hay grandes diferencias en la riqueza y poder entre las personas & $-5,21$ & 30 & $-3,50$ & 32 & $32,8 \%$ \\
\hline 8 & Todos pagan impuestos equitativamente, acorde con el ingreso y riqueza & $-4,88$ & 12 & $-5,60$ & 8 & $-14,6 \%$ \\
\hline 4 & Buena calidad de los servicios básicos (salud, educación, etc.) para todos & $-4,73$ & 4 & $-3,60$ & 4 & $23,9 \%$ \\
\hline 12 & Reducción de la contaminación medioambiental, desarrollo de fuentes de energia renovables & $-4,73$ & 19 & $-4,00$ & 12 & $15,4 \%$ \\
\hline \multirow[t]{3}{*}{21} & Capacidad para confiar en otras personas, incluso extraños & $-4,56$ & 31 & $-4,50$ & 21 & $1,3 \%$ \\
\hline & Promedio & $-5,22$ & & $-4,28$ & & $18,0 \%$ \\
\hline & Desvío estándar & 0,53 & & 0,89 & & \\
\hline 22 & Ciudad atractiva y bien planificada & $-3,35$ & 32 & $-1,70$ & 22 & $49,2 \%$ \\
\hline 15 & Se alienta la vida familiar y los valores de la familia & $-3,31$ & 15 & $-2,80$ & 15 & $15,3 \%$ \\
\hline 24 & Relaciones justas, limpias e independientes con otras naciones & $-3,31$ & 24 & $-2,10$ & 24 & $36,5 \%$ \\
\hline 26 & Vigorosa libertad de opinión, múltiples opiniones públicas (disensos) & $-3,27$ & 9 & $-1,80$ & 26 & $44,9 \%$ \\
\hline 31 & Generosidad en ayudar a regiones perjudicadas & $-2,81$ & 13 & $-0,80$ & 31 & $71,5 \%$ \\
\hline 28 & Atomización en la propiedad y control de los medios de comunicación & $-2,71$ & 33 & $-4,20$ & 28 & $-54,9 \%$ \\
\hline 35 & Las personas tienen valores sociales y estilos de vida similares & $-2,60$ & 34 & 0,10 & 35 & $103,9 \%$ \\
\hline 7 & Igualdad de oportunidades para hombres y mujeres & $-2,46$ & 7 & $-2,60$ & 7 & $-5,6 \%$ \\
\hline 34 & Establecer una economía fuerte antes que la equidad y las metas medioambientales & $-1,71$ & 35 & 1,60 & 34 & $193,5 \%$ \\
\hline \multirow[t]{3}{*}{23} & Protección de la libertad religiosa & $-1,10$ & 27 & $-0,70$ & 23 & $36,1 \%$ \\
\hline & Promedio & $\begin{array}{l}-2,66 \\
\end{array}$ & & $-1,50$ & & $43,6 \%$ \\
\hline & Desvio estándar & 0,75 & & 1,63 & & \\
\hline
\end{tabular}

Fuente: Elaboración propia. 
Considerando los diez (10) atributos con las mayores discrepancias en valor absoluto para los ciudadanos de Ensenada, y comparándolos con las discrepancias de esos atributos en Australia, las diferencias son muy significativas, siendo el promedio dieciocho (18) puntos porcentuales mayor en Ensenada que en Australia. En este grupo hay cinco (5) atributos que están dentro de los diez (10) más importantes para ambos.

En el lado opuesto de la tabla, en los diez (10) atributos con las menores discrepancias en valor absoluto para los ciudadanos de Ensenada, las diferencias son mucho más significativas, siendo el promedio más de cuarenta y tres (43) puntos porcentuales mayor en Ensenada que en Australia. En este grupo se encuentran los dos (2) atributos menos importantes para ambos.

Esto implica que tanto en Ensenada como en Australia parte de los atributos más importantes son los que menor desempeño tienen y viceversa, aunque para los ciudadanos de Ensenada el desempeño de los atributos está mucho más lejano de las importancias valoradas que en el caso de los australianos.

\section{Gravedad Percibida}

En la próxima tabla se comparan los resultados de la variable gravedad percibida y su jerarquía en la ciudad de Ensenada con los resultados en Australia. La última columna muestra la diferencia porcentual tomando como base la discrepancia en la ciudad de Ensenada.

Tabla 28

\begin{tabular}{|c|c|c|c|c|c|c|}
\hline \multirow[b]{2}{*}{ Item } & \multirow[b]{2}{*}{ Caracteristicas } & \multicolumn{2}{|c|}{$\begin{array}{l}\text { Gravedad Percibida en la } \\
\text { ciudad de Ensenada }\end{array}$} & \multicolumn{2}{|c|}{$\begin{array}{l}\text { Gravedad Percibida en } \\
\text { Australia }\end{array}$} & \multirow{2}{*}{$\begin{array}{l}\text { Diferencia \% } \\
\text { respecto a la } \\
\text { ciudad de } \\
\text { Ensenada }\end{array}$} \\
\hline & & $\begin{array}{c}\text { Ponderación } \\
\left(g=-d^{*} a\right)\end{array}$ & $\begin{array}{l}\text { Jerarquía 1-35 } \\
\left(\mathrm{g}^{\prime}\right)\end{array}$ & $\begin{array}{l}\text { Ponderación } \\
\left(g=-d^{*} a\right)\end{array}$ & $\begin{array}{c}\text { Jerarquía 1-35 } \\
\left(g^{\prime}\right)\end{array}$ & \\
\hline 1 & Altos niveles de honestidad en la polliça y la vida pública & 55,06 & 2 & 46,50 & 3 & $-15,5 \%$ \\
\hline 2 & Todos son tratados igualitaria y equitativamente por la ley & 51,37 & 4 & 36,27 & 9 & $-29,4 \%$ \\
\hline 3 & Los derechos humanos básicos de todos los ciudadanos están fuertemente protegidos & 44,42 & 10 & 22,75 & 23 & $-48,8 \%$ \\
\hline 4 & Buena calidad de los servicios básicos (salud, educación, etc.) para todos & 46,17 & 8 & 32,76 & 13 & $-29,0 \%$ \\
\hline 5 & Eliminación del crimen y la violencia & 61,85 & 1 & 51,87 & 1 & $-16,1 \%$ \\
\hline 6 & Protección del medioambiente, recursos y fauna & 38,98 & 19 & 31,85 & 14 & $-18,3 \%$ \\
\hline 7 & Igualdad de oportunidades para hombres y mujeres & 24,04 & 33 & 23,40 & 22 & $-2,7 \%$ \\
\hline 8 & Todos pagan impuestos equitativamente, acorde con el ingreso y riqueza & 46,27 & 7 & 50,40 & 2 & $8,9 \%$ \\
\hline 9 & Confanza justificada en que las instituciones públicas actúan con limpieza y justicia & 53,23 & 3 & 35,10 & 11 & $-34,1 \%$ \\
\hline 10 & Las comunidades locales tienen buena calidad de servicios públicos (transporte, luz, etc.) & 41,38 & 14 & 37,80 & 6 & $-8,7 \%$ \\
\hline 11 & Buena atención a las personas vulnerables, disminuidos y de clase baja & 37,60 & 21 & 28,16 & 16 & $-25,1 \%$ \\
\hline 12 & Reducción de la contaminación medioambiental, desarrollo de fuentes de energía renovables & 43,96 & 11 & 35,20 & 10 & $-19,9 \%$ \\
\hline 13 & Las personas se sienten responsables por cada uno de los demás y por la comunidad & 37,27 & 22 & 31,32 & 15 & $-16,0 \%$ \\
\hline 14 & Las personas que trabajan duramente pueden tener éxito en la vida & 33,79 & 24 & 15,48 & 25 & $-54,2 \%$ \\
\hline 15 & Se alienta la vida familiar y los valores de la familia & 32,54 & 26 & 24,08 & 20 & $-26,0 \%$ \\
\hline 16 & Las personas jóvenes son valoradas, $\mathrm{y}$ tienen perspectivas de futuro seguras & 39,60 & 17 & 36,98 & 8 & $-6,6 \%$ \\
\hline 17 & Eliminación de la pobreza & 40,19 & 16 & 41,28 & 4 & $2,7 \%$ \\
\hline 18 & Respeto por, y estricta aplicación de las leyes & 51,37 & 4 & 26,66 & 17 & $-48,1 \%$ \\
\hline 19 & Trabajos seguros, satisfactorios y equitativamente pagados para todos los que quieren trabajar & 42,71 & 12 & 37,84 & 5 & $-11,4 \%$ \\
\hline 20 & Fuerte protección social (edad, enfermedad, desempleo, etc.) & 41,85 & 13 & 26,35 & 18 & $-37,0 \%$ \\
\hline 21 & Capacidad para confiar en otras personas, incluso extraños & 40,62 & 15 & 37,80 & 6 & $-6,9 \%$ \\
\hline 22 & Ciudad atractiva y bien planificada & 30,48 & 29 & 14,11 & 27 & $-53,7 \%$ \\
\hline 23 & Protección de la libertad religiosa & 12,73 & 35 & 5,74 & 30 & $-54,9 \%$ \\
\hline 24 & Relaciones justas, limpias e independientes con otras naciones & 31,50 & 27 & 17,22 & 24 & $-45,3 \%$ \\
\hline 25 & Altos niveles de progreso cientifico y tecnológico & 34,85 & 23 & 10,53 & 29 & $-69,8 \%$ \\
\hline
\end{tabular}




\begin{tabular}{|c|c|c|c|c|c|c|}
\hline \multirow[b]{2}{*}{ Item } & \multirow[b]{2}{*}{ Caracteristicas } & \multicolumn{2}{|c|}{$\begin{array}{l}\text { Gravedad Percibida en la } \\
\text { ciudad de Ensenada }\end{array}$} & \multicolumn{2}{|c|}{$\begin{array}{l}\text { Gravedad Percibida en } \\
\text { Australia }\end{array}$} & \multirow{2}{*}{$\begin{array}{c}\text { Diferencia \% } \\
\text { respecto a la } \\
\text { ciudad de } \\
\text { Ensenada }\end{array}$} \\
\hline & & $\begin{array}{c}\text { Ponderación } \\
\left(g=-d^{*} a\right)\end{array}$ & $\begin{array}{c}\text { Jerarquía 1-35 } \\
\text { (g') }\end{array}$ & $\begin{array}{c}\text { Ponderación } \\
\left(g=-d^{*} a\right)\end{array}$ & $\begin{array}{c}\text { Jerarquía 1-35 } \\
\text { (g') }\end{array}$ & \\
\hline 26 & Vigorosa libertad de opinión, múltiples opiniones públicas (disensos) & 30,90 & 28 & 14,58 & 26 & $-52,8 \%$ \\
\hline 27 & Las personas participan en la toma de decisiones de hechos que los afectan & 38,04 & 20 & 24,30 & 19 & $-36,1 \%$ \\
\hline 28 & Atomización en la propiedad y control de los medios de comunicación & 25,67 & 32 & 33,18 & 12 & $29,2 \%$ \\
\hline 29 & Comunidades y organizaciones locales fuertes & 32,90 & 25 & 14,04 & 28 & $-57,3 \%$ \\
\hline 30 & Libertad para hacer lo que nos gusta siempre que no perjudiquemos a otros & 39,02 & 18 & 2,22 & 33 & $-94,3 \%$ \\
\hline 31 & Generosidad en ayudar a regiones perjudicadas & 26,65 & 30 & 5,60 & 31 & $-79,0 \%$ \\
\hline 32 & No hay grandes diferencias en la riqueza y poder entre las personas & 48,13 & 6 & 23,80 & 21 & $-50,6 \%$ \\
\hline 33 & Una fuerte economía de libre empresa y un gobierno eficiente en sus tareas básicas & 44,56 & 9 & 4,02 & 32 & $-91,0 \%$ \\
\hline 34 & Establecer una economía fuerte antes que la equidad y las metas medioambientales & 20,06 & 34 & $-8,32$ & 35 & $-141,5 \%$ \\
\hline \multirow[t]{2}{*}{35} & Las personas tienen valores sociales $\mathrm{y}$ estilos de vida similares & 26,13 & 31 & $-0,45$ & 34 & $-101,7 \%$ \\
\hline & Promedio & 38,45 & & 24,87 & & $-35,3 \%$ \\
\hline
\end{tabular}

Fuente: Elaboración propia.

Al analizar la tabla se aprecia que la gravedad percibida promedio es más de treinta y cinco (35) puntos porcentuales mayor en Ensenada que en Australia: 38,45 vs. 24,87 . Sólo dos (2) variables tienen una gravedad percibida menor para los ensenadenses:

- "Todos pagan impuestos equitativamente, acorde con el ingreso y riqueza"

- "Eliminación de la pobreza"

En la tabla de abajo se muestran las gravedades de las primeras y las últimas diez (10) características ordenadas por su jerarquía en la ciudad de Ensenada:

Tabla 29

\begin{tabular}{|c|c|c|c|c|c|c|}
\hline \multirow[b]{2}{*}{ Item } & \multirow[b]{2}{*}{ Caracteristicas } & \multicolumn{2}{|c|}{$\begin{array}{l}\text { Gravedad Percibida en la } \\
\text { ciudad de Ensenada }\end{array}$} & \multicolumn{2}{|c|}{$\begin{array}{c}\text { Gravedad Percibida en } \\
\text { Australia }\end{array}$} & \multirow{2}{*}{$\begin{array}{c}\text { Diferencia \% } \\
\text { respecto a la } \\
\text { ciudad de } \\
\text { Ensenada }\end{array}$} \\
\hline & & $\begin{array}{c}\text { Ponderación } \\
\left(g=-d^{*} a\right)\end{array}$ & $\begin{array}{c}\text { Jerarquía 1-35 } \\
\left(g^{\prime}\right)\end{array}$ & $\begin{array}{c}\text { Ponderación } \\
\left(g=-d^{*} a\right)\end{array}$ & $\begin{array}{c}\text { Jerarquía 1-35 } \\
\left(\mathrm{g}^{\prime}\right)\end{array}$ & \\
\hline 5 & Eliminación del crimen y la violencia & 61,85 & 1 & 51,87 & 1 & $-16,1 \%$ \\
\hline 1 & Altos niveles de honestidad en la pollica y la vida pública & 55,06 & 2 & 46,50 & 3 & $-15,5 \%$ \\
\hline 9 & Confianza justificada en que las instituciones públicas actúan con limpieza y justicia & 53,23 & 3 & 35,10 & 11 & $-34,1 \%$ \\
\hline 2 & Todos son tratados igualitaria y equitativamente por la ley & 51,37 & 4 & 36,27 & 9 & $-29,4 \%$ \\
\hline 18 & Respeto por, y estricta aplicación de las leyes & 51,37 & 4 & 26,66 & 17 & $-48,1 \%$ \\
\hline 32 & No hay grandes diferencias en la riqueza y poder entre las personas & 48,13 & 6 & 23,80 & 21 & $-50,6 \%$ \\
\hline 8 & Todos pagan impuestos equitativamente, acorde con el ingreso y riqueza & 46,27 & 7 & 50,40 & 2 & $8,9 \%$ \\
\hline 4 & Buena calidad de los servicios básicos (salud, educación, etc.) para todos & 46,17 & 8 & 32,76 & 13 & $-29,0 \%$ \\
\hline 33 & Una fuerte economía de libre empresa y un gobierno eficiente en sus tareas básicas & 44,56 & 9 & 4,02 & 32 & $-91,0 \%$ \\
\hline \multirow{3}{*}{3} & Los derechos humanos básicos de todos los ciudadanos están fuertemente protegidos & 44,42 & 10 & 22,75 & 23 & $-48,8 \%$ \\
\hline & Promedio & 50,24 & & 33,01 & & $-34,3 \%$ \\
\hline & Desvío estándar & 5,50 & & 14,63 & & \\
\hline
\end{tabular}

\begin{tabular}{|c|c|c|c|c|c|c|}
\hline 15 & Se alienta la vida familiar y los valores de la familia & 32,54 & 26 & 24,08 & 20 & $-26,0 \%$ \\
\hline 24 & Relaciones justas, limpias e independientes con otras naciones & 31,50 & 27 & 17,22 & 24 & $-45,3 \%$ \\
\hline 26 & Vigorosa libertad de opinión, múltiples opiniones públicas (disensos) & 30,90 & 28 & 14,58 & 26 & $-52,8 \%$ \\
\hline 22 & Ciudad atractiva y bien planificada & 30,48 & 29 & 14,11 & 27 & $-53,7 \%$ \\
\hline 31 & Generosidad en ayudar a regiones perjudicadas & 26,65 & 30 & 5,60 & 31 & $-79,0 \%$ \\
\hline 35 & Las personas tienen valores sociales $y$ estilos de vida similares & 26,13 & 31 & $-0,45$ & 34 & $-101,7 \%$ \\
\hline 28 & Atomización en la propiedad y control de los medios de comunicación & 25,67 & 32 & 33,18 & 12 & $29,2 \%$ \\
\hline 7 & Igualdad de oportunidades para hombres y mujeres & 24,04 & 33 & 23,40 & 22 & $-2,7 \%$ \\
\hline 34 & Establecer una economia fuerte antes que la equidad y las metas medioambientales & 20,06 & 34 & $-8,32$ & 35 & $-141,5 \%$ \\
\hline \multirow[t]{3}{*}{23} & Protección de la libertad religiosa & 12,73 & 35 & 5,74 & 30 & $-54,9 \%$ \\
\hline & Promedio & 26,07 & & 12,91 & & $-50,5 \%$ \\
\hline & Desvío estándar & 6,08 & & 12,48 & & \\
\hline
\end{tabular}

Fuente: Elaboración propia. 
La característica con mayor gravedad percibida coincide entre Ensenada y Australia: "Eliminación del crimen y la violencia", siendo dieciséis (16) puntos porcentuales mayor la gravedad en Ensenada respecto a Australia.

En las siguientes seis (6) características con mayor gravedad percibida en Ensenada están también la segunda y tercera características con mayor gravedad percibida en Australia:

- "Altos niveles de honestidad en la política y la vida pública" con jerarquía dos (2) en Ensenada y jerarquía tres (3) en Australia.

- "Todos pagan impuestos equitativamente, acorde con el ingreso y riqueza" con jerarquía siete (7) en Ensenada y jerarquía dos (2) en Australia.

Para las diez (10) primeras características por su jerarquía de gravedad percibida para la ciudad de Ensenada, el promedio de la variable es más de treinta y cuatro (34) puntos porcentuales mayor que en esas mismas características para Australia. Para las últimas diez (10) la diferencia porcentual es superior a los cincuenta (50) puntos porcentuales.

A diferencia de los ciudadanos de Ensenada, para los ciudadanos de Australia no hay entre los diez (10) atributos con mayor gravedad percibida ninguno de los considerados menos importantes, ni tampoco a la inversa.

Esto significa que las coincidencias en gravedades percibidas para los ciudadanos de Ensenada y los de Australia, a excepción de "Eliminación del crimen y la violencia" que es percibida por ambos como la de mayor gravedad, desaparecen.

\section{Conclusiones}

Claramente mirando estos resultados podemos asegurar que el PBI no tiene la única, y menos aún, la última palabra en la ciudad de Ensenada. El atributo con relación directa con este indicador: "Establecer una economía fuerte antes que la equidad y las metas medioambientales", fue evaluado como el menos importante por sus ciudadanos, con la jerarquía de importancia treinta y cinco (35).

Los cinco (5) atributos más importantes para sus ciudadanos son: "Eliminación del crimen y la violencia", "Los derechos humanos básicos de todos los ciudadanos están fuertemente protegidos", "Todos son tratados igualitaria y equitativamente por la ley", "Buena calidad de los servicios básicos (salud, educación, etc.) para todos", y "Confianza justificada en que las instituciones públicas actúan con limpieza y justicia". 
Estos aspectos se relacionan con los tipos de sociedades seguras, satisfechas, éticas, comunitariamente inclusivas, democráticas, justas, y diversas y tolerantes. La sociedad económicamente fuerte y productiva no tiene correlación con los atributos más importantes identificados.

Al analizar el total de los treinta y cinco (35) atributos considerados, evaluados con un promedio de importancia de 8,92, y con un desempeño promedio de 4,88 , se percibe una amplia brecha del $45 \%$ sobre la que se puede accionar para mejorar la situación de las características que consideran importantes los ciudadanos de Ensenada. Los aspectos por los que se debe empezar a trabajar para reducir esta divergencia son los que tienen las mayores discrepancias y gravedades percibidas, que en su mayoría coinciden con los de mayor importancia.

El primero en importancia, y con la mayor discrepancia y gravedad percibida, es "Eliminación del crimen y la violencia". Este aspecto no puede ser solucionado aisladamente a nivel municipal, las políticas que se definan para mejorar este aspecto deben articularse con los lineamientos que se determinen en provincia y nación, trabajando en conjunto.

El segundo y tercer aspectos, por discrepancias y gravedades percibidas, son "Altos niveles de honestidad en la política y la vida pública" y "Confianza justificada en que las instituciones públicas actúan con limpieza y justicia", directamente relacionados con el IPC. En el informe del año 2013 publicado por TI, Argentina ocupaba el puesto ciento seis (106), con un IPC de treinta y cuatro (34), sobre un total de ciento setenta y cinco (175) países. Para el ciudadano de Ensenada es muy importante que esto sea modificado.

Los siguientes aspectos tienen relación directa con la equidad y la justicia en la sociedad: "Todos son tratados igualitaria y equitativamente por la ley", "Respeto por, y estricta aplicación de las leyes", "No hay grandes diferencias en la riqueza y poder entre las personas", "Todos pagan impuestos equitativamente, acorde con el ingreso y riqueza", "Buena calidad de los servicios básicos (salud, educación, etc.) para todos", y "Los derechos humanos básicos de todos los ciudadanos están fuertemente protegidos".

Por el momento, si bien todos los aspectos son altamente valorados por los ciudadanos de Ensenada, no son prioridad absoluta el cuidado del medioambiente, la cultura, la educación, las oportunidades para los jóvenes, la libertad, la inclusión, por nombrar algunos.

Al extender el análisis a la región comprendida por las ciudades de la Plata, Berisso y Ensenada, se percibe que sus ciudadanos consideran importantes los mismos atributos que los ensenadenses, con un promedio de 9,46 vs. 9,54 para los diez (10) más importantes, de los cuáles nueve (9) coinciden. Al comparar el desempeño de las variables, tanto en la región como en la ciudad, se consideran los mismos aspectos entre los de mejor y peor desempeño, con un promedio de 4,82 vs. 4,88 para el total de los atributos.

Para ambos, ninguna característica presenta un desempeño alto, y además las variables con mejores desempeños son las consideradas menos importantes y viceversa. Esto implica que la brecha de discrepancia es grande 
en ambos casos y que los aspectos sobre los que se deben trabajar primero son los mismos, lo que se confirma al analizar que los cinco (5) atributos con mayores gravedades percibidas son los mismos en ambos casos: "Eliminación del crimen y la violencia", "Altos niveles de honestidad en la política y la vida pública", "Confianza justificada en que las instituciones públicas actúan con limpieza y justicia", "Todos son tratados igualitaria y equitativamente por la ley", y "Respeto por, y estricta aplicación de las leyes".

Para la región, al igual que para la ciudad de Ensenada, los principales aspectos sobre los que se debe trabajar tienen que ver con la eliminación de la delincuencia, la disminución de la corrupción, y el aumento de la equidad y la justicia. Sería óptimo articular políticas comunes a nivel regional, e incluso extenderlas a nivel provincial, buscando darle solución a los mismos.

Al analizar los resultados de Australia, vemos que sus ciudadanos asignan una menor valoración de importancia a los treinta y cinco (35) atributos que los de Ensenada, siendo el promedio total de 8,23 vs. 8,92. Sin embargo, ambos ciudadanos coinciden en cuatro (4) de los cinco (5) aspectos considerados como los más importantes: "Eliminación del crimen y la violencia", "Los derechos humanos básicos de todos los ciudadanos están fuertemente protegidos", "Todos son tratados igualitaria y equitativamente por la ley", y "Buena calidad de los servicios básicos (salud, educación, etcétera) para todos".

Al evaluar los desempeños, los australianos asignan valores mayores a esta variable respecto a los ensenadenses, con un promedio de 5,37 vs. 4,88, es decir que consideran que los atributos evaluados se cumplen más en su sociedad. Sin embargo, coinciden en ocho (8) de los diez (10) aspectos considerados con más alto desempeño en ambos casos: "Protección de la libertad religiosa", "Igualdad de oportunidades para hombres y mujeres", "Generosidad en ayudar a regiones perjudicadas", "Vigorosa libertad de opinión, múltiples opiniones públicas (disensos)", "Altos niveles de progreso científico y tecnológico", "Libertad para hacer lo que nos gusta siempre que no perjudiquemos a otros", "Los derechos humanos básicos de todos los ciudadanos están fuertemente protegidos", y "Establecer una economía fuerte antes que la equidad y las metas medioambientales".

Esta menor valoración de la importancia y mayor valoración del desempeño que hacen los ciudadanos de Australia, trae como consecuencia que la brecha entre lo que quieren y perciben es considerablemente menor que la que aprecian los ciudadanos de Ensenada. Esto se confirma al comparar los promedios de discrepancia: $-2,86$ vs. $-4,04$, y de gravedad percibida: 24,87 vs. 38,54 . Tanto para los australianos como para los ensenadenses entre los diez (10) atributos con mayor gravedad percibida existen tres (3) que son comunes: "Eliminación del crimen y la violencia", "Altos niveles de honestidad en la política y la vida pública", y "Todos pagan impuestos equitativamente, acorde con el ingreso y riqueza", relacionados a la eliminación de la delincuencia, la disminución de la corrupción, y el aumento de la equidad. 
Comparando los resultados en Ensenada con los de Australia se evidencia que existen algunas similitudes, pero hay diferencias profundas en la percepción que tienen los ciudadanos en cada caso, haciendo que las mejores políticas a llevar adelante necesariamente no sean las mismas. Esto confirma la dificultad que existe al intentar medir el "bienestar social" con un indicador genérico, porque los factores que influencian en cada sociedad, y la percepción que sus ciudadanos tienen de ellos, es particular y se encuentran afectados por la cultura, la historia, la realidad actual, la ubicación geográfica, etcétera, de cada sociedad.

Esta es la principal ventaja de los indicadores comunitarios, ya que bajan las ideas sobre el bienestar a nivel local, convocando a los ciudadanos a participar en la definición de los atributos más importantes, y siendo partícipes del proceso de medición del progreso hacia la consecución de los mismos, contando con mayor información acerca de los recursos necesarios y las limitaciones existentes.

Claramente sería óptimo articular políticas en pos de la consecución de estos objetivos, no sólo a nivel municipal en Ensenada, sino a nivel regional en La Plata y alrededores, dada la similitud analizada en sus realidades. Sin embargo, si esto no fuese posible, quizás deba ser Ensenada quién dé el primer paso y muestre el camino de los indicadores comunitarios, trabajando sobre lo que sus ciudadanos más valoran y midiendo el progreso hacia su logro. 


\section{Bibliografía}

- Banco Mundial (1997). Crimen y violencia como temas de desarrollo en América Latina y el Caribe. Washington D.C., Banco Mundial.

- Banco Mundial (1997). Ampliando la medición de riqueza: indicadores de desarrollo sostenible del medioambiente. Washington D.C., Banco Mundial.

- Figueroa Díaz, M. E. (2006). Políticas culturales para el desarrollo en un contexto mundializado.

- Instituto Internacional de Gobernabilidad Barcelona (1998). Douglass C. North: La teoría económica neo-institucionalista y el desarrollo latinoamericano. Proyecto PNUD "Red para la Gobernabilidad y el Desarrollo en América Latina".

- Instituto Nacional de Estadísticas y Censos (2011). Censo Nacional de Población, Hogares y Viviendas 2010 de Argentina.

- Kennedy, R. (1968). Speech at University of Kansas. 18 de Marzo de 1968.

- Kliksberg, B. (2000). Capital social y cultura: claves olvidadas del desarrollo. Banco de Intercambio de Desarrollo. Departamento de Integración y Programas Regionales. Publicaciones del Instituto para la Integración de América Latina y el Caribe. Buenos Aires, Argentina.

- Klugman, J. (2010). La verdadera riqueza de las naciones: Caminos al desarrollo humano (Informe sobre desarrollo humano). Edición del Vigésimo Aniversario.

- Kuznets, S. (1962). Problems of definition and measurement. National Bureau of Economic Research.

- Maraña, M. (2010). Cultura y desarrollo: evolución y perspectivas. UNESCO Etxea.

- Popper, S. K. R. (1985). La sociedad abierta y sus enemigos. Orbis.

- Programa de las Naciones Unidas para el Desarrollo. (2013). Informe sobre Desarrollo Humano 2013: El ascenso del Sur: Progreso humano en un mundo diverso.

- Reino de Bután (1999). "25 years, a king". Publicación del Comité Directivo Nacional para la conmemoración de las bodas de plata del Rey Jigme Singye Wangchuck

- Rojas, M. G. (2011). La Medición del Progreso y del Bienestar. Propuestas desde América Latina.

- Salvaris, M. (2000). Community and social indicators: How citizens can measure progress?. Institute for Social Research, Swinburne University of Technology, Melbourne. 
- Saúl, J. (1997). "Power in the Modern State: Corporation over Democracy" The Sydney Papers, Vol. 9, no. 2.

- Sen, A. (1980). "Equality of What?" The 1979 Tanner Lecture on Human Values. Delivered at Stanford University, May 22, 1979.

- Sen, A. (1996). "Capacidad y Bienestar". En: Nusbaum, M.C. y Sen, A. La Calidad de Vida. Fondo de Cultura Económica, primera reimpresión en español, México D.F.

- Sen, A. (1998). La cultura como base del desarrollo contemporáneo. Instituto Veracruzano de Cultura.

- Steffan, A. (2006). "Happy Planet Index". World Changing.

- Stiglitz, J., Sen, A., \& Fitoussi, J. P. (2010). "Mis-measuring our lives, Why GDP doesn't add up". The New Press, New York.

- Talberth J., Cobb, C., \& Slattery, N. (2006) "The Genuine Progress Indicator 2006". A tool for Sustainable Development. Redefining Progress, Oakland, CA.

- Transparencia Internacional (1998). La hora de la transparencia en América Latina. Transparencia Internacional para América Latina y el Caribe.

- UNESCO (1982). Declaración de México sobre las políticas culturales. Conferencia Mundial sobre las Políticas Culturales. México DF, 26 de julio6 de agosto de 1982.

- Vázquez Barquero, A. (1988). Desarrollo Local. Una estrategia de creación de empleo. Ed. Pirámide. Madrid. Pág. 78. 


\section{Anexos}

\section{Anexo I: Modelo de encuesta}

\begin{tabular}{|c|c|c|c|c|}
\hline \multicolumn{4}{|c|}{ Influencia de los valores de la Sociedad en su desarrollo } & \multirow[b]{2}{*}{ Resp } \\
\hline $\mathbf{N}^{\circ}$ & ¿Cuán importante es para usted... & Resp & Califique en que medida se da en la realidad... & \\
\hline 1 & $\begin{array}{l}\text { que existan altos niveles de honestidad en la vida } \\
\text { pública y política? }\end{array}$ & & $\begin{array}{l}\text { la existencia de altos niveles de honestidad en la vida } \\
\text { pública y política. }\end{array}$ & \\
\hline 2 & $\begin{array}{l}\text { que todos los ciudadanos sean tratados igualitaria y } \\
\text { equitativamente por la ley? }\end{array}$ & & $\begin{array}{l}\text { que todos los ciudadanos son tratados igualitaria y } \\
\text { equitativamente por la ley. }\end{array}$ & \\
\hline 3 & $\begin{array}{l}\text { que los derechos humanos básicos de todos los } \\
\text { ciudadanos estén fuertemente protegidos? }\end{array}$ & & $\begin{array}{l}\text { que los derechos humanos básicos de todos los } \\
\text { ciudadanos están fuertemente protegidos. }\end{array}$ & \\
\hline 4 & $\begin{array}{l}\text { una buena calidad de los servicios básicos (salud, } \\
\text { educación, etc.) para todos? }\end{array}$ & & $\begin{array}{l}\text { la existencia de una buena calidad de los servicios } \\
\text { básicos (salud, educación, etc.) para todos. }\end{array}$ & \\
\hline 5 & la eliminación del crimen y la violencia? & & $\begin{array}{l}\text { una tendencia a la eliminación del crimen y la } \\
\text { violencia. }\end{array}$ & \\
\hline 6 & $\begin{array}{l}\text { la protección del medioambiente, los recursos y la } \\
\text { fauna? }\end{array}$ & & $\begin{array}{l}\text { la protección del medioambiente, los recursos y la } \\
\text { fauna. }\end{array}$ & \\
\hline 7 & $\begin{array}{l}\text { la igualdad de oportunidades para hombres y } \\
\text { mujeres? }\end{array}$ & & la igualdad de oportunidades para hombres y mujeres. & \\
\hline 8 & $\begin{array}{l}\text { que todos paguen impuestos equitativamente acorde } \\
\text { con el ingreso y la riqueza? }\end{array}$ & & $\begin{array}{l}\text { que todos pagan impuestos equitativamente acorde } \\
\text { con el ingreso y la riqueza. }\end{array}$ & \\
\hline 9 & $\begin{array}{l}\text { que las instituciones públicas actúen con limpieza y } \\
\text { justicia? }\end{array}$ & & $\begin{array}{l}\text { que las instituciones públicas actúan con limpieza y } \\
\text { justicia. }\end{array}$ & \\
\hline 10 & $\begin{array}{l}\text { una buena calidad de servicios públicos (transportes, } \\
\text { luz, etc.)? }\end{array}$ & & $\begin{array}{l}\text { la existencia de una buena calidad de servicios } \\
\text { públicos (transportes, luz, etc.) }\end{array}$ & \\
\hline 11 & $\begin{array}{l}\text { una buena atención a las personas vulnerables, } \\
\text { disminuidas y de clase baja? }\end{array}$ & & $\begin{array}{l}\text { una buena atención a las personas vulnerables, } \\
\text { disminuidas y de clase baja. }\end{array}$ & \\
\hline 12 & $\begin{array}{l}\text { la reducción de la contaminación medioambiental y el } \\
\text { desarrollo de fuentes de energía renovables? }\end{array}$ & & $\begin{array}{l}\text { la reducción de la contaminación medioambiental y el } \\
\text { desarrollo de fuentes de energía renovables. }\end{array}$ & \\
\hline 13 & $\begin{array}{l}\text { que las personas se sientan responsables por cada } \\
\text { uno de los demás y por la comunidad? }\end{array}$ & & $\begin{array}{l}\text { que las personas se sienten responsables por cada } \\
\text { uno de los demás y por la comunidad. }\end{array}$ & \\
\hline 14 & $\begin{array}{l}\text { que se cumpla que las personas que trabajan } \\
\text { duramente puedan tener éxito en la vida? }\end{array}$ & & $\begin{array}{l}\text { que las personas que trabajan duramente tengan éxito } \\
\text { en la vida. }\end{array}$ & \\
\hline 15 & la vida familiar y los valores de la familia? & & $\begin{array}{l}\text { que se dé importancia a la vida familiar y a los valores } \\
\text { de la familia. }\end{array}$ & \\
\hline 16 & $\begin{array}{l}\text { que las personas jóvenes sean valoradas y tengan un } \\
\text { futuro asegurado? }\end{array}$ & & $\begin{array}{l}\text { que las personas jóvenes son valoradas y tienen un } \\
\text { futuro asegurado. }\end{array}$ & \\
\hline 17 & $\begin{array}{l}\text { trabajar para la eliminación de la pobreza en nuestra } \\
\text { zona? }\end{array}$ & & $\begin{array}{l}\text { que se trabaja para la eliminación de la pobreza en } \\
\text { nuestra zona. }\end{array}$ & \\
\hline 18 & el respeto y la estricta aplicación de las leyes? & & el respeto y la estricta aplicación de las leyes. & \\
\hline 19 & $\begin{array}{l}\text { que existan trabajos seguros y equitativamente } \\
\text { pagados para todos los que quieren trabajar? }\end{array}$ & & $\begin{array}{l}\text { la existencia de trabajos seguros y equitativamente } \\
\text { pagados para todos los que quieren trabajar. }\end{array}$ & \\
\hline 20 & $\begin{array}{l}\text { la protección social (edad, enfermedad, desempleo, } \\
\text { etc.)? }\end{array}$ & & $\begin{array}{l}\text { la protección social (edad, enfermedad, desempleo, } \\
\text { etc.) }\end{array}$ & \\
\hline 21 & $\begin{array}{l}\text { que se puede confiar en otras personas, incluso en } \\
\text { extraños? }\end{array}$ & & $\begin{array}{l}\text { que se puede confiar en otras personas, incluso en } \\
\text { extraños. }\end{array}$ & \\
\hline 22 & que la ciudad sea atractiva y bien planificada? & & que la ciudad es atractiva y bien planificada. & \\
\hline 23 & que exista la libertad de religión? & & la existencia de la libertad de religión. & \\
\hline 24 & $\begin{array}{l}\text { que se den relaciones justas, limpias e } \\
\text { independientes con otras naciones? }\end{array}$ & & $\begin{array}{l}\text { que se dan relaciones justas, limpias e } \\
\text { independientes con otras naciones. }\end{array}$ & \\
\hline 25 & $\begin{array}{l}\text { que se den altos niveles de progreso científico y } \\
\text { tecnológico? }\end{array}$ & & $\begin{array}{l}\text { que se dan altos niveles de progreso científico y } \\
\text { tecnológico. }\end{array}$ & \\
\hline 26 & que exista la libertad de opinión y el disenso? & & la existencia de la libertad de opinión y el disenso. & \\
\hline 27 & $\begin{array}{l}\text { que las personas participen en la toma de decisiones } \\
\text { de hechos que las afectan? }\end{array}$ & & $\begin{array}{l}\text { que las personas participan en la toma de decisiones } \\
\text { de hechos que las afectan. }\end{array}$ & \\
\hline 28 & $\begin{array}{l}\text { la atomización en la propiedad y control de los medios } \\
\text { de comunicación? }\end{array}$ & & $\begin{array}{l}\text { la atomización en la propiedad y control de los medios } \\
\text { de comunicación. }\end{array}$ & \\
\hline 29 & $\begin{array}{l}\text { que la comunidad y las organizaciones locales sean } \\
\text { fuertes? }\end{array}$ & & $\begin{array}{l}\text { que la comunidad y las organizaciones locales son } \\
\text { fuertes. }\end{array}$ & \\
\hline 30 & $\begin{array}{l}\text { que no perjudiquemos a otros cuando libremente } \\
\text { hacemos lo que nos gusta? }\end{array}$ & & $\begin{array}{l}\text { que no perjudicamos a otros cuando libremente } \\
\text { hacemos lo que nos gusta. }\end{array}$ & \\
\hline 31 & $\begin{array}{l}\text { que haya generosidad en ayudar a regiones } \\
\text { perjudicadas? }\end{array}$ & & $\begin{array}{l}\text { que hay generosidad en ayudar a regiones } \\
\text { perjudicadas. }\end{array}$ & \\
\hline 32 & $\begin{array}{l}\text { que no haya grandes diferencias en la riqueza y poder } \\
\text { entre las personas? }\end{array}$ & & $\begin{array}{l}\text { que no hay grandes diferencias en la riqueza y poder } \\
\text { entre las personas. }\end{array}$ & \\
\hline 33 & $\begin{array}{l}\text { que exista una fuerte economía de libre empresa y un } \\
\text { gobierno eficiente en sus tareas básicas? }\end{array}$ & & $\begin{array}{l}\text { la existencia de una fuerte economía de libre empresa } \\
\text { y un gobierno eficiente en sus tareas básicas. }\end{array}$ & \\
\hline 34 & $\begin{array}{l}\text { que se establezca una economía fuerte antes que la } \\
\text { equidad y las metas medioambientales? }\end{array}$ & & $\begin{array}{l}\text { el establecimiento de una economía fuerte antes que } \\
\text { la equidad y las metas medioambientales. }\end{array}$ & \\
\hline 35 & $\begin{array}{l}\text { que las personas tengan valores sociales y estilos de } \\
\text { vida similares? }\end{array}$ & & $\begin{array}{l}\text { que las personas tienen valores sociales y estilos de } \\
\text { vida similares. }\end{array}$ & \\
\hline
\end{tabular}




\section{Perfil del respondente}

Sexo: $\quad 1 \square$ Masculino $\quad 2 \square$ Femenino

Edad:

Nivel de Educación
$1 \square$ Sin instrucción
$2 \square$ Primaria Incompleta
$3 \square$ Primaria Completa
$4 \square$ Secundaria Incompleta
$5 \square$ Secundaria Completa

$6 \square$ Terciaria o Univ. Incompleta

$7 \square$ Terciaria o Univ. Completa

$8 \square$ Posgrado Completo

$9 \square \mathrm{Ns} / \mathrm{Nc}$

$\begin{aligned} \text { Trabaja: } & 1 \square \text { Desocupado } \\ & 2 \square \text { Jubilado } \\ & 3 \square \text { Ama de casa } \\ & \square \text { Relación de dependencia } \\ & \quad \text { tiempo parcial } \\ 5 & \square \text { Relación de dependencia } \\ & \text { tiempo completo }\end{aligned}$

$6 \square$ Profesional independiente

$7 \square$ Comerciante

$8 \square$ Empresario

$9 \square \mathrm{Ns} / \mathrm{Nc}$ tiempo completo 
Anexo II: Resultados obtenidos a través del análisis Etha Cuadrado

\begin{tabular}{|c|c|c|c|c|}
\hline \multicolumn{5}{|c|}{ RESULTADOS ETHA CUADRADO - ANÁLISIS POR ZONA } \\
\hline Ítem & Importancia & Desempeño & Discrepancia & $\begin{array}{l}\text { Gravedad } \\
\text { Percibida }\end{array}$ \\
\hline 1 & 0,10 & 0,14 & 0,15 & 0,15 \\
\hline 2 & 0,09 & 0,15 & 0,15 & 0,15 \\
\hline 3 & 0,12 & 0,17 & 0,15 & 0,14 \\
\hline 4 & 0,09 & 0,08 & 0,07 & 0,07 \\
\hline 5 & 0,17 & 0,17 & 0,17 & 0,16 \\
\hline 6 & 0,12 & 0,13 & 0,14 & 0,14 \\
\hline 7 & 0,11 & 0,14 & 0,15 & 0,14 \\
\hline 8 & 0,12 & 0,08 & 0,10 & 0,11 \\
\hline 9 & 0,10 & 0,12 & 0,10 & 0,09 \\
\hline 10 & 0,16 & 0,09 & 0,10 & 0,11 \\
\hline 11 & 0,13 & 0,10 & 0,12 & 0,12 \\
\hline 12 & 0,13 & 0,16 & 0,15 & 0,16 \\
\hline 13 & 0,10 & 0,11 & 0,08 & 0,07 \\
\hline 14 & 0,12 & 0,10 & 0,07 & 0,09 \\
\hline 15 & 0,13 & 0,19 & 0,19 & 0,19 \\
\hline 16 & 0,09 & 0,20 & 0,17 & 0,16 \\
\hline 17 & 0,07 & 0,09 & 0,11 & 0,11 \\
\hline 18 & 0,18 & 0,11 & 0,12 & 0,13 \\
\hline 19 & 0,05 & 0,09 & 0,05 & 0,05 \\
\hline 20 & 0,09 & 0,12 & 0,14 & 0,15 \\
\hline 21 & 0,05 & 0,10 & 0,08 & 0,06 \\
\hline 22 & 0,11 & 0,18 & 0,15 & 0,14 \\
\hline 23 & 0,07 & 0,14 & 0,13 & 0,13 \\
\hline 24 & 0,12 & 0,18 & 0,14 & 0,15 \\
\hline 25 & 0,15 & 0,18 & 0,22 & 0,22 \\
\hline 26 & 0,08 & 0,06 & 0,06 & 0,06 \\
\hline 27 & 0,07 & 0,12 & 0,09 & 0,09 \\
\hline 28 & 0,13 & 0,15 & 0,13 & 0,16 \\
\hline 29 & 0,12 & 0,18 & 0,18 & 0,17 \\
\hline 30 & 0,17 & 0,19 & 0,19 & 0,18 \\
\hline 31 & 0,14 & 0,12 & 0,14 & 0,16 \\
\hline 32 & 0,07 & 0,09 & 0,09 & 0,12 \\
\hline 33 & 0,15 & 0,06 & 0,08 & 0,09 \\
\hline 34 & 0,12 & 0,14 & 0,13 & 0,12 \\
\hline 35 & 0,07 & 0,13 & 0,06 & 0,08 \\
\hline
\end{tabular}

Fuente: Elaboración propia. 


\begin{tabular}{|c|c|c|c|c|}
\hline \multicolumn{5}{|c|}{ RESULTADOS ETHA CUADRADO - ANÁLISIS POR EDAD } \\
\hline Ítem & Importancia & Desempeño & Discrepancia & $\begin{array}{l}\text { Gravedad } \\
\text { Percibida }\end{array}$ \\
\hline 1 & 0,22 & 0,15 & 0,19 & 0,21 \\
\hline 2 & 0,15 & 0,20 & 0,23 & 0,23 \\
\hline 3 & 0,13 & 0,22 & 0,24 & 0,23 \\
\hline 4 & 0,15 & 0,15 & 0,17 & 0,17 \\
\hline 5 & 0,20 & 0,14 & 0,17 & 0,18 \\
\hline 6 & 0,17 & 0,15 & 0,18 & 0,18 \\
\hline 7 & 0,19 & 0,21 & 0,22 & 0,21 \\
\hline 8 & 0,17 & 0,18 & 0,20 & 0,20 \\
\hline 9 & 0,24 & 0,17 & 0,22 & 0,23 \\
\hline 10 & 0,21 & 0,17 & 0,21 & 0,22 \\
\hline 11 & 0,12 & 0,15 & 0,17 & 0,17 \\
\hline 12 & 0,19 & 0,12 & 0,12 & 0,14 \\
\hline 13 & 0,19 & 0,18 & 0,18 & 0,19 \\
\hline 14 & 0,13 & 0,08 & 0,12 & 0,12 \\
\hline 15 & 0,14 & 0,17 & 0,18 & 0,18 \\
\hline 16 & 0,16 & 0,14 & 0,16 & 0,17 \\
\hline 17 & 0,14 & 0,22 & 0,20 & 0,19 \\
\hline 18 & 0,23 & 0,19 & 0,23 & 0,23 \\
\hline 19 & 0,17 & 0,19 & 0,20 & 0,18 \\
\hline 20 & 0,09 & 0,16 & 0,16 & 0,15 \\
\hline 21 & 0,20 & 0,14 & 0,23 & 0,23 \\
\hline 22 & 0,12 & 0,11 & 0,11 & 0,12 \\
\hline 23 & 0,17 & 0,08 & 0,17 & 0,15 \\
\hline 24 & 0,18 & 0,08 & 0,14 & 0,14 \\
\hline 25 & 0,21 & 0,16 & 0,19 & 0,20 \\
\hline 26 & 0.16 & 0,18 & 0.22 & 0.22 \\
\hline 27 & 0.21 & 0.19 & 0.20 & 0.19 \\
\hline 28 & 0.20 & 0,14 & 0.22 & 0.23 \\
\hline 29 & 0.20 & 0.14 & 0.15 & 0.14 \\
\hline 30 & 0.17 & 0.18 & 0.17 & 0.16 \\
\hline 31 & 0,08 & 0,20 & 0,18 & 0,17 \\
\hline 32 & 0,18 & 0,20 & 0,20 & 0,19 \\
\hline 33 & 0,18 & 0,24 & 0,19 & 0,17 \\
\hline 34 & 0,16 & 0,19 & 0,17 & 0,15 \\
\hline 35 & 0,16 & 0,16 & 0,16 & 0,15 \\
\hline
\end{tabular}

Fuente: Elaboración propia. 


\begin{tabular}{|c|c|c|c|c|}
\hline \multicolumn{5}{|c|}{ RESULTADOS ETHA CUADRADO - ANÁLISIS POR SEXO } \\
\hline Ítem & Importancia & Desempeño & Discrepancia & $\begin{array}{l}\text { Gravedad } \\
\text { Percibida }\end{array}$ \\
\hline 1 & 0,04 & 0,06 & 0,07 & 0,07 \\
\hline 2 & 0,02 & 0,12 & 0,12 & 0,11 \\
\hline 3 & 0,03 & 0,06 & 0,04 & 0,03 \\
\hline 4 & 0,03 & 0,13 & 0,11 & 0,10 \\
\hline 5 & 0,07 & 0,07 & 0,08 & 0,08 \\
\hline 6 & 0,02 & 0,12 & 0,08 & 0,08 \\
\hline 7 & 0,07 & 0,04 & 0,00 & 0,00 \\
\hline 8 & 0,07 & 0,09 & 0,11 & 0,10 \\
\hline 9 & 0,07 & 0,10 & 0,12 & 0,12 \\
\hline 10 & 0,00 & 0,10 & 0,08 & 0,08 \\
\hline 11 & 0,01 & 0,10 & 0,08 & 0,07 \\
\hline 12 & 0,10 & 0,17 & 0,08 & 0,06 \\
\hline 13 & 0,07 & 0,16 & 0,09 & 0,05 \\
\hline 14 & 0,08 & 0,06 & 0,02 & 0,07 \\
\hline 15 & 0,05 & 0,08 & 0,03 & 0,07 \\
\hline 16 & 0,03 & 0,08 & 0,08 & 0,08 \\
\hline 17 & 0,05 & 0,07 & 0,04 & 0,02 \\
\hline 18 & 0,07 & 0,11 & 0,12 & 0,12 \\
\hline 19 & 0,05 & 0,00 & 0,03 & 0,05 \\
\hline 20 & 0,02 & 0,07 & 0,05 & 0,05 \\
\hline 21 & 0,03 & 0,05 & 0,03 & 0,01 \\
\hline 22 & 0,11 & 0,06 & 0,11 & 0,12 \\
\hline 23 & 0,01 & 0,03 & 0,02 & 0,01 \\
\hline 24 & 0,04 & 0,02 & 0,05 & 0,06 \\
\hline 25 & 0,11 & 0,20 & 0,22 & 0,23 \\
\hline 26 & 0,03 & 0,03 & 0,04 & 0,05 \\
\hline 27 & 0,00 & 0,10 & 0,09 & 0,08 \\
\hline 28 & 0,07 & 0,10 & 0,13 & 0,13 \\
\hline 29 & 0,06 & 0,09 & 0,11 & 0,12 \\
\hline 30 & 0,02 & 0,01 & 0,02 & 0,02 \\
\hline 31 & 0,02 & 0,10 & 0,09 & 0,08 \\
\hline 32 & 0,06 & 0,08 & 0,09 & 0,09 \\
\hline 33 & 0,06 & 0,00 & 0,05 & 0,03 \\
\hline 34 & 0,00 & 0,01 & 0,00 & 0,01 \\
\hline 35 & 0,02 & 0,08 & 0,03 & 0,00 \\
\hline
\end{tabular}

Fuente: Elaboración propia. 


\begin{tabular}{|c|c|c|c|c|}
\hline \multicolumn{5}{|c|}{ RESULTADOS ETHA CUADRADO - ANÁLISIS POR NIVEL EDUCATIVO } \\
\hline Ítem & Importancia & Desempeño & Discrepancia & $\begin{array}{l}\text { Gravedad } \\
\text { Percibida }\end{array}$ \\
\hline 1 & 0,24 & 0,14 & 0,20 & 0,22 \\
\hline 2 & 0,08 & 0,18 & 0,21 & 0,21 \\
\hline 3 & 0,13 & 0,16 & 0,16 & 0,17 \\
\hline 4 & 0,17 & 0,15 & 0,18 & 0,19 \\
\hline 5 & 0,18 & 0,22 & 0,25 & 0,25 \\
\hline 6 & 0,10 & 0,14 & 0,16 & 0,16 \\
\hline 7 & 0,18 & 0,17 & 0,18 & 0,17 \\
\hline 8 & 0,10 & 0,18 & 0,19 & 0,20 \\
\hline 9 & 0,14 & 0,15 & 0,15 & 0,15 \\
\hline 10 & 0,19 & 0,17 & 0,20 & 0,20 \\
\hline 11 & 0,12 & 0,23 & 0,23 & 0,23 \\
\hline 12 & 0,10 & 0,17 & 0,18 & 0,17 \\
\hline 13 & 0,14 & 0,20 & 0,24 & 0,23 \\
\hline 14 & 0,16 & 0,05 & 0,15 & 0,14 \\
\hline 15 & 0,13 & 0,18 & 0,19 & 0,19 \\
\hline 16 & 0,19 & 0,18 & 0,23 & 0,23 \\
\hline 17 & 0,08 & 0,18 & 0,18 & 0,18 \\
\hline 18 & 0,16 & 0,18 & 0,22 & 0,22 \\
\hline 19 & 0,23 & 0,14 & 0,18 & 0,19 \\
\hline 20 & 0,14 & 0,13 & 0,14 & 0,14 \\
\hline 21 & 0,19 & 0,13 & 0,21 & 0,23 \\
\hline 22 & 0,22 & 0,14 & 0,21 & 0,22 \\
\hline 23 & 0,13 & 0,18 & 0,19 & 0,18 \\
\hline 24 & 0,17 & 0,18 & 0,20 & 0,21 \\
\hline 25 & 0,09 & 0,14 & 0,16 & 0,15 \\
\hline 26 & 0,15 & 0,15 & 0,16 & 0,17 \\
\hline 27 & 0,09 & 0,19 & 0,14 & 0,12 \\
\hline 28 & 0,17 & 0,09 & 0,14 & 0,15 \\
\hline 29 & 0,12 & 0,08 & 0,15 & 0,17 \\
\hline 30 & 0,14 & 0,17 & 0,16 & 0,15 \\
\hline 31 & 0,18 & 0,10 & 0,10 & 0,10 \\
\hline 32 & 0,16 & 0,14 & 0,20 & 0,22 \\
\hline 33 & 0,19 & 0,12 & 0,21 & 0,24 \\
\hline 34 & 0,17 & 0,11 & 0,13 & 0,22 \\
\hline 35 & 0,18 & 0,13 & 0,21 & 0,22 \\
\hline
\end{tabular}

Fuente: Elaboración propia. 


\begin{tabular}{|c|c|c|c|c|}
\hline \multicolumn{5}{|c|}{ RESULTADOS ETHA CUADRADO - ANÁLISIS POR SITUACIÓN LABORAL } \\
\hline Ítem & Importancia & Desempeño & Discrepancia & $\begin{array}{l}\text { Gravedad } \\
\text { Percibida }\end{array}$ \\
\hline 1 & 0,13 & 0,21 & 0,17 & 0,15 \\
\hline 2 & 0,11 & 0,16 & 0,18 & 0,19 \\
\hline 3 & 0,16 & 0,11 & 0,10 & 0,11 \\
\hline 4 & 0,11 & 0,17 & 0,17 & 0,16 \\
\hline 5 & 0,22 & 0,17 & 0,19 & 0,19 \\
\hline 6 & 0,10 & 0,13 & 0,09 & 0,09 \\
\hline 7 & 0,16 & 0,14 & 0,11 & 0,11 \\
\hline 8 & 0,19 & 0,21 & 0,23 & 0,24 \\
\hline 9 & 0,06 & 0,11 & 0,09 & 0,09 \\
\hline 10 & 0,19 & 0,19 & 0,16 & 0,16 \\
\hline 11 & 0,17 & 0,16 & 0,13 & 0,12 \\
\hline 12 & 0,16 & 0,18 & 0,15 & 0,15 \\
\hline 13 & 0,18 & 0,11 & 0,18 & 0,18 \\
\hline 14 & 0,17 & 0,16 & 0,15 & 0,14 \\
\hline 15 & 0,12 & 0,11 & 0,10 & 0,12 \\
\hline 16 & 0,16 & 0,09 & 0,16 & 0,16 \\
\hline 17 & 0,13 & 0,17 & 0,14 & 0,13 \\
\hline 18 & 0,11 & 0,12 & 0,13 & 0,13 \\
\hline 19 & 0,19 & 0,09 & 0,15 & 0,16 \\
\hline 20 & 0,09 & 0,13 & 0,10 & 0,10 \\
\hline 21 & 0,12 & 0,18 & 0,19 & 0,18 \\
\hline 22 & 0,17 & 0,08 & 0,14 & 0,14 \\
\hline 23 & 0,11 & 0,12 & 0,09 & 0,09 \\
\hline 24 & 0,16 & 0,12 & 0,13 & 0,13 \\
\hline 25 & 0,09 & 0,10 & 0,08 & 0,09 \\
\hline 26 & 0,19 & 0,19 & 0,15 & 0,15 \\
\hline 27 & 0,18 & 0,16 & 0,14 & 0,14 \\
\hline 28 & 0,13 & 0,15 & 0,15 & 0,17 \\
\hline 29 & 0,16 & 0,11 & 0,12 & 0,12 \\
\hline 30 & 0,06 & 0,10 & 0,08 & 0,08 \\
\hline 31 & 0,17 & 0,16 & 0,18 & 0,18 \\
\hline 32 & 0,18 & 0,10 & 0,16 & 0,17 \\
\hline 33 & 0,20 & 0,15 & 0,16 & 0,18 \\
\hline 34 & 0,20 & 0,16 & 0,12 & 0,12 \\
\hline 35 & 0,14 & 0,16 & 0,11 & 0,10 \\
\hline
\end{tabular}

Fuente: Elaboración propia. 


\begin{tabular}{|c|c|c|c|}
\hline \multirow[b]{2}{*}{ Item } & \multirow[b]{2}{*}{ Características } & \multicolumn{2}{|c|}{$\begin{array}{c}\text { Importancia en } \\
\text { Australia }\end{array}$} \\
\hline & & $\begin{array}{c}\text { Calificación 1-10 } \\
\text { (a) }\end{array}$ & $\begin{array}{c}\text { Jerarquía 1-35 } \\
\text { (a') }\end{array}$ \\
\hline 1 & Altos niveles de honestidad en la pollíca y la vida pública & 9,30 & 1 \\
\hline 2 & Todos son tratados igualitaria y equitativamente por la ley & 9,30 & 2 \\
\hline 3 & Los derechos humanos básicos de todos los ciudadanos están fuertemente protegidos & 9,10 & 3 \\
\hline 4 & Buena calidad de los servicios básicos (salud, educación, etc.) para todos & 9,10 & 4 \\
\hline 5 & Eliminación del crimen y la violencia & 9,10 & 5 \\
\hline 6 & Protección del medioambiente, recursos y fauna & 9,10 & 6 \\
\hline 7 & Igualdad de oportunidades para hombres y mujeres & 9,00 & 7 \\
\hline 8 & Todos pagan impuestos equitativamente, acorde con el ingreso y riqueza & 9,00 & 8 \\
\hline 9 & Confianza justificada en que las instituciones públicas actúan con limpieza y justicia & 9,00 & 9 \\
\hline 10 & Las comunidades locales tienen buena calidad de servicios públicos (transporte, luz, etc.) & 9,00 & 10 \\
\hline 11 & Buena atención a las personas vulnerables, disminuidos y de clase baja & 8,80 & 11 \\
\hline 12 & Reducción de la contaminación medioambiental, desarrollo de fuentes de energía renovables & 8,80 & 12 \\
\hline 13 & Las personas se sienten responsables por cada uno de los demás y por la comunidad & 8,70 & 13 \\
\hline 14 & Las personas que trabajan duramente pueden tener éxito en la vida & 8,60 & 14 \\
\hline 15 & Se alienta la vida familiar y los valores de la familia & 8,60 & 15 \\
\hline 16 & Las personas jóvenes son valoradas, $y$ tienen perspectivas de futuro seguras & 8,60 & 16 \\
\hline 17 & Eliminación de la pobreza & 8,60 & 17 \\
\hline 18 & Respeto por, y estricta aplicación de las leyes & 8,60 & 18 \\
\hline 19 & Trabajos seguros, satisfactorios y equitativamente pagados para todos los que quieren trabajar & 8,60 & 19 \\
\hline 20 & Fuerte protección social (edad, enfermedad, desempleo, etc.) & 8,50 & 20 \\
\hline 21 & Capacidad para confiar en otras personas, incluso extraños & 8,40 & 21 \\
\hline 22 & Ciudad atractiva y bien planificada & 8,30 & 22 \\
\hline 23 & Protección de la libertad religiosa & 8,20 & 23 \\
\hline 24 & Relaciones justas, limpias e independientes con otras naciones & 8,20 & 24 \\
\hline 25 & Altos niveles de progreso cientifico y tecnológico & 8,10 & 25 \\
\hline 26 & Vigorosa libertad de opinión, múltiples opiniones públicas (disensos) & 8,10 & 26 \\
\hline 27 & Las personas participan en la toma de decisiones de hechos que los afectan & 8,10 & 27 \\
\hline 28 & Atomización en la propiedad y control de los medios de comunicación & 7,90 & 28 \\
\hline 29 & Comunidades y organizaciones locales fuertes & 7,80 & 29 \\
\hline 30 & Libertad para hacer lo que nos gusta siempre que no perjudiquemos a otros & 7,40 & 30 \\
\hline 31 & Generosidad en ayudar a regiones perjudicadas & 7,00 & 31 \\
\hline 32 & No hay grandes diferencias en la riqueza y poder entre las personas & 6,80 & 32 \\
\hline 33 & Una fuerte economía de libre empresa y un gobierno eficiente en sus tareas básicas & 6,70 & 33 \\
\hline 34 & Establecer una economía fuerte antes que la equidad y las metas medioambientales & 5,20 & 34 \\
\hline \multirow[t]{3}{*}{35} & Las personas tienen valores sociales y estilos de vida similares & 4,50 & 35 \\
\hline & Promedio & 8,23 & \\
\hline & Desvío estándar & 1,08 & \\
\hline
\end{tabular}

Fuente: Encuesta nacional "Puntos de referencia de la ciudadanía australiana" - 1999. 


\begin{tabular}{|c|c|c|c|}
\hline \multirow[b]{2}{*}{ Item } & \multirow[b]{2}{*}{ Características } & \multicolumn{2}{|c|}{$\begin{array}{c}\text { Desempeño en } \\
\text { Australia }\end{array}$} \\
\hline & & $\begin{array}{c}\text { Calificación 1-10 } \\
\text { (b) }\end{array}$ & $\begin{array}{c}\text { Jerarquía 1-35 } \\
\text { (b') }\end{array}$ \\
\hline 1 & Altos niveles de honestidad en la política y la vida pública & \begin{tabular}{|l|}
4,30 \\
\end{tabular} & 27 \\
\hline 2 & Todos son tratados igualitaria y equitativamente por la ley & 5,40 & 19 \\
\hline 3 & Los derechos humanos básicos de todos los ciudadanos están fuertemente protegidos & 6,60 & 6 \\
\hline 4 & Buena calidad de los servicios básicos (salud, educación, etc.) para todos & 5,50 & 17 \\
\hline 5 & Eliminación del crimen y la violencia & 3,40 & 33 \\
\hline 6 & Protección del medioambiente, recursos y fauna & 5,60 & 15 \\
\hline 7 & Igualdad de oportunidades para hombres y mujeres & 6,40 & 8 \\
\hline 8 & Todos pagan impuestos equitativamente, acorde con el ingreso y riqueza & 3,40 & 33 \\
\hline 9 & Confianza justificada en que las instituciones públicas actúan con limpieza y justicia & 5,10 & 21 \\
\hline 10 & Las comunidades locales tienen buena calidad de servicios públicos (transporte, luz, etc.) & 4,80 & 24 \\
\hline 11 & Buena atención a las personas vulnerables, disminuidos y de clase baja & 5,60 & 15 \\
\hline 12 & Reducción de la contaminación medioambiental, desarrollo de fuentes de energía renovables & 4,80 & 24 \\
\hline 13 & Las personas se sienten responsables por cada uno de los demás y por la comunidad & 5,10 & 21 \\
\hline 14 & Las personas que trabajan duramente pueden tener éxito en la vida & 6,80 & 3 \\
\hline 15 & Se alienta la vida familiar y los valores de la familia & 5,80 & 14 \\
\hline 16 & Las personas jóvenes son valoradas, $y$ tienen perspectivas de futuro seguras & 4,30 & 27 \\
\hline 17 & Eliminación de la pobreza & 3,80 & 31 \\
\hline 18 & Respeto por, y estricta aplicación de las leyes & 5,50 & 17 \\
\hline 19 & Trabajos seguros, satisfactorios y equitativamente pagados para todos los que quieren trabajar & 4,20 & 29 \\
\hline 20 & Fuerte protección social (edad, enfermedad, desempleo, etc.) & 5,40 & 19 \\
\hline 21 & Capacidad para confiar en otras personas, incluso extraños & 3,90 & 30 \\
\hline 22 & Ciudad atractiva y bien planificada & 6,60 & 6 \\
\hline 23 & Protección de la libertad religiosa & 7,50 & 1 \\
\hline 24 & Relaciones justas, limpias e independientes con otras naciones & 6,10 & 11 \\
\hline 25 & Altos niveles de progreso cientifico y tecnológico & 6,80 & 3 \\
\hline 26 & Vigorosa libertad de opinión, múltiples opiniones públicas (disensos) & 6,30 & 9 \\
\hline 27 & Las personas participan en la toma de decisiones de hechos que los afectan & 5,10 & 21 \\
\hline 28 & Atomización en la propiedad y control de los medios de comunicación & 3,70 & 32 \\
\hline 29 & Comunidades y organizaciones locales fuertes & 6,00 & 13 \\
\hline 30 & Libertad para hacer lo que nos gusta siempre que no perjudiquemos a otros & 7,10 & 2 \\
\hline 31 & Generosidad en ayudar a regiones perjudicadas & 6,20 & 10 \\
\hline 32 & No hay grandes diferencias en la riqueza y poder entre las personas & 3,30 & 35 \\
\hline 33 & Una fuerte economía de libre empresa y un gobierno eficiente en sus tareas básicas & 6,10 & 11 \\
\hline 34 & Establecer una economía fuerte antes que la equidad y las metas medioambientales & 6,80 & 3 \\
\hline \multirow[t]{3}{*}{35} & Las personas tienen valores sociales y estilos de vida similares & 4,60 & 26 \\
\hline & Promedio & 5,37 & \\
\hline & Desvío estándar & 1,16 & \\
\hline
\end{tabular}

Fuente: Encuesta nacional "Puntos de referencia de la ciudadanía australiana" - 1999. 


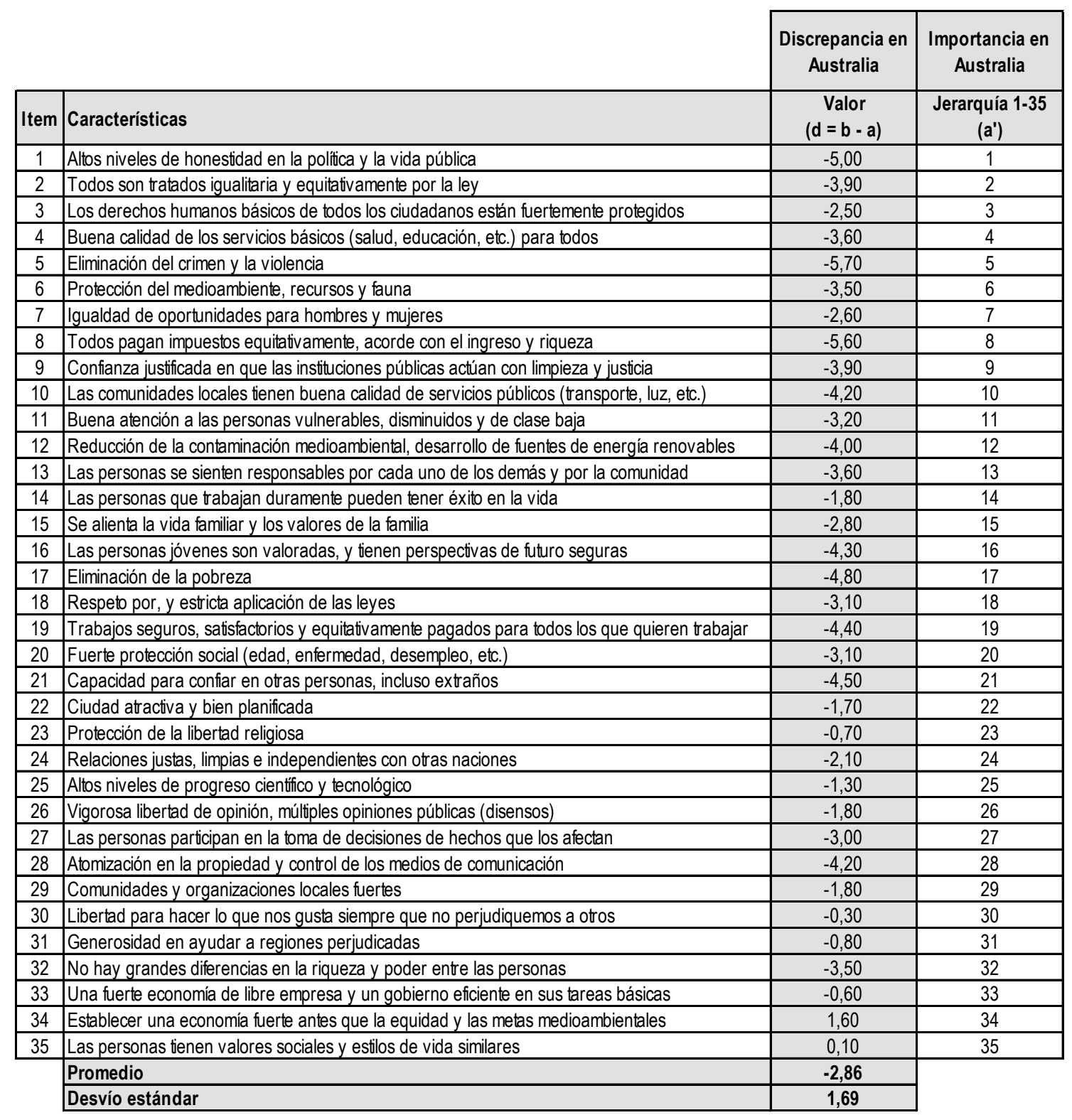

Fuente: Encuesta nacional "Puntos de referencia de la ciudadanía australiana" - 1999. 


\begin{tabular}{|c|c|c|c|}
\hline \multirow[b]{2}{*}{ Item } & \multirow[b]{2}{*}{ Características } & \multicolumn{2}{|c|}{$\begin{array}{c}\text { Gravedad Percibida en } \\
\text { Australia }\end{array}$} \\
\hline & & $\begin{array}{l}\text { Ponderación } \\
\left(g=-d^{*} a\right)\end{array}$ & $\begin{array}{c}\text { Jerarquía 1-35 } \\
\left(g^{\prime}\right)\end{array}$ \\
\hline 1 & Altos niveles de honestidad en la pollíca y la vida pública & 46,50 & 3 \\
\hline 2 & Todos son tratados igualitaria y equitativamente por la ley & 36,27 & 9 \\
\hline 3 & Los derechos humanos básicos de todos los ciudadanos están fuertemente protegidos & 22,75 & 23 \\
\hline 4 & Buena calidad de los servicios básicos (salud, educación, etc.) para todos & 32,76 & 13 \\
\hline 5 & Eliminación del crimen y la violencia & 51,87 & 1 \\
\hline 6 & Protección del medioambiente, recursos y fauna & 31,85 & 14 \\
\hline 7 & Igualdad de oportunidades para hombres y mujeres & 23,40 & 22 \\
\hline 8 & Todos pagan impuestos equitativamente, acorde con el ingreso y riqueza & 50,40 & 2 \\
\hline 9 & Confianza justificada en que las instituciones públicas actúan con limpieza y justicia & 35,10 & 11 \\
\hline 10 & Las comunidades locales tienen buena calidad de servicios públicos (transporte, luz, etc.) & 37,80 & 6 \\
\hline 11 & Buena atención a las personas vulnerables, disminuidos y de clase baja & 28,16 & 16 \\
\hline 12 & Reducción de la contaminación medioambiental, desarrollo de fuentes de energía renovables & 35,20 & 10 \\
\hline 13 & Las personas se sienten responsables por cada uno de los demás y por la comunidad & 31,32 & 15 \\
\hline 14 & Las personas que trabajan duramente pueden tener éxito en la vida & 15,48 & 25 \\
\hline 15 & Se alienta la vida familiar y los valores de la familia & 24,08 & 20 \\
\hline 16 & Las personas jóvenes son valoradas, $y$ tienen perspectivas de futuro seguras & 36,98 & 8 \\
\hline 17 & Eliminación de la pobreza & 41,28 & 4 \\
\hline 18 & Respeto por, y estricta aplicación de las leyes & 26,66 & 17 \\
\hline 19 & Trabajos seguros, satisfactorios y equitativamente pagados para todos los que quieren trabajar & 37,84 & 5 \\
\hline 20 & Fuerte protección social (edad, enfermedad, desempleo, etc.) & 26,35 & 18 \\
\hline 21 & Capacidad para confiar en otras personas, incluso extraños & 37,80 & 6 \\
\hline 22 & Ciudad atractiva y bien planificada & 14,11 & 27 \\
\hline 23 & Protección de la libertad religiosa & 5,74 & 30 \\
\hline 24 & Relaciones justas, limpias e independientes con otras naciones & 17,22 & 24 \\
\hline 25 & Altos niveles de progreso cientifico y tecnológico & 10,53 & 29 \\
\hline 26 & Vigorosa libertad de opinión, múltiples opiniones públicas (disensos) & 14,58 & 26 \\
\hline 27 & Las personas participan en la toma de decisiones de hechos que los afectan & 24,30 & 19 \\
\hline 28 & Atomización en la propiedad y control de los medios de comunicación & 33,18 & 12 \\
\hline 29 & Comunidades y organizaciones locales fuertes & 14,04 & 28 \\
\hline 30 & Libertad para hacer lo que nos gusta siempre que no perjudiquemos a otros & 2,22 & 33 \\
\hline 31 & Generosidad en ayudar a regiones perjudicadas & 5,60 & 31 \\
\hline 32 & No hay grandes diferencias en la riqueza y poder entre las personas & 23,80 & 21 \\
\hline 33 & Una fuerte economía de libre empresa y un gobierno eficiente en sus tareas básicas & 4,02 & 32 \\
\hline 34 & Establecer una economía fuerte antes que la equidad y las metas medioambientales & $-8,32$ & 35 \\
\hline 35 & Las personas tienen valores sociales y estilos de vida similares & $-0,45$ & 34 \\
\hline & Promedio & 24,87 & \\
\hline & Desvío estándar & 14,83 & \\
\hline
\end{tabular}

Fuente: Encuesta nacional "Puntos de referencia de la ciudadanía australiana" - 1999. 